\title{
II. Die Gründung der Demokratischen Bauernpartei Deutschlands 1948
}

\section{Politische Rahmenbedingungen 1948}

\section{Sowjetische Deutschlandpolitik und die Entwicklung des Parteiensystems}

Die sowjetische Besatzungsmacht wirkte stärker als bislang vermutet auf die Entwicklung des Parteienblocks ein ${ }^{1}$. Die bürgerlichen Parteien, die den Block mittrugen, waren gewichtige Faktoren im Kalkül der sowjetischen Deutschlandpolitik, zumal sie als „Reichsleitungen“ mit gesamtdeutschem Anspruch auftraten. Das politische Selbstvertrauen ihrer Parteiführung basierte auf der erhofften parlamentarischen Funktion in einer gesamtdeutschen demokratischen Regierung. Diesen potentiellen Bedeutungsgewinn vor Augen, zeigten sich CDU wie LDP bei jenen Fragen gegenüber der SED begrenzt konzessionsbereit, die sie für eher unerheblich hielten ${ }^{2}$.

Innerhalb der sowjetischen Deutschlandpolitik nahmen die bürgerlichen Parteien als politische Akteure aus zweierlei Gründen eine wichtige Rolle ein. Zum ersten erhöhten sie die Möglichkeiten Moskaus, in die westlichen Besatzungszonen hineinzuwirken, und sie galten als institutionelle Kerne für die Zukunft. Denn beide Parteien waren bis Anfang 1948 an zonenübergreifenden „Arbeitsgemeinschaften" zusammen mit westlichen Pendants beteiligt, die bei einer Vereinigung der Besatzungsgebiete als Fusionskerne hätten dienen sollen³. Die CDU der SBZ darf als politischer Faktor dabei nicht unterschätzt werden: dank ihres organisatorischen Vorsprungs gegenüber den westlichen Verbänden 1945, eines hohen finanziellen Potentials aufgrund der erfolgreichen Parteipresse und nicht zuletzt wegen der wachsenden Mitgliederzahlen ${ }^{4}$. Für CDU und LDP eröffnete sich ein größeres Handlungsfeld als Gesprächspartner im Westen, dort wo die SED ihrem Parteiverständnis gemäß nicht auftreten konnte bzw. wo man sie für weniger glaubwürdig hielt als Vertreter bürgerlicher Parteien. Allerdings wurden beide Parteien dabei in der Regel zum Sprachrohr der sowjetisch gesteuerten SED-Deutschlandpolitik degradiert ${ }^{5}$. Zum zweiten dienten die bürgerlichen Parteien für die sowje-

1 Wichtige Dokumente sind der Edition von Bonwetsch u.a. (Hg.), Politik, zu entnehmen; Naimark, Russians, S. 410, hebt besonders die Rolle der Propagandaverwaltung hervor.

2 So auch Richter, Entstehung, S. $2538 \mathrm{f}$.

3 Sommer, Liberal-Demokratische Partei Deutschlands, S. 49f.; Suckut, Erwartung, S. 415; Koch u.a., Versuch, S. 104 ff.; Richter, Ost-CDU, S. 37-41.

4 Suckut, Christlich Demokratische Union Deutschlands, S. 519-522.

5 Bode, Liberal-Demokraten; Engelmann, Verbindungen; Rißmann, „Die Differenzierung fördern“, S. 195-200; Richter, Ost-CDU, S. 170 ff., 334 ff., 374 f.; Suckut, Erwartung; so fügte die LDP im Oktober 1951 ihrem Namen ein D für Deutschland hinzu und erhoffte sich mehr Schlagkraft in der damals laufenden SED-Kampagne für eine Wiedervereinigung; Sommer, Liberal-Demokratische Partei Deutschlands, S. 9. 
tischen Besatzungspolitiker zur Stabilisierung ihrer Herrschaft in der SBZ. Diese Funktion hatte zumindest bis zur Verfestigung der Teilung 1948 immer auch eine gesamtdeutsche Komponente. Denn die SBZ mußte als "Standbein“ und operative Ausgangsbasis für weitere deutschlandpolitische Vorstöße Moskaus zu allererst gesichert werden ${ }^{6}$. Dazu sollten die Blockparteien als schichtenspezifische "Transmissionsparteien" den seit 1945 betriebenen wirtschaftlichen und gesellschaftlichen Umwälzungsprozeß im Innern flankieren, indem sie jene Bevölkerungskreise binden, mobilisieren und gegebenenfalls neutralisieren sollten, die die KPD/SED gewöhnlich nicht erreichte und mit denen sich die formierende Kaderpartei nicht belasten wollte. Der Einheitsfrontausschuß war dabei die zentrale Bühne, auf der die Parteiführungen für die gesellschaftspolitischen Ziele der SMAD eingeschworen werden sollten, um diesen ein höheres Maß an Glaubwürdigkeit und politischer Legitimität zu verleihen.

Dieser anspruchsvolle Aufgabenzuschnitt für CDU und LDP verstärkte zugleich den Kontrollanspruch der sowjetischen Machthaber. Um sie für ihre Aufgaben zu wappnen, mußten sie in den Augen von SMAD und KPD/SED durch politische und personelle "Transformation “7 erst zurechtgeschliffen werden. Vor persönlichen Verfolgungen scheuten die Sowjets dabei nicht zurück ${ }^{8}$. Andererseits minderte diese Umformung die Akzeptanz von CDU und LDP als Gesprächspartner für die westliche Bevölkerung. Man riskierte damit, die Mitgliederbasis im Osten zu verlieren, wenn für diese keine Differenz zur SED-Programmatik mehr erkennbar war. Der Handlungsspielraum und die Mittel von CDU und LDP waren zu begrenzt, um den Gleichschaltungsdruck erfolgreich abwehren zu können.

Schließlich muß unter deutschlandpolitischen Auspizien noch ein Blick auf die SED geworfen werden. Die KPD war fraglos eine Partei, die auch in den Westzonen Fuß fassen wollte, aber kaum in die westlichen Länder hineinwirken konnte. Hingegen ist die Gründung der SED im Frühjahr 1946 unter deutschlandpolitischen Gesichtspunkten umstritten. Die Vereinigung von SPD und KPD ist bislang meist als Vorgang mit spaltendem Effekt gesehen worden, weil sie wegen ihres zwanghaften Charakters als Zeichen für den umfassenden Machtanspruch der Kommunisten, den gesellschaftlichen Umwälzungsprozeß in der SBZ und damit für das Auseinanderdriften der Besatzungszonen interpretiert worden ist ${ }^{9}$. Wilfried Loth - und ihm folgen inzwischen andere - hat die SED-Gründung

6 Zur Terminologie „Standbein“ und „Spielbein“ siehe Laufer, Konfrontation, S. 58. Unübersehbar war das Parteiensystem so angelegt, daß es auf die phasenweise mit unterschiedlicher Intensität verfochtenen deutschlandpolitischen Ziele reagieren konnte. Angesichts einer schwindenden Aussicht, ganz Deutschland politisch und sozial umformen zu können, diente das SBZ-Parteiensystem zur Machtsicherung in der SBZ; so Koch u.a., Versuch, S. 105; Staritz, Sozialismus, S. $146 \mathrm{ff}$.

7 Vgl. Weber, Einleitung, S. $11 \mathrm{ff}$.

8 Die Mittel sowjetischer Stellen nennt ebd., S. 37-48, der komplizierte Prozeß für die CDU bei Richter ausgeführt, Richter, Ost-CDU, S. 370, 385 ff.; zu den CDU-Opfern sowjetischer Verfolgung, Kaff (Hg.), „Gefährliche politische Gegner“; Verfolgt und entrechtet.

9 Weber, Geschichte, S. 116; zum Vorgang: Malycha (Hg.), Weg, S. LXIV-CIX, ders., Partei, S. 41-54. 
im Frühjahr 1946 anders, nämlich als gesamtdeutsch angelegten Akt Stalins interpretiert. Die Vereinigung sei nur sinnvoll im Rahmen einer Strategie zu erklären, „bei der die Kommunisten damit zu rechnen hatten, sich freien Wahlen stellen zu müssen"10. Wenn es der Sowjetunion nur um einen besseren Zugriff auf die eigene Besatzungszone gegangen wäre, so Loth, wäre sie mit einer schlagkräftigen kleinen Kaderpartei besser beraten gewesen als mit einer zunächst von Integrationsproblemen gebeutelten Massenpartei der Arbeiterbewegung.

Beide Erklärungsversuche sind bislang nicht empirisch bewiesen, sondern beruhen auf Plausibilitätserwägungen. Für die offizielle deutschlandpolitische Strategie der KPD, die wiederum mit ziemlicher Sicherheit diejenige der Sowjetunion spiegelt, ist in diesem Zusammenhang eine Notiz Wilhelm Piecks vom 6. Februar 1946 aufschlußreich. Sie referiert einen Bericht Ulbrichts über Stalins Ausführungen in Moskau zur Deutschlandpolitik im Zusammenhang mit der SED-Gründung. Demzufolge gab es zwei Reichweiten der damaligen deutschlandpolitischen Konzeption: Ein „Maximalprogramm“ sah die „Einheit Deutschland“ vor (dazu sollte auch der Name KPD in den Westzonen in Sozialistische Einheitspartei Deutschlands verwandelt werden); ein „Minimalprogramm“ stand unter dem $\mathrm{Si}$ gnum der „Übergangsfrage“ und unterschied die Ausgangslage für eine kommunistische Machterringung in westlichen Demokratien deutlich von derjenigen in Rußland. Dort habe man die „Herrschaft der Arbeiterklasse“ über den „kürzesten Weg“ herstellen können, im parlamentarisch geprägten Westen jedoch komme man nur „auf demokrat. Weg - zur Arbeitermacht"11.

Ohne die deutschlandpolitische Problematik hier näher zu erörtern, seien zwei Aspekte angemerkt, die Stadien bedingten Einheitswillens in der sowjetischen Deutschlandpolitik erläutern sollen: (1) Zwar rangierte in dieser Niederschrift die Einheit Deutschlands vor einer Erlangung der Macht durch die „Arbeiterklasse“ in einem vereinten Deutschland; dies scheint nur folgerichtig zu sein: Bei allem Revolutionswillen wäre ein "Sieg der Arbeiterklasse“ in allen Besatzungszonen, also vor der Bildung eines vereinten Gesamtstaates, aufgrund des Einflusses der Westalliierten in ihren Zonen eine unrealistische Konzeption gewesen. In diesem Sinne mußte daher die Vereinigung der Zonen vorrangig, als Ausgangsbasis für weiteres kommunistisches Wirken, erreicht werden. Diese Vorrangigkeit der Einheit Deutschlands bedeutet jedoch nicht, daß die sowjetischen Besatzer bereit gewesen wären, ihre bestehenden, an die Beherrschung der SBZ gebundenen deutschlandpolitischen Handlungsmöglichkeiten zu riskieren; die Ausgangsbasis SBZ mit einer sowjetisch kontrollierten Einheitspartei durfte in diesem Sinne nicht leichtfertig zugunsten eines gesamtdeutschen Staates aufgeben werden ${ }^{12}$.

10 Loth, Stalins ungeliebtes Kind, S. 44-55, bes. 53 f., Zitat S. 53. Die bürgerlichen Blockparteien hätten sich durch diesen Akt nicht sonderlich alarmiert gezeigt; die CDU habe sich bessere Chancen für die Mitgliederwerbung unter der SPD-Klientel erhofft; Naimark, Russians, S. 275-284, bes. 276.

11 Badstübner/Loth (Hg.), Wilhelm Pieck-Aufzeichnungen, S. 68f., hier 68. Diese Konzeption auch im Artikel Anton Ackermanns, "Gibt es einen besonderen deutschen Weg zum Sozialismus?", in: Einheit, Februar 1946.

12 Anders Loth. 
Offenbar jedoch verkannte die sowjetische Politik die abschreckende Wirkung der Vereinigung auf die westliche Sozialdemokratie und sah zu wenig das Spaltende. Vielmehr gab man sich der Illusion hin, trotz zwanghafter Art der „Gewinnung " der Sozialdemokratie letztlich eine stärkere gesamtdeutsche Ausgangsbasis zu erreichen. Nach Loths Sicht gewann die Einheitspartei auch im Zusammenhang mit den Verhandlungen der Pariser Außenministerratstagung ab 25. April 1946 an „strategischem Gewicht“: Denn im Falle eines raschen Endes der Besatzungszeit wäre sie der einzige Hebel gewesen, um eine „Demokratisierungspolitik" nach sowjetischem Verständnis und die Reparationsforderungen zu bekräftigen ${ }^{13}$. In der Tat: Wären alle Sozialdemokraten Deutschlands mitgezogen, so hätte eine gesamtdeutsche SED durchaus nationale Durchschlagskraft besessen - dies ist allerdings eine hypothetische Überlegung. Im historischen Kontext und vor dem Hintergrund des diktatorischen Charakters der sowjetischen Besatzungspolitik belegt dieser Vorgang Naimarks Gesamtinterpretation, derzufolge in der sowjetischen Politik die unflexiblen Züge dominierten. Vor allem aber war im Gedankenhorizont der Besatzer ein anderes Beherrschungskonzept prinzipiell nicht vorgesehen ${ }^{14}$. Bis Mai 1947 waren alle Versuche versandet, die SED als Neugründung in den westlichen Zonen zu etablieren. Zuletzt äußerten die Sowjets nur noch die Absicht, die KPD in SED umzubenennen ${ }^{15}$.

(2) Eine weitere Episode der SED-Parteigeschichte ist bislang ohne Klärung der Zusammenhänge geblieben. In den Debatten über ein gesamtdeutsches Parteiengesetz im Alliierten Kontrollrat hatten die Vertreter der USA und Großbritanniens die Wiederzulassung der SPD in der sowjetischen Zone als Voraussetzung genannt ${ }^{16}$. Akten zeigen inzwischen, daß Stalin seit Dezember 1946 offenbar erwog - und dies im Frühjahr 1947 anläßlich eines Besuches der SED-Führungsspitze in Moskau als seinen Willen aussprach -, die SPD in der SBZ wieder zuzulassen ${ }^{17}$. Hier ist besonders die Verquickung des deutschlandpolitischen Arguments mit den Fragen der Beherrschung der SBZ zu unterstreichen. Unabhängig davon, ob er dies tatsächlich intendierte oder nicht, führte seine Äußerung der SED eine mögliche Konkurrenzsituation mit einer wiederzugelassenen SPD vor Augen. Der Ausgang der Wahlen im Herbst 1946 - insbesondere in Berlin -, die trotz aller Unterstützung der SMAD letztlich nur einen knapp errungenen SEDSieg herbeigeführt hatten, zeigte ganz deutlich, wie unattraktiv diese SED selbst in der sowjetisch kontrollierten Zone agierte und wie sehr sie bei gesamtdeutschen Wahlen scheitern würde. Mit einer SED, die sich, sowjetischen Rückhalts gewiß, zu sehr in Sicherheit wiegte und im Kampf um die Massen erlahmte, war jedoch

13 Loth, Stalins ungeliebtes Kind, S. 60-63.

14 Naimark, Russians, S. $466 \mathrm{ff}$.

15 So wie es im übrigen auch die Pieck-Notiz vom 6. 2. 1946 vorgesehen hatte, Badstübner/ Loth (Hg.), Wilhelm Pieck-Aufzeichnungen, S. $68 \mathrm{f}$. Eingehend dazu die Regionalstudie von Vorholt/Zaib, SED; Müller, Entstehung, S. $2354 \mathrm{f}$.

16 Müller, Entstehung, S. 2354 f., zum sowjetischen Vorgehen im Alliierten Kontrollrat in dieser Frage 1946, Loth, Stalins ungeliebtes Kind, S. 62 f.; Mai, Kontrollrat, S. 128-140.

17 Bonwetsch/Bordjugov, Stalin, S. 289ff.; Loth, Stalins ungeliebtes Kind, S. 79-81; Naimark, Russians, S. 299-301. 
weder in der SBZ und erst recht nicht in einem Gesamtdeutschland als verläßliche Kraft für sowjetische Interessen zu rechnen. Die Androhung des Privilegienentzugs sollte die SED zu verstärkter Anstrengung anspornen, damit sie sich zu einem schlagkräftigeren Instrument der Sowjetunion in der SBZ und davon ausgehend für das gesamtdeutsche Parkett entwickle. Freilich konnte sich die SED ausrechnen, daß Kurt Schumachers Linie, der eine Wiederzulassung der SPD im Osten und damit eine nationale Repräsentation der SPD von der Abschaffung des Blockprinzips abhängig machte, dieser Drohung Stalins ihre unmittelbare Schärfe nahm. Eine künstliche Belebung des Umgangs mit den Blockparteien war auch Teil einer veränderten sowjetischen Strategie in der blockpolitischen Stagnation und Krise 1947/48, die in der Forschung bislang wenig berücksichtigt worden ist.

\section{Blockpolitik in der Krise 1947/1948}

Die Blockpolitik von 1947 bis Anfang 1949 ist ein Beispiel dafür, daß aufgrund neu zugänglicher sowjetischer Quellen ein differenzierteres Bild der Deutschlandpolitik zu zeichnen ist; es erweitert die bislang bekannten Motive zumindest zur Gründung der Bauernpartei - jene zur Gründung der NDPD sind noch eigens zu untersuchen - und rückt sie insgesamt in ein anderes Licht. Was war im Einheitsfrontausschuß seit seiner Gründung geschehen? Bald zeichneten sich Konflikte ab, die Themen wie Methoden der Blockpolitik betrafen, wie sie die SED offensichtlich mit weitgehender Rückendeckung der sowjetischen Besatzer betrieb. Im Zusammenhang mit der Bodenreform war es seit dem Sommer 1945 zu massiven Zusammenstößen mit den Führungen der bürgerlichen Parteien gekommen. Zu den umstrittenen Themen im Block gehörten u.a. die Industrieenteignungen in Form der Sequestrierungen von Betrieben bzw. Vermögen von NS-Aktivisten und „Kriegsverbrechern“ und die Frage der Zustimmung zur sogenannten Volkskongreßbewegung. Meist überwogen jedoch tagespolitische Fragen. Die bürgerlichen Parteien ergriffen im zentralen Block selten die Initiative, sie verfolgten jedoch eine Politik der "hemmend modifizierenden “ Einflußnahme, die die Kooperationsfähigkeit der SED-Führung laufend prüfte und ihr zugleich die Grenzen des blockpolitischen Instrumentariums vorführte. Sie suchten die Strategie der Einheitssozialisten zu durchkreuzen, die bei Konflikten in den Parlamenten den Block als Hebel zur Durchsetzung ihrer Interessen benutzen wollte ${ }^{18}$. Ein Grund für diese verhaltene Strategie der Bürgerlichen im Einheitsfrontausschuß lag sicherlich darin, daß sie die Blockpolitik gerade nicht als Alternative zu den Parlamenten aufwerten wollten.

Schon seit der drohenden Gewichtsverschiebung im Gefolge der SED-Gründung 1946 - die SED beanspruchte die Gesamtzahl der Plätze, die vordem KPD und SPD eingenommen hatten ${ }^{19}$ - liefen die bürgerlichen Parteien Gefahr, in den Blöcken majorisiert zu werden. Zwar widersetzten sie sich erfolgreich dem höchstwahrscheinlich von der SED initiierten Antrag des FDGB vom Mai 1946

18 Suckut, Blockpolitik, S. 26 f.; Zitat Staritz, Entstehung, S. 100; Suckut, Krise, S. 682. Reinert, Parteien, S. 85 f., 88f., 93-100.

19 Suckut, Blockpolitik, S. 27. 
um Aufnahme in den Berliner Block, indem sie argumentierten, nur Parteien und eben keine Massenorganisationen seien dazu berechtig ${ }^{20}$. Auch gelang es ihnen, regionale Vorstöße der KPD/SPD und dann der SED abzuwehren. So wiesen CDU und LDP Anfang 1946 in Brandenburg die Forderung von KPD und SPD zurück, zur Vorbereitung der Wahlen im Herbst die Beratende Versammlung bei der Provinzialverwaltung neben den Blockparteien mit Vertretern des FDGB zu besetzen; das gleiche Ansinnen der SED hatte der zentrale Block zuvor schon abgelehnt $^{21}$. Die Aufnahme des FDGB in den Einheitsfrontausschuß war nur ein Punkt, den die SED mit sowjetischer Hilfe in der zweiten Jahreshälfte 1947 erneut anging 22 und der zusammen mit anderen Faktoren zu einer krisenhaften Zuspitzung der Blockpolitik führte.

Die Hauptursache für den massiven Konflikt im Parteiensystem, der streckenweise zum völligen Erlahmen der Blockarbeit in der zweiten Jahreshälfte 1947 in den Ländern und seit dem Frühjahr 1948 auch im zentralen Einheitsfrontausschuß führte, lag im Anspruch der SED auf die politische Führung, der den Gründungsvereinbarungen des Blocks widersprach ${ }^{23}$. Im Vorfeld ihres II. Parteitages im September 1947 meldete die SED den Führungsanspruch offiziell an. Ein ideologischer Transformationsschub in der Blockpolitik war Mitte 1947 auch daran abzulesen, daß die SED ihre Partner offentlich in „fortschrittliche“ und „reaktionäre" unterschied 24 .

Parallel zur ideologischen Aufrüstung der SED, die sich seit Anfang 1947 unter sowjetischer Rückendeckung vollzog ${ }^{25}$, sahen CDU und LDP 1947 ihre Entwicklungschancen als Parteien wie auch ihre Beteiligung am politischen Leben immer mehr zurückgedrängt. Ihre Forderungen nach Positionen in den Verwaltungen waren meist nur unter großen Anstrengungen durchzusetzen, die Schlüsselpositionen wie die Innenverwaltung behielt sich die SED vor. Die Gestaltung der Landesverfassungen entzündete heftige Debatten ${ }^{26}$. Die Eingriffe sowjetischer Behörden in die inneren Parteiangelegenheiten durch „Säuberungen“ und die Förde-

20 Ebd., S. 27 f., Dok. 72, S. 138, Dok. 75, Protokoll Sitzung vom 29. 5. 1946, S. 143 f.

21 Reinert, Parteien, S. 118-120. Diese erneuten Initiativen in Brandenburg stammten nachweislich aus SED-Feder.

22 Aufschlußreich dazu die internen Besprechungen der CDU, abgedruckt bei Suckut, Blockpolitik, S. 216-219, Sitzung des erweiterten Vorstandes der CDU, 12. 7. 1947. Als Landsberg aus Berlin auf die Funktion der "horizontalen Ständeorganisationen“ in der leninschen Konzeption hinwies, und damit gegen eine FDGB-Beteiligung plädierte, wurde er von Hauptmann Kratin - in der Informationsverwaltung der SMAD für die CDU zuständig - unterbrochen mit dem Rat, nochmals genauer dort nachzulesen. Die Aufnahme des FDGB war also eine Forderung der SMAD.

23 Vgl. die Kritik Generalleutnant Bokows vom Dez. 1946 über die zu „unverbindlich, breit angelegte“ Gründungserklärung vom 12.8. 1945, die den bürgerlichen Parteien zu viel Handlungsspielraum geboten habe. Foitzik, Struktur, S. 373.

24 Staritz, Gründung, S. 153; Reinert, Parteien, S. 120-123.

25 Malycha, Partei, S. $78 \mathrm{ff}$., $86 \mathrm{ff} . ;$ Creuzberger, Besatzungsmacht, S. 106-110; entsprechend die Ausrichtung der Parteischulung schon 1947 an der KPdSU, Kluttig, Parteischulung, S. 60 .

26 Am Beispiel Brandenburgs führt Reinert diese Konflikte und ihren Niederschlag in der Blockpolitik vor, Reinert, Parteien, S. 126-138; Creuzberger, Besatzungsmacht, S. 124 133; Baus, CDUD, S. 341-343. 
rung "fortschrittlicher" Kräfte bewiesen den engen Handlungsradius und unterwarfen die bürgerlichen Parteien einem permanenten Umformungsdruck ${ }^{27}$.

In dieser Situation verfolgte die Moskauer Deutschlandpolitik und die Politik der Besatzer in der SBZ mit ziemlicher Sicherheit eine einvernehmliche Linie ${ }^{28}$. Erstere basierte auf einer zunehmenden Ostorientierung und Verselbständigung in der $\mathrm{SBZ}^{29}$, in der die mit dem Einheitsfrontausschuß verknüpfte gesamtdeutsche Blickrichtung in den Hintergrund rückte. Insofern nahmen die sowjetischen Besatzer ein Erlahmen des Blocks als Folge ihrer Transformationspolitik in Kauf. Zwar hatte Stalin noch im Frühjahr 1947 mit der Rede über eine mögliche Wiederzulassung der SPD in der SBZ deutschlandpolitische Rücksichtnahmen hinsichtlich der Umformung von Staat und Gesellschaft angedeutet. Mit dem Scheitern der Moskauer Außenministerkonferenz (März/April 1947), dem Fehlschlag der sowjetischen Politik zur Verhinderung des Marshallplanes, der Gründung des Kominform-Büros und der Shdanowschen „Zwei-Lager-Theorie“ traten diese Rücksichtnahmen aber in den Hintergrund ${ }^{30}$.

Die besatzungspolitische Linie der Informationsverwaltung der SMAD und ihrer Länderverwaltungen wurde von den Schlußfolgerungen aus der Wahlanalyse Anfang 1947 beeinflußt. Diese sahen vor, von der bisherigen Praxis strikter Kontrolle und Regelung bis ins einzelne abzukommen und den Handlungsspielraum der SED auszuweiten, um sie so als eigenständige Kraft zu stärken. Nur sie allein wurde - im Unterschied zu den bürgerlichen Parteien - als Garant für eine dauerhafte "Demokratisierungspolitik“ im Sinne der Sowjets angesehen ${ }^{31}$.

Die gesellschaftliche Transformationspolitik und der Führungsanspruch der SED führten in der zweiten Jahreshälfte 1947 zu einer ablehnenden Haltung der bürgerlichen Parteien gegenüber Gesetzesvorhaben der SED in den Landtagen und zu einem Erlahmen der Blockpolitik in den Ländern. So meldete die SED wieder Rückschläge in der Umwälzungspolitik: „Bürgerliche“ Einflüsse in den Ministerien unterliefen die Bodenreform; Abgeordnete von CDU und LDP lehnten im thüringischen Landtag die Überführung der Bergwerke und Bodenschätze in Landeseigentum ab und verschleppten eine solche Entscheidung in Sachsen-

27 Weber, Einleitung, S. 37-48; Sommer, Liberal-Demokratische Partei Deutschlands, S. $43 \mathrm{ff}$.; Richter, Ost-CDU, S. $385 \mathrm{ff}$.

28 Vgl. Creuzberger, Besatzungsmacht, S. $186 \mathrm{ff}$. Diese wird zuweilen berechtigt bezweifelt.

29 Institutionelle Kerne waren bereits Ende 1946 mit der Gründung der Deutschen Verwaltung des Innern geschaffen worden; Laufer, Ursprünge. Schon 1947 war die SBZ in das Wirtschaftsgefüge der osteuropäischen Volksdemokratien einbezogen worden; Foitzik, Struktur, S. 380.

30 Zur Außenministerkonferenz Kessel, Westeuropa, S. 211-257; zur sowjetischen internen Reaktion auf den Marshallplan bis zur schließlichen Ablehnung auf sowjetischer Aktenbasis, Parrish/Narinsky, Evidence, bes. S. 4 ff., $13 \mathrm{ff} ., 25 \mathrm{ff}$.; Loth, Stalins ungeliebtes Kind, S. 83-88, $92 \mathrm{f}$. Allerdings wurde die SED trotz Drängens ihrer Führung nie in das Kominformbüro aufgenommen, Friedrich, Kominform, S. 327 ff.; Malycha, Partei, S. 94.

31 Einem entsprechenden Grundsatzreferat des thüringischen SMA-Chefs, Kolesnitschenko, vom Januar 1947, verlieh Sokolowski Weisungscharakter. Ein Großteil der von Kolesnitschenko aufgestellten Vorschläge (radikale Änderung des Arbeitsstil der SMA) verlief im Sande. An der massiven Unterstützung der SED änderte dies nichts; Creuzberger, Besatzungsmacht, S. 106-110. 
Anhalt ${ }^{32}$. Die bürgerlichen Parteien Brandenburgs erhoben im November 1947 Bedenken gegen den Antrag der SED, die Überführung enteigneter Betriebe in Landeseigentum verfassungsmäßig zu verankern ${ }^{33}$.

Als Jakob Kaiser sich weigerte, einen von der SED eingebrachten Aufruf zur Unterstützung der sogenannten Volkskongreßbewegung für die CDU zu unterzeichnen und eine Beteiligung von CDU-Mitgliedern an dieser Bewegung ablehnte, spitzte sich die Krise des Einheitsfrontausschusses $\mathrm{zu}^{34}$. Die Weigerung lieferte der SMAD nur den letzten Anlaß, um Jakob Kaiser und Ernst Lemmer am 19. Dezember 1947 abzusetzen und ermöglichte es ihr, eine "von außen gesteuerte Krise in die Union hineinzutragen "35. Kaiser hatte sich durch seine Kritik an der Ostintegration der SBZ längst zuvor desavouiert. Der entscheidende Grund für die Ablösungen lag darin, daß sich die CDU unter beider Führung in einer Frage, die auf Gesamtdeutschland bezogen war, dem sowjetischen Kalkül entzog. Sie schmälerte damit die Legitimation der sowjetischen Deutschlandpolitik in einer kritischen Situation ${ }^{36}$.

Zwischen dem 13. Februar und dem 5. August 1948 trat der Einheitsfrontausschuß nicht mehr zusammen. In dieser Zeit wurden wichtige innenpolitische Weichenstellungen getroffen, die auf eine weitere Ostorientierung und den Ausbau vorstaatlicher Institutionen hinausliefen. Dazu gehörte die Erweiterung der gesetzgebenden Rechte der $\mathrm{DWK}^{37}$, der Übergang zu einer langfristigen Wirtschaftsplanung, der Beginn der Ausarbeitung einer Verfassung im Volksrat und die völlige Ausrichtung des Staatsapparates auf die SED ${ }^{38}$. Hatte der LDP-Vorstand der Volkskongreßbewegung noch mehrheitlich zugestimmt, so lavierte die Partei nach dem Tod von Külz führungslos und profilierte sich seit dem Sommer 1948 offen als gegnerische Kraft zur SED. Dies brachte ihr einen enormen Mitgliederzustrom. Auch die Mitgliederstatistik der CDU verbuchte im Dezember 1947 mit 200757 ihren bis dahin höchsten Stand ${ }^{39}$.

Seit geraumer Zeit erstellte der Apparat der KPdSU zu den Verhältnissen in der SBZ wie auch zur Politik der Informationsverwaltung Analysen ${ }^{40}$. Mit der krisen-

32 Staritz, Gründung, S. 154.

33 Reinert, Parteien, S. $99 \mathrm{f}$.

34 Näher dazu Bauer, Krise.

35 Baus, CDUD, S. 397.

36 Richter, Ost-CDU, S. 32-34; Suckut, Blockpolitik, S. 32, ebd. Dok. Nr. 147, 148, demnach berichtete Kaiser Pieck über die abschlägigen Antworten von Josef Müller u.a.; Baus, CDUD, S. 397-408.

37 SMAD-Befehl Nr. 32 (12. 2. 1948) abgedruckt in: Um ein antifaschistisch demokratisches Deutschland, S. $585 \mathrm{f}$.

${ }^{38}$ Suckut, Blockpolitik, S. 39; Staritz, Gründung, S. 133-141; Deutsche Geschichte, Bd. 9, S. $367 \mathrm{ff}$.

39 Diese Zahl bei Baus, CDUD, S. 483; Suckut, Krise, S. 682f.; zu den Auseinandersetzungen zwischen SED und Ost-CDU um die Blockpolitik 1948: Richter, Ost-CDU, S. 41, 55 , 68-71; Dowidat, Veränderung, S. 513; zur Zurückdrängung der LDP im Sommer 1948: Sommer, Liberal-Demokratische Partei Deutschlands, S. 50-56, Bode, Liberal-Demokraten, S. 113-122, Louis, Liberal-Demokratische Partei, S. 127, 149-151.

40 Eine Reihe von ihnen bezweckte, Tjulpanows Arbeit zu kontrollieren. Seine politische Bedeutung, die Hintergründe des Vorgehens gegen ihn und die Umstände, die ihn offenbar immer wieder retteten, sind nach wie vor ungeklärt. Naimark, Russians, S. 318-352, 
haften Zuspitzung im Block und der wirtschaftlichen Lage im Herbst 1947 intensivierten sich in Moskau Diskussionen um eine Modifizierung der besatzungspolitischen und darin inbegriffen der bündnispolitischen Konzeption. Bei der Frage nach den Motiven für die Gründung von DBD und NDPD dominiert bislang die Erklärung, daß damit in erster Linie die bürgerlichen Parteien politisch zurückgedrängt werden sollten ${ }^{41}$. Wernet-Tietz vermutete plausibel auch Unzulänglichkeiten der VdgB und Reibungen in der SED aufgrund ihrer „Bauernpolitik“42. Einige Autoren gehen irrtümlich davon aus, daß die Gründungen von der SED initiiert gewesen seien ${ }^{43}$. Beide Gründungen waren, so wird zu zeigen sein, von der SMAD lanciert. Zumindest im Fall der hier untersuchten DBD mußte die Gründung gegen den Willen der SED vorangetrieben werden. Ohne die langfristig eintretende Zurückdrängung der bürgerlichen Parteien bestreiten zu wollen, sind die Parteineugründungen ursprünglich jedoch in eine Debatte in Moskau und im Stab des „Politischen Beraters“ der SMAD einzubetten, die um eine Modifizierung und Neubestimmung der Besatzungspolitik kreiste. Die Diskussionen deuten auf ein deutschlandpolitisches Lavieren Moskaus in der ersten Jahreshälfte 1948 hin.

Im SMAD-Apparat gab es verschiedene Stellen, die sich mit den Parteien und der Blockpolitik beschäftigten ${ }^{44}$. Neben dem „Politischen Berater" Semjonow, bei dem offenbar die Richtlinienkompetenz lag, übernahm die Informationsverwaltung unter Tjulpanow einen erheblichen Teil der täglich auszuführenden Arbeit ${ }^{45}$. Tjulpanow ließ gegenüber den bürgerlichen Parteien keinen Zweifel daran, daß er ihre politische Arbeit und Führung für höchst unzureichend hielt und er warf ihnen vor, letztlich nicht auf der Seite der Sowjetunion zu stehen ${ }^{46}$. Seit Sommer 1947 notierten sowjetische Stellen besorgt, daß sich die ökonomische Lage in der SBZ laufend verschärfe und einen besseren Rückhalt der SED bei der Arbeiterschaft verhindere ${ }^{47}$. Mit dem völligen Stillstand im Einheitsfrontausschuß und der offenen Profilierung der LDP als gegnerische politische Instanz standen Tjulpa-

Bonwetsch/Bordjugov, Affäre Tjul'panov, S. $250 \mathrm{ff}$., siehe Bonwetschs Einleitung zu der von ihm u.a. besorgten Edition, Politik, S. XXIX-XXXIX. Während manche Forscher die mächtige Rolle Tjulpanows unterstreichen (u.a. Strunk, Loth), warnt Foitzik vor einer Überbetonung seiner Funktion und plädiert für dessen Einordnung in die Machthierarchien der SMAD-Organisation, Foitzik, Struktur, S. 117, 122-124. Siehe Naimark, Russians, S. 319, 406, und seine Einleitung in der Edition von Bonwetsch u. a., Politik, S. Xf.

41 So in der Literatur der 60er Jahre, Mattedi, Gründung, S. 127 f., aber auch bei Suckut, Krise, S. 685 f., Richter, Ost-CDU, S. 102, Loth, Stalins ungeliebtes Kind, S. 133, Jesse, Parteien, S. 88, Wettig, Bereitschaft, S. $137 \mathrm{f}$.

42 Wernet-Tietz, Bauernverband, S. $101 \mathrm{f}$.

43 Suckut, Krise, S. 685; so noch Reinert, Parteien, S. 125.

44 Eingehender dazu Kap. IV.1. Kompetenzverteilung und Einflußszenario innerhalb der SMAD sind bislang nur unzureichend durchleuchtet, wie die Auseinandersetzung um die Rolle Tjulpanows belegt.

45 Siehe dazu Dok. Nr. 55 vom 19. 9. 1946, in: Bonwetsch u.a. (Hg.), Politik, S. 235-242. Demnach nannte der für Parteien in der Informationsverwaltung zuständige Oberstleutnant Nasarow Tjulpanow und Bokow als jene, die die inhaltliche Arbeit der Abteilung bestimmten.

46 Naimark, Russians, S. 329-335, hier 332.

47 Ebd., S. $304 \mathrm{f}$. 
now und die Informationsverwaltung im Feuer der Kritik des Zentralkomitees der KPdSU. Hingegen zeigte man in Moskau Verständnis für die höherrangigen politisch Verantwortlichen in der SBZ, Sokolowski und Makarow. Ihnen hielt man zugute, daß sie es aufgrund anderer Aufgaben oder im Falle Makarows wegen einer längeren Krankheit versäumt hatten, Tjulpanows harten Kurs gegenüber den bürgerlichen Parteien deutlicher zu kontrollieren ${ }^{48}$.

Im Mai 1948 erhob eine neu eingesetzte Überprüfungskommission schwere Vorwürfe gegen Tjulpanows Informationsverwaltung. In einem ausführlichen Bericht an Shdanow kritisierte sie eine „Politik der wirtschaftlichen Strangulierung des kleinen und mittleren Bürgertums“, das bei diesen einen „Zustand der Unsicherheit und Verwirrung" erzeuge und es veranlasse, "sich mißtrauisch gegenüber der sowjetischen Besatzungsmacht und der SED zu verhalten“ und schließlich ,in die Arme der Reaktion" treibe ${ }^{49}$. Besonders massiv waren die Vorwürfe hinsichtlich der Block- und Parteienpolitik:

„Die Informationsverwaltung hat die Bedeutung des Blocks der antifaschistischen Parteien als eines mächtigen Hebels zur Lösung der politischen Hauptaufgaben der gegenwärtigen Periode der Entwicklung Deutschlands - der Eroberung der Volksmassen - nicht verstanden. Sie betrachtet diesen Block als eine nur vorübergehende, oberflächliche Verbindung der politischen Parteien, nur geschaffen zur Lösung dieser oder jener praktischen Frage und hat keinerlei wirksame Maßnahmen zur Festigung des Blocks ergriffen.“

Außerdem verfolge die Informationsverwaltung eine „unrichtige Linie“ gegenüber den bürgerlichen Parteien, da sie diese „bereits zum gegenwärtigen Zeitpunkt als völlig feindlich “ betrachte. Sie versuche nicht, die Kräfteverhältnisse in beiden Parteien zugunsten der "progressive[n] Kerne“ zu verändern. Statt dessen gestatte sie der SED, sich in einigen Dokumenten „in aufdringlicher Weise“ als einzige Partei darzustellen, die am Aufbau eines "neuen, demokratischen Deutschland“ teilnehmen könne. Dieses Vorgehen widerspreche den „Prinzipien des Blocks" und vertreibe die bürgerlichen Parteien. Da diese „ihre Liquidierung“ und die Errichtung einer „SED-Herrschaft" fürchteten, führten sie einen „antisowjetischen Kampf“ und opponierten gegen die SED. Beider „Mißtrauen“ sei „so sehr angewachsen, daß sie die Einberufung des Volkskongresses als Maßnahme zu ihrer Vernichtung ansehen. All dies hat dazu geführt, daß die Durchführung der Block-Politik auf äußerste Schwierigkeiten stößt." Diese Politik führe jedoch nicht zu einer tatsächlichen Stärkung der SED, denn für sie würden „Treibhausbedingungen geschaffen, und die Partei wird nicht im ununterbrochenen Kampf mit den Feinden gestählt." Die Analyse forderte abschließend Tjulpanows Ablösung, da er die „historischen Perspektiven der Entwicklung Deutschlands“ nicht verstehe $^{50}$. Unabhängig davon, ob die herben Vorwürfe gegen Tjulpanow lediglich

48 Dennoch wurde auch Makarow im Mai 1948 abgelöst; ebd., S. 341; Bonwetsch u.a. (Hg.), Politik, Dok. Nr. 63, S. 278.

49 Memorandum der Kommission des ZK der KPdSU(B) für A. Shdanow über das Ergebnis der Überprüfung der Arbeit der Informationsverwaltung der SMAD (Auszug), undatiert, nach 5. 5. 1948, ebd., Dok. Nr. 63, S. 275-280, auch folgende Zitate S. $276 \mathrm{f}$.

50 Ebd., S. 278. 
ein Steinchen im undurchschaubaren Dickicht politischer Attacken gegen ihn waren, belegen sie die Absicht des ZK der KPdSU, diese Art von Besatzungspolitik gegenüber den bürgerlichen Parteien zu ändern.

Die Gründung von DBD und NDPD ${ }^{51}$ war folglich eingebettet in eine Diskussion um die Belebung der Blockpolitik, als deren Fürsprecher der „politische Berater" Semjonow auftrat ${ }^{52}$. Aus der Sicht der SMAD war die Gründung von zwei neuen Parteien dazu geeignet, den bürgerlichen Parteien zu signalisieren, daß man am Mehrparteiensystem und an der Blockpolitik festhalten wolle. Die SMAD reagierte damit auf die Befürchtung der bürgerlichen Parteien, daß ihren Organisationen in einer SED-dominierten Parteienlandschaft das Ende drohe. Die sowjetischen Stellen wollten vielmehr gegenüber CDU und LDP bekräftigen, daß man sie weiterhin brauche und nicht plane, die SED als alleinige politische Kraft zu installieren. Letzteres hing auch mit der Einschätzung des Besatzungsapparates zusammen, der die SED noch nicht für dazu fähig hielt. Auch die weitere Kritik an Tjulpanow nach den offiziell erfolgten Parteineugründungen im Hochsommer 1948 ist dazu geeignet, die Schlußfolgerung zu begründen, daß ursprünglich weitere, vielfältiger angelegte Ziele als dann tatsächlich eingetretene Wirkungen mit den Neugründungen verknüpft waren. Denn laut Moskauer Kritik betrieben er und Teile des sowjetischen Besatzungsapparates einen Kurs der Schwächung der bürgerlichen Parteien und Blöcke in den Ländern, der nicht mit der Moskauer Linie übereinstimmte. Nach wie vor würden Tjulpanow und andere sowjetische Stellen in den Ländern eine Politik der Liquidierung der Blockarbeit verfolgen und in Thüringen die Gründung der DBD dazu benutzen, für eine „Volksfrontpolitik “ zu plädieren ${ }^{53}$. Die dargelegte Moskauer Zielformulierung für die Politik gegenüber den bürgerlichen Parteien beschränkte sich nicht auf - sicherlich auch taktische - Kritik und Absichtsbekundungen, sondern ist auch an Handlungen abzulesen. So gestattete man der CDU, parallel zur Gründung der Bauernpartei in verstärktem Maße Ortsgruppen zu bilden. Diese Erlaubnis unterschied sich vom restriktiven Kurs in dieser Frage, wie er gerade im Vorfeld der Wahlen 1946 zur Herbeiführung des SED-Sieges praktiziert worden war. Im SED-Landesverband Mecklenburg - dem Kernland der DBD-Gründung - debattierte man über die Existenz eines SMAD-Befehls, der die Neugründung von CDU-Ortsgruppen einräumte ${ }^{54}$. Letzteres ist auch durch eine Pieck-Notiz vom 14. Mai 1948 zu einem Gespräch mit Tjulpanow und Nasarow über den organisatorischen Ablauf

51 Für den organisatorischen Aufbau der Parteien war Tjulpanow verantwortlich; Naimark, Russians, S. 347.

52 Zumindest beschuldigte Semjonow Tjulpanow bei Konstantinowski, daß dieser seine Anweisungen zur Behandlung der bürgerlichen Parteien bewußt ignoriere und den Mitarbeitern der Informationsverwaltung den Auftrag gebe, diese nicht zu beachten; Naimark, Russians, S. 344.

53 Memorandum Oberstleutnant G. Konstantinowkis für I. Schikin über das Ergebnis der Überprüfung der Informationsverwaltung der SMAD, 17. 8. 1948, Bonwetsch u.a. (Hg.), Politik, S. 283-289, S. 284.

54 MLHA BPA Schwerin IV/2/1/27, Protokoll Landesvorstandssitzung SED, 24. 5. 1948, Beitrag Bürger, Bl. 31. Richter erwähnt, daß die Registrierung von Ortsgruppen bis 1948 sehr restriktiv gehandhabt wurde, Richter, Ost-CDU, S. 88. 
der Parteineugründungen belegt, die vermerkt: „CDU - Zulassung in allen Orten" 55 . Tjulpanow berichtet in seinen Memoiren über eine Zusammenkunft Sokolowskis und Semjonows mit der CDU-Führung, bei der der Partei ihre Existenzängste genommen werden sollten. Außerdem sicherte man ihr die Abhaltung von Wahlen $\mathrm{zu}^{56}$. Offenbar wollte sich die SMAD während der Berlinkrise und einer sich vertiefenden Teilung zugleich der gesamtdeutschen Funktion der CDU versichern. Tjulpanow ermutigte die Thüringer CDU auf ihrem Parteitag im Dezember $1948 \mathrm{zu}$ einer offensiveren politischen Fortentwicklung ihrer Partei ${ }^{57}$, freilich innerhalb solcher politischen Vorgaben, die auf einen ostintegrierten Teilstaat hinausliefen, gegen den Kaiser 1947 noch hartnäckig opponiert hatte. Nach offenkundigen Differenzen in der Frage der Behandlung der bürgerlichen Parteien zwischen Semjonow und Tjulpanow zum Jahreswechsel 1947/1948 arbeiteten die beiden im Frühjahr und Sommer 1948 im Gleichklang58.

Dieser Gleichklang umfaßte auch die zwar schon vorher eingeleitete, aber dezidiert erst im Mai 1948 proklamierte Umwandlung der SED in eine „Partei Neuen Typs "59. Der beharrlich weiter betriebene organisatorische und ideologische Ausbau der SED zu einer ideologisch fest im Lager der Sowjetunion verankerten Partei stand in Verbindung mit der gewünschten Wiederbelebung der Blockarbeit, dem moderateren Kurs gegenüber den Blockparteien und den Parteineugründungen: Sie sollte sich im Kampf mit anderen stählen. Auch Stalins Zurechtweisung der SED-Spitze anläßlich ihrer Reise nach Moskau im Dezember 1948, in der er ihr einschärfte, daß die SBZ noch keine „Volksdemokratie“ sei, änderte nichts am Umwandlungskurs der SED. Anfang 1949 war der Ausbau der Blockpolitik verkoppelt mit weiteren Maßnahmen zur Stalinisierung der SED und zur Flankierung dieser Stalinisierung durch DBD und NDPD. Äußerungen Sokolowskis auf einer Versammlung des Parteiaktivs der SMAD im März 1949 belegen diese Funktion: So sollten beide „diejenigen Elemente stärken und unter ihren Einfluß bringen, die aufgrund einer ganzen Reihe von Bedingungen für die Sozialistische Einheitspartei noch nicht reif sind. Zusammen mit der Sozialistischen Einheitspartei werden sie erfolgreich um den Einfluß auf die Massen kämpfen, die [noch] unter dem Einfluß der CDU und der Liberal-Demokratischen Partei stehen." Erst nachdem der Block seit August 1948 wieder arbeitete und die bürgerlichen Parteien wieder handlungsfähig waren, schätzte Sokolowski an den Neugründungen auch, daß dadurch „zugleich die Position der beiden anderen bürgerlichen Parteien geschwächt“ werde, weil die Mitglieder von DBD und NDPD „unter den

55 Badstübner/Loth (Hg.), Wilhelm Pieck-Aufzeichnungen, S. 228.

56 Tjulpanow, Deutschland, S. $249 \mathrm{f}$.

57 Naimark, Russians, S. 347.

58 Ebd., S. 550, Fußnote 96.

59 Allg. dazu ebd., S. 308-317; Malycha, Partei, bes. S. 89-118; vgl. schriftliche Fassung eines Vortrags von Tjulpanow, abgedruckt in: Badstübner/Loth (Hg.), Wilhelm Pieck-Aufzeichnungen, S. 216-227, die von Pieck auf einer Parteivorstandssitzung am 12.5. 1948 übernommen wurde, SAPMO DY 30 IV 2/1/23, Bl. 60-74; Staritz, SED, Stalin und der „Aufbau des Sozialismus“, S. 690-692. 
Einfluß fortschrittlicher Parteien" gerieten, in „demokratischem Geist" erzogen und „im Block mit der Sozialistischen Einheitspartei" geführt würden ${ }^{60}$.

Somit ist die Entstehung der Bauernpartei in ein vielschichtigeres Faktorengeflecht eingebunden, als bislang angenommen wurde: Die Gründung von DBD wie NDPD sollte das Vorgehen der Sowjetunion in Deutschland in mehrfacher Hinsicht stärken. Beiden Parteien war von Beginn an eine Rolle zugedacht, die die sowjetische Deutschlandpolitik unterstützte. Die Konstruktion von zwei neuen Parteien gehörte außerdem zum Kalkül gegenüber CDU und LDP. In der ersten Jahreshälfte 1948 war die sowjetische Zielsetzung noch nicht einseitig auf die Zurückdrängung der bürgerlichen Parteien ausgerichtet, sondern sie bezweckte in erster Linie eine Belebung der Blockpolitik auch als deutschlandpolitisches Instrumentarium; dazu signalisierten sowjetische Stellen besonders den „fortschrittlichen" Mitgliedern in CDU und LDP, daß sie mit ihrer Mitarbeit rechneten.

Darüber hinaus sollte die DBD zur politischen Absicherung der bis dahin durchgesetzten wirtschaftlich-sozialen Umwälzung auf dem Land beitragen. Die SMAD erwartete von der Arbeit der DBD eine integrierende Wirkung auf hilfesuchende und bisher politisch distanzierte ländliche Schichten. Hierfür mußte sich die DBD klar als Bodenreformpartei profilieren und den parteipolitisch unentschiedenen oder nur lose an die SED gebundenen Klein- und Mittelbauern eine politische Heimat anbieten. Gerade im Bodenreformland Mecklenburg sollte sie sich der Neubauernschaft annehmen und darunter auch die Vertriebenen und Flüchtlinge umwerben, für die keine eigene politische Repräsentation vorgesehen war. Dieser spezifisch zugeschnittene Mitgliederauftrag für die DBD eignete sich außerdem dazu, manche jener Folgewirkungen aufzufangen, die durch die Umwandlung der SED in eine „Partei Neuen Typs“ in Gang gesetzt wurden. Ein Teil des für die SED nicht mehr opportun erscheinenden Mitgliederreservoirs kam für die DBD durchaus noch in Frage.

\section{Der Gründungsprozeß 1948}

\section{Initiative, Vorbereitung, Akteure}

Die entscheidende Initiative zur Gründung von zwei neuen Blockparteien ging im ersten Quartal des Jahres 1948 von der sowjetischen Militärverwaltung aus. Die Überlegungen der KPD und Stalins 1945 zu einer politischen Repräsentation der ländlichen Bevölkerung mündeten zunächst in eine Einbeziehung der bäuerlichen Bevölkerung in die potentielle Mitgliederschaft der KPD. Staritz vermutete, daß sich die Pläne zur Gründung weiterer Parteien Ende 1947 verdichteten und beruft sich auf eine Besprechung Tjulpanows mit Offizieren der politischen Abteilungen der Ländermilitärverwaltungen, die sich auf die Gründung einer bäuerlichen und einer nationaldemokratisch orientierten Partei verständigt haben sollen ${ }^{61}$. Zwar

60 Bonwetsch u.a. (Hg.), Politik, Dok. Nr. 47, S. 201-207, Zitate S. 205, eckige Klammer lt. Edition.

61 Staritz, National-Demokratische Partei Deutschlands, S. 42, aufgrund von Unterlagen im Archiv des Ostbüros der SPD, übernommen von Wernet-Tietz, Bauernverband, S. 102, 
rückt dies die Idee zur Gründung der NDPD nahe an die SMAD-Befehle zur Beendigung der Entnazifizierung heran (Nr. 201 vom 9. Oktober 1947 und Nr. 35 vom 26. Februar 1948), jedoch ist weder für die NDPD noch für die DBD ein gesicherter Zusammenhang mit der Gründung erkennbar ${ }^{62}$. Die folgenden Beobachtungen für die SBZ und einzelne Länder dürfen nicht darüber hinwegtäuschen, daß der eigentliche Entschluß in Moskau gefallen ist.

Die Bildung einer Bauernpartei ist anläßlich eines Besuches von Pieck und Grotewohl in Moskau vor Stalin am 26. März 1948 noch vage als „evtl. 5. Partei“ erörtert worden ${ }^{63}$. Alles deutet jedoch darauf hin, daß bei dieser Reise die Gründung der DBD endgültig beschlossen wurde. Die Bildung der NDPD war hingegen mit dem Erscheinen der "National-Zeitung" am 22. März schon offiziell im Gange. Offenbar mußte die SED hinnehmen, daß der Aufbau einer Partei für die ländliche Bevölkerung fester Bestandteil der sowjetischen Vorstellungen im Frühjahr 1948 war. Die SMAD spornte die SED zur gleichen Zeit dazu an, ihren Einfluß auf das landwirtschaftliche Genossenschaftswesen zu erhöhen ${ }^{64}$. Ab Mitte April 1948 äußerte sich die SED-Spitze zu einer möglichen Umbildung des Parteiensystems. Ulbricht schnitt dieses Thema intern in einem Instruktionsreferat am 16. April in der SED-Parteischule an, Wilhelm Pieck sprach zwei Tage später öffentlich auf einer Berliner SED-Kundgebung über eine Veränderung der Parteienlandschaft ${ }^{65}$. Darin bezeichnete Pieck das Dreiparteiensystem als nicht elastisch genug, um allen Menschen eine politische Heimat zu geben. Daher billige die SED jeder Partei eine Existenzberechtigung zu, wenn sie die „Sache des werktätigen Volkes“ vertrete und für die demokratische Einheit Deutschlands sei. Die SED erhebe keinerlei Totalitätsansprüche und wolle auch kein Ein-Parteien-System.

Zum letztgenannten Zeitpunkt war allerdings der öffentliche Startschuß zur Gründung einer Bauernpartei schon gefallen: Am 17. April 1948 fand in Wismar eine Versammlung der Kreisvorstände der VdgB statt. Wie die Zeitung der VdgB „Der Freie Bauer" am 25. April 1948 meldete, hätten „werktätige Bauern“ die Gründung einer Bauernpartei gefordert. In einem offenen Brief an alle Bauern Mecklenburgs rief die Versammlung zur Bildung einer Partei auf ${ }^{66}$. Diese parteioffizielle Lesart des Gründungsaufrufes versuchte den Anfang der Partei als interessengeleitete Bewegung von unten zu definieren.

Reichelt, Blockflöte, S. 16. Mit sowjetischer Überlieferung bezüglich der Gründung ab Mai 1948 siehe Wettig, Bereitschaft, S. $137 \mathrm{f}$.

62 Gottberg, Gründung, S. $75 \mathrm{f}$.

63 Badstübner/Loth (Hg.), Wilhelm Pieck-Aufzeichnungen, Aufenthalt von Pieck und Grotewohl in Moskau, 25. 3.-1. 4. 1948, S. 190-202, hier S. 201. Bonwetsch u. a. (Hg.), Politik, Dok. Nr. 38, Bericht der ZK-Abt. für Außenpolitik für M. Suslov über die Tagung des Parteivorstands der SED vom 14.-15. April 1948, April 1948, S. 159-162.

64 Vgl. hierzu Schöne, Genossenschaftswesen der SBZ/DDR, S. 165 f., der ein Treffen von SED-Agrarpolitikern mit der Abt. Planung der SMAD am 23. 3. 1948 erwähnt.

65 Wernet-Tietz, Bauernverband, S. 103, und Richter, Ost-CDU, S. 102 f., die sich auf Leonhard, Revolution, S. 427, stützen. Zu Piecks Rede siehe Artikel in „Thüringer Volk“, 24. 4. 1948.

$66 \mathrm{Zu}$ dieser offiziell lancierten Gründungsgeschichte vgl. Wernet-Tietz, Bauernverband, S. 103, sowie die Presseartikel in "Der Freie Bauer“ vom 25.4. 1948 und in "Tägliche Rundschau“, 18.6. 1948. 
Der aus Akten rekonstruierte Weg zum Gründungsaufruf widerlegt diese Legende. Vielmehr ging dem Aufruf neben den genannten deutschlandpolitischen Implikationen eine längere Debatte über Auswege aus der politischen Krise der SED auf dem Land voraus. Im sowjetischen Auftrag bemühte sich die SED seit Jahresbeginn, die organisatorischen und personalpolitischen Schwächen im Umgang mit der VdgB zu mindern. Ende 1947 waren Fragen der organisatorischen Verquickung zwischen beiden beraten worden; ab 23. März sollte die SED auch in den landwirtschaftlichen Genossenschaften um mehr Einfluß ringen ${ }^{67}$. Dennoch hielt die SMAD die Gründung einer speziellen Bauernpartei für unverzichtbar und setzte die gezielte Vorbereitung in Gang. Die Umsetzung der einzelnen Gründungsschritte war trotz aller Planungsabsicht von der Improvisation der Akteure geprägt; sie berücksichtigte die spezifische Situation im Bodenreformland Mecklenburg. Zwar zeichneten sich schon Ende Februar 1948 Aktivitäten der unterschiedlichen beteiligten Institutionen $a b$-, namentlich der Landesverbände von SED und VdgB in Mecklenburg - diese mündeten sicher aber erst nach der Moskaureise in eine zielgerichtete Vorbereitung der Parteigründung. Wichtige personelle Entscheidungen wurden in enger Absprache mit der SMA Mecklenburg getroffen. Überall dort, wo die wenigen Spuren unmittelbarer Unterstützung durch die SMA nachweisbar sind, bezeugen diese, mit welch hoher Aufmerksamkeit die SMA die Gründung der DBD begleitete.

Eine Reihe von Indizien deutet darauf hin, daß das Sekretariat des SED-Landesvorstandes bereits im Februar 1948 über die potentielle Gründung einer Bauernpartei in Mecklenburg in Kenntnis gesetzt worden war. Mit ziemlicher Sicherheit war Ernst Goldenbaum - im Februar 1948 hoher Ministerialbeamter im Schweriner Landwirtschaftsministerium, später Vorsitzender des Landesgründungsausschusses und dann Parteivorsitzender - zu diesem Zeitpunkt für eine leitende Position in der neuen Partei vorgesehen. Er erschien aus verschiedenen Gründen als der geeignete Mann dafür. Er verfügte über agrarpolitische Kompetenz, war als Vorsitzender der Landesbodenkommission Aktivist der Bodenreform und engagierte sich im VdgB-Landesverband. Als ehemaliges KPD-Mitglied, Vorsitzender der KPD-Landtagsfraktion in der Weimarer Republik und als Häftling des KZ Neuengamme wies er eine lupenreine Kaderbiographie auf. Der entscheidende Hinweis auf die Eignung seiner Person für die Bauernpartei wurde höchstwahrscheinlich von Hans Warnke, Innenminister in Mecklenburg, an das Zentralsekretariat in Berlin weitergeleitet. Im Januar 1948 schlug Warnke ihn statt seiner als Teilnehmer der ersten agrarpolitischen Großkonferenz der SED vor. Warnke und Goldenbaum hatten zusammen die Bodenreform in Mecklenburg vorangetrieben, Warnke als 1. Vizepräsident der Landesverwaltung und Leiter des Ressorts Innere Verwaltung, Goldenbaum als Geschäftsführer der Landeskommission für Bodenreform und Leiter der Abteilung Bodenreform in der Landesverwaltung ${ }^{68}$. Für den zuständigen Sachbearbeiter in der Abteilung Landwirt-

67 Vgl. Kurek, VdgB, S. 122 f., zu den ldw. Genossenschaften Schöne, Genossenschaftswesen und Agrarpolitik, S. 40-42.

68 SBZ-Handbuch, S. 1051; Barth u. a. (Hg.), DDR, S. 649; zur Tätigkeit beider vgl. Kuntsche, "Gemeinwirtschaft". 
schaft des Zentralsekretariats, Rudolf Reutter, war die Teilnahme Goldenbaums keineswegs selbstverständlich; nach Rücksprache mit Paul Merker, der im Zentralsekretariat der SED für Landwirtschaft zuständig war, hielt er eine Beteiligung Goldenbaums ausdrücklich für nicht erwünscht ${ }^{69}$. Dieser geringe Bekanntheitsgrad sprach eher für dessen Eignung, eine Spitzenposition in der Bauernpartei einzunehmen. Denn allzu exponierte SED-Funktionäre schieden als Vorsitzende aus, um den gesteuerten Charakter der Parteigründung nicht von vornherein offenzulegen. Aufgrund einer Entscheidung des Zentralsekretariats der SED wies ihn das Sekretariat des mecklenburgischen SED-Landesverbandes im Februar 1948 an, sich gegenüber einer Kandidatur für das Amt des Landwirtschaftsministers, wofür ihn die VdgB voraussichtlich nominieren wolle, dilatorisch zu verhalten. Das Zentralsekretariat hatte den Schweriner Genossen zuvor eingeschärft, einen eigenen Parteikandidaten für den wichtigen Posten im Agrarland Mecklenburg durchzusetzen ${ }^{70}$.

Die offizielle Geschichtsschreibung der DBD zur Gründung unterstreicht die tragende Rolle der VdgB Mecklenburgs bei diesem Vorgang. Die VdgB hatte Ende 1947/Anfang 1948 noch mit Geburtswehen und den schwierigen Bedingungen der Landwirtschaft Mecklenburgs, die stark von der Bodenreform gezeichnet war, zu kämpfen. Im Unterschied zu anderen Landesverbänden stand sie organisatorisch auf schwachen Beinen und verlor ständig an Einfluß in der ländlichen Bevölkerung. Diese Einschätzung teilten sowohl andere Landesverbände, z.B. der sächsische, wie auch die sowjetischen und deutschen politisch Verantwortlichen in Schwerin ${ }^{71}$. An einer Krisensitzung am 8. Januar 1948 beim Landesverband der VdgB nahm neben Goldenbaum, zu diesem Zeitpunkt stellvertretender Landesvorsitzender der $\mathrm{VdgB}$, u. a. auch der Generalsekretär des Zentralsekretariats der VdgB, Kurt Vieweg, teil. Obwohl sich die Teilnehmer im Urteil über die Krise einig waren, verfochten sie keine einheitliche Lösung. Vieweg unterstrich, daß das VdgB-Zentralsekretariat nach zahlreichen Hinweisen der SMA beschlossen habe, endlich auch in Mecklenburg einen funktionierenden Landesverband zu errichten $^{72}$. Das bisherige Versagen führte er auf die unzureichende Unterstützung der Landes-SED zurück, die vor allem keine geeigneten Agrarfunktionäre aus der Parteiarbeit abgebe. Goldenbaum brachte als Ministerialbeamter die Belange der Regierung in die Diskussion ein; er vermied staatliche finanzielle Zusagen für den Ausbau. Vieweg drohte hingegen mit dem Einsatz aller Mittel, insbesondere dem Kontakt zur SMA, um einen arbeitsfähigen Landesverband herzustellen. Immerhin beschloß man, daß Hans Mirau (SED), Agrarfunktionär der VdgB im Kreis

69 SAPMO DY 30 IV 2/7/20, Bl. 234, Warnke an ZS, 22. 1. 1948; ebd., Bl. 235, Reutter an Warnke, 31. 1. 1948.

70 MLHA BPA Schwerin IV/2/3/79, Sekretariatssitzungen SED Mecklenburg, Bl. 78, Sitzung 9. 2. 1948: Warnke und Höcker sollten mit SMA über einen neuen Minister sprechen. Ebenda, Sekretariatssitzungen SED Mecklenburg, Bl.79f., Sitzung 15. 2. 1948; SAPMO DY 30 IV 2/2.1/175, Protokoll ZS, 19. 2. 1948, Bl. 1, TOP 1; MLHA LV VdgB 5, Protokoll Sitzung des LV, 16. 2. 1948.

71 Das SED-Landessekretariat wurde vom ZS entsprechend angewiesen, siehe SAPMO DY 30 IV 2/2.1/175, Protokoll ZS, 19. 2. 1948, Bl. 1, TOP 1.

72 MLHA LV VdgB Mecklenburg, 5, Protokoll Sitzung des LV, 8. 1. 1948 in Schwerin. 
Wismar, am 1. Februar 1948 seine Tätigkeit als 1. Sekretär beim Landesverband der VdgB aufnehmen solle. Das Vorgehen zwischen VdgB und SED im Land war damals noch nicht voll koordiniert. Entgegen den Absichten der Partei, die ihm offenbar nicht mitgeteilt worden sind, schlug Mirau Ernst Goldenbaum am 16. Februar 1948 als VdgB-Kandidaten für das Amt des Landwirtschaftsministers vor. Der SED-Landesvorstand kündigte in der gleichen VdgB-Sitzung eine eigene Kandidatur an; er setzte seinen Anwärter, Bernhard Quandt, den ehemaligen Landrat von Güstrow und Mitglied des Landesvorstands der SED, schließlich mit Rückendeckung aus Berlin erwartungsgemäß durch ${ }^{73}$.

Diese Vorgänge legen folgende Schlüsse nahe: Mitte Februar 1948 wußte der Landesverband der VdgB noch nichts über einen möglichen Wechsel Goldenbaums in eine neue Bauernpartei. Eventuell waren Teile des SED-Landesvorstandes bereits eingeweiht und hielten diesen daher als Kandidaten für das Ministeramt zurück. Goldenbaum gehörte nicht zum inneren Führungskern der LandesSED, und das Zentralsekretariat in Berlin traute ihm den Posten des Landwirtschaftsministers nicht $\mathrm{zu}$. Bekanntlich bekleidete er ab Ende 1949 dieses Amt für die DDR, wenngleich er weiterhin nicht der Wunschkandidat der SED war. Das Sekretariat des SED-Landesvorstands war Goldenbaum gegenüber skeptisch; 1947 war Kritik an Goldenbaums zögerlicher Haltung laut geworden. Die Landes-SED stieß sich an seiner Unentschlossenheit in der Frage, welche Funktion er vornehmlich ausüben wolle, die als Ministerialrat oder die als 1. Sekretär des Landesvorstands der VdgB. Für letzteres Amt hatte ihn der bisherige gewählte 1. Sekretär, Hans Mirau, gewinnen wollen, der dieses Amt nur aus der Ferne, von Wismar aus, bekleidete und nicht nach Schwerin wechseln wollte, wie es der desolate Zustand des Verbandes erfordert hätte ${ }^{74}$. Zwischen Mirau und Goldenbaum herrschte zu dieser Zeit ein vertrauensvolles Verhältnis. Mirau hatte die SED im Kreis Wismar aufgebaut, kannte die Gegend bestens und war zugleich in einer führenden Position in der VdgB des Landes. Mit hoher Wahrscheinlichkeit ist er ein wichtiger Teil des Netzwerkes, das die Einfädelung der VdgB-Kreisvorstandssitzung in Wismar betrieb, die die Forderung zur Gründung einer Bauernpartei erhob.

Der Landesverband der VdgB berief für 12. April 1948, also vier Tage vor Ulbrichts Äußerungen und fünf Tage vor der Wismarer Zusammenkunft, eine Sitzung aller Kreisbauernsekretäre ein. Dem Protokoll zufolge wurde über die Frühjahrsbestellung gesprochen ${ }^{75}$. Höchstwahrscheinlich nutzte man diese Gelegenheit, um einzelne Genossen in das Projekt der Parteineugründung einzuweihen. Zumindest der dort anwesende Fritz Darga, landwirtschaftlicher Sachbearbeiter aus dem Landkreis Anklam, übernahm später eine Parteifunktion der DBD in Mecklenburg. Auch Goldenbaum war darüber informiert, welch wichtige Aufgaben

73 Ebd., Protokoll Sitzung des LV, 16. 2. 1948. Das ZS bestätigte Quandt, SAPMO DY 30 IV 2/2.1/175, Protokoll ZS, 19. 2. 1948, Bl. 1, TOP 1; zu Quandt: SBZ-Handbuch, S. 999.

${ }^{74}$ MLHA BPA Schwerin IV/2/3/78, Sekretariatssitzung SED Mecklenburg, 2.6. 1947, Bl. 14-16; ebd., Sekretariatssitzung SED Mecklenburg, 15. 8. 1947, Bl. 27.

75 MLHA LV VdgB Mecklenburg, 5, Sitzung mit Kreisbauernsekretären am 12.4. 1948. 
auf ihn warteten und bestellte am 14. April 1948 per Telegramm einen Freund aus gemeinsamen Zeiten in Parchim, der sich zufällig brieflich bei ihm gemeldet hatte, umgehend nach Schwerin ein ${ }^{76}$.

\section{Schauplatz Mecklenburg}

Das Zentrum des Gründungsgeschehens der DBD lag in Mecklenburg. Zunächst war die Entscheidung zur Gründung nur einem sehr engen Personenkreis bekannt. Wilhelm Pieck, der die Gespräche der SED in Moskau führte, gehörte zu den Eingeweihten und beteiligte sich an der Personalsuche für die neue Partei. Die Initiierung der Gründung ist mit ziemlicher Sicherheit zwischen Moskau und hohen Vertretern der SMAD in Deutschland vereinbart worden. Das Zentralsekretariat der SED fällte hingegen erst spät, am 19. Juli 1948, Personalbeschlüsse bezüglich der DBD. Grundentscheidungen gehen aller Wahrscheinlichkeit nach auf direkte Veranlassung der SMAD zurück, nachweisbar ist die enge Absprache zwischen Pieck und sowjetischen Führungskräften in Berlin. Eine maßgebliche Rolle im Gründungsvorgang fiel jedoch den SMA in den Ländern, vor allem in Mecklenburg zu.

Die VdgB-Zeitung „Der Freie Bauer" veröffentlichte am 25. April 1948 eine Zuschrift des Kreisvorstandes der VdgB in Wismar. Danach habe am 17. April auf einer Versammlung der VdgB Wismar anläßlich der Frühjahrsbestellung eine Gruppe von Bauern eine Vorlage eingebracht, die zur Gründung einer demokratischen Bauernpartei aufforderte. Der Aufruf "An alle Bauern Mecklenburgs!“ führte eine Reihe von Mängeln in der Politik gegenüber den Bauern als Begründung an: Diese umfaßten Klagen, wonach die Bestimmungen der Besatzungsmacht etwa zum Viehausgleich, in Fragen der Differenzierung, also der Festlegung der Ablieferungsnormen nach Hektargruppen (SMAD-Befehl Nr. 60), oder des Befehls 209 über die Errichtung von Neubauernhäusern nicht zur Zufriedenheit der Bauern durchgeführt würden. Außerdem seien die Bauern in den Selbstverwaltungsorganen, den Länder- und Kommunalparlamenten, unzureichend vertreten. Unterstrichen wurde, daß eine Bauernpartei keineswegs im Gegensatz zu anderen demokratischen Parteien stehen würde und Arbeiter und Bauern eine unzertrennliche Einheit bildeten. Die Bauernpartei würde die Tätigkeit des antifaschistischen Blockes ergänzen und die Demokratie festigen. Das Gründungskomitee des Kreises lud daher alle Bauern ein, am 29. April 1948 im „Niederländischen Hof “ in Schwerin zu einer Konferenz zusammenzutreffen, um ein Landesgründungskomitee zu wählen ${ }^{77}$. Inhaltlich fügte sich dieses Schriftstück nahtlos in

76 MLHA Schwerin, MLF 3210, Schreiben Georg Müllers am 16.4. 1948 an Goldenbaum; Telegramm ebd.

77 Den Aufruf unterzeichneten acht, pauschal als „Bauern“ bezeichnete Männer aus Dörfern im Kreis Wismar: Burmeister aus Gaegelow, Moelke und Fligge aus Ravensruh, Reder aus Steinhausen, Muttersbach aus Gamehl, Gollnick und Schulz aus Zurow, Albrecht aus Wietow sowie der VdgB-Kreisvorsitzende Hans-Joachim Friedländer. Bei Albrecht handelt es sich um Ernst Albrecht, geb. am 22. 2. 1913 in Köritz, Kreis Ruppin, „Umsiedler“ aus Stettin, vor und nach 1933 parteilos, seit 1946 Mitglied der SED und Vorsitzender der VdgB in Wietow, dort Neubauer auf 8,27 ha lt. Teilnehmerzettel der Landesgründungs- 
die bisherigen agrarpolitischen Grundlinien der Besatzer ein und es beschrieb für die bäuerliche Bevölkerung ein durchaus attraktives Vorhaben; schon im Vokabular unterschied es sich erheblich von den stärker ideologisch durchdrungenen Aufrufen der SED.

Diese Version des Aufrufes und die Berichterstattung in der „Täglichen Rundschau" sollten den Eindruck erwecken, als sei die Gründungsinitiative von unten erfolgt, im kommunistischen Jargon von "Bauernaktivisten "78. Die von politischen Gegnern stets behauptete Vermutung, die Parteigründung sei von SMAD und SED gesteuert worden, ist jedoch anhand der Akten eindeutig zu belegen. Rudolf Reutter von der Abteilung Landwirtschaft der SED berichtete am 20. April 1948 über seine Reise vom Vortag nach Schwerin und von einer Besprechung mit dem dortigen Vorsitzenden des SED-Landesverbandes, Kurt Bürger, über die Bauernpartei ${ }^{79}$. Aus seinem Bericht geht hervor, daß sich die ursprüngliche Fassung des Aufrufes vom 17. April noch an alle Bauern der Zone gewandt hatte. Die regionalen Planungen für die Bauernpartei waren zur Zeit von Reutters Ankunft in Schwerin, die sich wegen einer Reifenpanne verzögerte, bereits voll im Gange. D.h. die Entscheidungsträger vor Ort, voran die SMA und der SED-Landesvorstand, warteten nicht auf dezidierte Anweisungen der SED-Zentrale in Berlin. Reutter konnte zunächst nicht mit Bürger allein reden. Er wurde zu einer Besprechung desselben mit Oberst Beljajew - Leiter der Abteilung Propaganda/ Information in Mecklenburg - und vier weiteren Offizieren des Stabes der SMA hinzugebeten. In dieser Unterredung wurde der später publizierte Aufruf nochmals überarbeitet. Reutter war vom Zentralsekretariat über die Gründung der Bauernpartei nicht näher informiert worden, was er im Bericht heftig kritisierte. Er konnte aus Berlin nur „Gedanken zu einem Aufruf“ überreichen, die dann in die veröffentlichte Fassung mit einflossen. Den überarbeiteten Text brachte Karl Lawonn, ein Mitarbeiter der Abteilung Landwirtschaft der SED Mecklenburgs, noch am Abend des 19. April 1948 zu einer zweiten Sitzung der bäuerlichen Initiativgruppe nach Wismar mit. Erst auf dieser internen Sitzung des Komitees sollte der Termin für eine Landeskonferenz festgelegt werden. Die SMA sprach sich Reutter zufolge für Schwerin als Tagungsort dieser Konferenz aus.

Nach Reutters Bericht war sich die SED Mecklenburgs darüber im klaren, daß sie und die VdgB bei der Parteibildung im Hintergrund bleiben müßten. Man stünde vor dem Problem, für die Führung geeignete Leute zu finden, vorrangig aus dem Kreis der parteilosen VdgB-Mitglieder, „die immerhin politisch so stark sind, dass sie eine Gewähr für eine wirklich demokratische fortschrittliche Linie

ausschußsitzung am 29. 4. 1948, ACDP VI-052-0001/a. Wernet-Tietz hält Ernst Albrecht irrtümlich für Rudolf Albrecht, der die Gründung der DBD in Brandenburg mittrug. Wernet-Tietz, Bauernverband, S. 103. Paul Reder war in der SED Mecklenburgs wohlbekannt (siehe Schriftwechsel zwischen dem SED-LV und dem ZS von 1948-1950, MLHA BPA Schwerin IV/L/2/5/156). Außer Albrecht waren gesichert auch Reder, Burmeister (vgl. „Thüringer Volk“, 20.4. 1948) und Gollnick Neubauern. Gollnick gehörte wie Friedländer zunächst der SPD an und war in sowjetischer Kriegsgefangenschaft gewesen (ACDP VI-052-0327, Protokoll Sekretariat, 19.12. 1961).

78 Vgl. Artikel von T. Sergejew in „Tägliche Rundschau“, 18. 6. 1948.

79 SAPMO DY 30 IV 2/7/170, Bl. 244-246. 
dieser Bauernpartei geben können." 80 Weiter müßten diese Bauern fachlich qualifiziert sein und bei der ländlichen Bevölkerung Autorität und Ansehen genießen. Am 19. April hatte die SED noch keine Führungspersönlichkeit für die Landesebene der DBD im Visier - Goldenbaum dürfte schon für die Zentrale vorgesehen gewesen sein. Ein ursprünglich in Betracht gezogener Mann komme aufgrund von Belastungen in der Vergangenheit dafür nicht mehr in Frage, hieß es $^{81}$. Bei dieser Person handelte es sich aller Wahrscheinlichkeit nach um Hans-Joachim Friedländer.

Am 29. April 1948 fand die Landesgründungskonferenz der Bauernpartei Mecklenburgs im "Niederländischen Hof" in Schwerin statt. Wie viele Personen insgesamt und wie viele bäuerliche Delegierte sich dort einfanden, läßt sich nicht mehr zweifelsfrei rekonstruieren. Höchstwahrscheinlich nahmen 126 Personen teil, die sich in die Delegiertenliste der Bauernpartei eintrugen ${ }^{82}$; es waren jedoch mehr Personen anwesend, da nachweislich Journalisten, Landräte und Bürgermeister angereist waren, die die Liste dann nicht enthält. Offizielle Dokumente der DBD gaben später 91 bäuerliche Delegierte aus $17 \mathrm{Kreisen}$ an ${ }^{83}$. Damit versuchte man, die Rolle der bäuerlichen Delegierten in den Vordergrund zu schieben, um den Eindruck zu erwecken, daß sie vorrangig als Mitglieder in Frage kamen und man weniger auf jene Angehörigen der dörflichen Führungsschicht zielte, die durch ihre zahlreiche Anwesenheit ebenso reges Interesse bekundet hatten.

Friedländer leitete die Sitzung. Das Hauptreferat hielt Paul Reder, ebenfalls Mitglied der Wismarer Aktivistengruppe. In einer Grundsatzrede sollte Reder Aufgaben und Ziele der künftigen Partei erläutern ${ }^{84}$. Besonders unterstrich er, daß die Partei dem Aufbau der Ernährungswirtschaft dienen werde, auf dem Boden der Bodenreform stehe und sich der Arbeiterklasse dankbar verbunden fühle. $\mathrm{Er}$

80 Ebd., Bl. 246.

81 Ebd.

${ }^{82}$ MLHA BPA Schwerin IV/L/2/13/624, Bl. 2-4, Bericht des LV der SED Mecklenburg, undatiert [vor 3. 5. 1948]. Über den Ablauf berichten verschiedene Dokumente. Vgl. auf 29. 4. 1948 rückdatiertes Schreiben Goldenbaums an den Chef der SMA Mecklenburgs, ACDP VI-052-0001/a, korrigierte und unkorrigierte Fassung, und der zeitlich dem Ereignis am nächsten liegende Bericht Friedländers an verschiedene Zeitungsredaktionen vom 29. 4. 1948; dort unterzeichnete noch er für den Landesgründungsausschuß, ebenda. Ebenso eine Aufstellung der 72 Parteikollegen der DBD, die der Sitzung am 29.4. 1948 in Schwerin beiwohnten.

${ }^{83}$ Lt. MLHA BPA Schwerin IV/L/2/13/624, Bericht des LV der SED Mecklenburg, Bl. 2: 69 Bauerndelegierte, 38 Neubauern, 27 Altbauern, 4 Großbauern über 50 ha. Lt. ACDPVI-052-0001/a, gaben 72 Tagungsteilnehmer auf Befragungsbögen Auskunft zu ihrer sozialen Herkunft und Parteimitgliedschaften. Dabei dürfte es sich um die späteren Mitglieder der Bauernpartei gehandelt haben. Unter den 72 Teilnehmern waren demnach 31 Altbauern, 60 bezeichneten sich als Bauern. 67 machten Angaben darüber, ob sie „Umsiedler" waren, dies traf nach eigenen Angaben auf $23 \mathrm{zu}$. 69 machten Angaben über ihre Parteizugehörigkeit vor 1933: $21 \mathrm{KPD}, 8 \mathrm{SPD}, 34$ parteilos, 1 NSDAP, 5 gehörten einer anderen Partei an. Über die Parteimitgliedschaft im Jahr 1948 gaben nicht alle Personen Auskunft: 11 parteilos, 17 derzeit SED, 1 derzeit CDU und 4 gaben an, nach 1933 in der NSDAP gewesen zu sein. 60 Teilnehmer gaben an, VdgB-Mitglied zu sein. Lt. Artikel im "Thüringer Volk“, 4. 5. 1948, waren 126 Delegierte aus 17 Kreisen anwesend.

84 Das folgende nach dem überlieferten Teil des Referates und der Diskussion darüber in ACDP VI-052-0001/a. 
distanzierte sich vom Konzept einer berufsständischen Partei in Anlehnung an die Tradition des Reichsnährstandes und betonte, daß die Herstellung der Einheit Deutschlands an der Spitze der Bemühungen stehe. Um Goldenbaums Einstieg in die Partei einzufädeln, erwähnte Reder, daß die Partei Vertreter im Landwirtschaftsministerium suche. Er griff den Bürokratismus im allgemeinen an und kritisierte explizit nur jene sogenannten Fachleute in den Ministerien, die die Bodenreform noch nicht voll anerkennen würden, weil sie aufgrund ihrer Ausbildung noch den junkerlichen Verhältnissen verhaftet seien. Er wiederholte die schon im Aufruf angemahnten Kritikpunkte in der Umsetzung der Agrarpolitik. Die Bauern fühlten sich von den anderen Parteien nicht immer genügend vertreten, da selbst Hilfestellungen der Besatzungsmacht wie der SMAD-Befehl Nr. 209 nur unzureichend ausgeführt würden. Zum Verhältnis zur VdgB führte er an, daß diese nie als politische Vertretung gedacht war, ihre Aufgabe beschränke sich auf die "gegenseitige Bauernhilfe". Die Bauernpartei wolle die VdgB stärken und wünsche sich, daß parteilose VdgB-Mitglieder der DBD beitreten würden.

$\mathrm{Zu}$ Reders Referat fand eine aufschlußreiche Debatte statt, für die ein allerdings nicht vollständiges Wortprotokoll überliefert ist ${ }^{85}$. Im Mittelpunkt stand die Frage, wer Mitglied der Bauernpartei werden könne. Offensichtlich hatte Reder absichtlich oder mißverständlich davon gesprochen, daß die Bauernpartei nur für Neubauern gedacht sei. In seiner Argumentation hatte er Großbauern und Altbauern in einen Topf geworfen und ihnen den Willen zum "demokratischen Aufbau" abgesprochen. Franz Pilarski aus Greifswald empfahl sich in seinem Diskussionsbeitrag zu diesem heiklen Punkt als spätere Führungsfigur der DBD Mecklenburgs. Er präzisierte den Sinn von Reders Ausführungen dahingehend, daß nur diejenigen Großbauern, die noch nichts für den Wiederaufbau getan hätten, nicht aufgenommen werden könnten. Gleichzeitig warnte er davor, Großbauern pauschal aufzunehmen, weil sie sich über ihren Einfluß und ihr umfangreiches Wissen schnell Führungspositionen sichern könnten. Seine Ausführungen vermittelten stärker als die Reders zwischen den unterschiedlichen bäuerlichen Gruppen ${ }^{86}$. Darin traf sich Pilarski mit Kurt Menger aus Ludwigslust und Robert Koch aus Anklam, die dafür eintraten, die in ihren Augen kleine Gruppe von altbäuerlichen "Mitläufern" der NSDAP in die Partei aufzunehmen. Franz Hoja, seit den zwanziger Jahren politisch aktiv, plädierte dafür, auch Landarbeiter zu erfassen. Verschiedene Stimmen knüpften an politische Traditionen der Weimarer Republik an. Ernst Treß, Vertreter der Aktivistengruppe aus Rügen, hoffte darauf, daß die Bauernpartei fest in der Hand von „alten Sozialisten“ bleibe. Da er selbst vor 1933 der SPD angehört hatte ${ }^{87}$, dürfte er damit seine alte Partei gemeint haben, und grenzte davon offensichtlich all jene ab, die erst seit kurzem SED-Genossen waren. Ein

85 Die Diskussion bezieht sich auf Punkte der Rede, die im überlieferten Redetext fehlen.

86 Interessanterweise wurde im Protokoll versucht, Teile einer Passage unkenntlich zu machen, und zwar von Pilarski: „Die Demokratische Bauernpartei, die muss sich natürlich zur Aufgabe stellen, alle Bauern, vor allem eingesessene Altbauern, zusammenzufassen und zu unterstützen."

87 ACDP VI, unverz. Best. LV Mecklenburg, Übersichten und Aufstellungen zu den Kreisvorständen 1948/1949, Kreis Rügen. 
Redner namens Ruddat aus Neustrelitz trat als Verfechter von Methoden der parlamentarischen Demokratie auf und hoffte auf die Kraft des "Stimmzettels“ als politische Waffe der Bauern. Insgesamt zeigte die Diskussion, daß unter den Anwesenden zwar bestimmte politische Vorstellungen zur Bauernpartei als demokratische und nicht-ständische Partei vorhanden waren. Sie illustrierte aber zugleich die noch im Fluß befindliche programmatische Debatte, bevor diese erstarrte.

Die Konferenz wählte schließlich einen Landesgründungsausschuß, über dessen Zusammensetzung je nach Provenienz und Erstellungsdatum der Quelle unterschiedliche Versionen vorliegen. Nach der ursprünglichen Fassung ${ }^{88}$, die unmittelbar nach der Versammlung erstellt worden war und in unkorrigierter Form vorliegt, wurden 14 Personen in einer bestimmten Reihenfolge gewählt ${ }^{89}$. Außer Arnim Dietz und Waldemar Schulz, letzterer bewirtschaftete rund 50 ha, waren alle anderen nachweislich vor $1933 \mathrm{KPD}-$ Mitglieder gewesen 90 . Jeder Kreis stellte einen Vertreter, nur der Kreis Wismar war durch die Aktivistengruppe vom 17. April 1948 überproportional berücksichtigt worden.

Das Sekretariat der SED Mecklenburgs war mit dem Verlauf und dem Wahlergebnis der Landesgründungskonferenz unzufrieden. Zur Vorbereitung der Konferenz hatte es Paul Reder und Hans-Joachim Friedländer dezidierte Anweisungen erteilt, die beide nicht genau eingehalten hatten. Aufgrund der Eigendynamik der Versammlung hatten sie sich als unfähig erwiesen, den Parteiauftrag strikt umzusetzen. Der Bericht eines SED-Beobachters hielt fest, daß es Reder an politischer Grundlage fehle, er allenfalls im Kreismaßstab eingesetzt werden könne. Die Rede, die er vormittags von der SED erhalten hatte, habe er weder gut vorgetragen noch ihre politische Tragweite erkannt. Vor allem seine Schlußworte, in denen er dazu Stellung nahm, wer Mitglied der Bauernpartei werden könne diese Passage fehlt in der DBD-Überlieferung - sei völlig ungenügend gewesen ${ }^{91}$. Friedländer habe einige Regiefehler begangen, die er aber wieder "ausmerzen“ konnte. Für eine Sekretariatsposition war er in den Augen des Berichterstatters

88 Diese Fassung entspricht den Angaben, die Friedländer in einem Pressebericht machte, den er noch vor einer weiteren Aussprache mit der SED, die sich an die Sitzung anschloß, abschloß; ACDP VI-052-0001/a, sie führt nur 14 Mitglieder auf, nicht 15 wie die anderen Versionen, die nachweislich später angefertigt wurden; deren Originale liegen in den Handakten Goldenbaums, der wiederum erst zu einem späteren Zeitpunkt an die Führungsspitze der DBD aufrückte.

89 Der Reihe nach: Franz Hoja, Kreis Hagenow, Hermann Evert, Kreis Schöneberg, Arnim Dietz, Kreis Güstrow, Walter Hahn, Kreis Lützow, Ernst Goldenbaum, Schwerin, Franz Theel, Kreis Parchim, Franz Pilarski, Kreis Greifswald, Kurt Menger, Kreis Ludwigslust, Else Hauth, Kreis Rostock, Karl Preuss, Kreis Randow, Otto Korsinkowski, Kreis Waren, Joachim Friedländer, Kreis Wismar, Waldemar Schulz, Kreis Wismar und zuletzt Paul Reder, Kreis Wismar.

90 Beide wurden bis 1949 aus dem Landesvorstand entfernt, Bauer, Gründung, S. 306. MLHA MLF 3208, Bl. 11; lt. Aufstellungen der Kreisvorstände der DBD Mecklenburg 1948 waren zumindest auch Kurt Menger und Otto Korsinkowski vor 1933 KPD-Mitglieder, ACDP VI, unverz. Best. LV Mecklenburg.

91 MLHA BPA Schwerin IV/L/2/13/624, Bericht über die Bauerndelegiertenkonferenz am 29. 4. 1948, Bl. 2-4. 
ungeeignet. Außerdem kritisierte der Bericht die anwesenden Genossen aus den Kreisen, die sich nicht wie vereinbart bei der Kandidatenaufstellung zurückhielten und die parteilosen Bauern unterstützten, sondern selbst auf die Wahlliste zum Landesgründungsausschuß gesetzt werden wollten. Statt wie ursprünglich vorgesehen sieben wurden 15 Mitglieder in den Landesgründungsausschuß gewählt, davon seien zehn bis zwölf SED-Mitglieder. Dieser Fehler Friedländers sei im Anschluß an die Sitzung korrigiert worden, indem man einen engeren Ausschuß aus sechs Personen bildete, dem Else Hauth, Hans-Joachim Friedländer, Paul Reder, Kurt Menger, Walter Hahn und Ernst Goldenbaum, so die Reihenfolge im Dokument, angehörten ${ }^{92}$.

Erst nach dieser Sitzung begann der offizielle Aufstieg Goldenbaums zur Führungsfigur. Sein wachsender Einfluß nach der Konferenz am 29. April ist daran abzulesen, daß er nun ein auf den 29. April 1948 rückdatiertes Schreiben des Landesgründungsausschusses an den Chef der SMA Mecklenburgs persönlich zeichnete ${ }^{93}$. Dieses Schreiben liegt in zwei Versionen vor, einmal mit Goldenbaums handschriftlichen Änderungen und einmal als Reinschrift, die diese Änderungen berücksichtigt. Mit drei unterschiedlichen Stiften wurden Korrekturen vorgenommen. Goldenbaums Eingriffe sind mittels Schriftvergleich an anderen überlieferten Dokumenten festzustellen ${ }^{94}$. Aus dem Aktenzusammenhang geht hervor, daß das korrigierte Schriftstück Goldenbaum einmal auch zugesandt oder überbracht worden ist, d.h. das Schriftstück ist sicher von SED und SMA überprüft und höchstwahrscheinlich auch korrigiert worden ${ }^{95}$. Für die Gründungsgeschichte der DBD sind folgende Änderungen bedeutsam: Goldenbaum rückte auf der Liste des Landesgründungsausschusses von der letzten Position Nummer 15 auf Position 1 und verdrängte Else Hauth auf Platz 13. Nach Goldenbaums Korrekturen sollte sich der engere Gründungsausschuß wie folgt zusammensetzen: Goldenbaum, Reder, Dietz, Schulz und Broschhardt - also ohne Friedländer.

Friedländer fiel durch eine zeitlich höchstwahrscheinlich später vorgenommene Änderung, die nicht aus der Feder Goldenbaums stammen dürfte, aus dem Gründungsausschuß heraus, an dessen ersten Sitzungen er noch teilgenommen hatte ${ }^{96}$.

92 In dieser Besetzung arbeitete der Gründungsausschuß bis zur ersten Sitzung am 3. 5. 1948. Dann wurde intern die endgültige Zusammensetzung des geschäftsführenden Ausschusses mit Goldenbaum (Kreis Schwerin), Paul Reder (Kreis Wismar), Arnim Dietz (Kreis Güstrow), Waldemar Schulz (Kreis Wismar) und Broschhardt (Kreis Hagenow) festgelegt.

93 Die Originalversion dieses Schreibens ist in Goldenbaums Handakten im Landwirtschaftsministerium Mecklenburg abgelegt, MLHA MLF 3208, Bl. 11. Kopien im Bestand der DBD, ACDP VI-052-0001/a. Hierbei ist zu berücksichtigen, daß die im ACDP überlieferten Akten zur Gründung nicht nach dem Provenienzprinzip, sondern dem Pertinenzprinzip zusammengestellt wurden. Goldenbaum war von Friedländer und Reder erst mit Schreiben vom 27. 4. 1948 zu dieser Sitzung eingeladen worden, MLHA MLF 3208, Bl. 10.

94 Vgl. Goldenbaums Handschrift z.B. MLHA MLF 3207, Kritische Bemerkungen zur Durchführung des Befehls 60.

95 Dies belegt ein an ihn adressiertes Kuvert in unmittelbarer Nähe der beiden Fassungen.

96 Im Vergleich zum ursprünglich gewählten Ausschuß fiel Max Schröer, Kreis Parchim, vor 1933 KPD-Mitglied, heraus. Dafür wurde Broschhardt aus Zapel, Kreis Hagenow, aufge- 
Über die Gründe für sein Ausscheiden aus der Gründungsriege informieren Dokumente des SED-Landesverbandes. Friedländer gehörte in den fünfziger Jahren und später zu den außerordentlich angesehenen Persönlichkeiten in der DBD. Der DBD-internen Überlieferung zufolge hegte die SED jedoch - aus ungenannten Gründen - Bedenken gegen ihn. In den DBD-Akten versuchte man des öfteren, seine vorherige Parteimitgliedschaft in der SPD zu verschleiern. Auch in Beurteilungen aus DBD-Federn 1948 wurden Friedländers politische Qualitäten eher skeptisch eingeschätzt: Er vertrete keine marxistische Linie, wurde ihm von seinem Rivalen Franz Pilarski, dem damaligen Landesvorsitzenden, vorgehalten"7. Als der Parteivorstand im Dezember 1948 erwog, das Mecklenburger Sekretariat personell zu verstärken, wurde der Vorschlag Friedländer mit der Bemerkung "nicht möglich“ abgetan ${ }^{98}$.

Der geschäftsführende Ausschuß des Landesgründungsausschusses traf sich am 3. Mai 1948 im Hotel Rieck in Schwerin zur ersten Sitzung99. Dabei dürfte die endgültige Zusammensetzung des geschäftsführenden Landesgründungsausschusses, wie sie zwischenzeitlich mit SED und SMAD abgesprochen worden war, intern verbindlich bekanntgegeben worden sein. Wortführer war höchstwahrscheinlich Goldenbaum, die Formulierungen des Protokolls geben keine Auskunft darüber. Friedländer war anwesend und wurde als Mitglied des Landesgründungsausschusses bezeichnet, obwohl er im offiziellen Dokument, das an die SMAD gesandt wurde, nicht mehr als Mitglied dieses Gremiums firmierte. Außerdem genehmigte die Versammlung laut Tagesordnung das Schreiben an den Chef der SMA Schwerin zwecks Bestätigung des Landesgründungsausschusses und des geschäftsführenden Ausschusses, also die personellen Veränderungen seit dem 29. April 1948. Diese Formulierung darf nicht darüber hinwegtäuschen, daß die Entscheidung bereits gefallen war und keiner Zustimmung des Gremiums bedurfte. Vermutlich sollte intern mitgeteilt werden, daß Friedländer für die SED nicht tragbar war.

Ein Schreiben an Marschall Sokolowski zwecks Genehmigung der Bauernpartei in der gesamten SBZ sollte in der Woche bis zum 5. Mai 1948 vorbereitet wer-

nommen. Dies wird darauf zurückzuführen sein, daß mit Goldenbaum bereits jemand aus Parchim, wenn auch damals Schweriner, vertreten war.

97 ACDP VI-052-213/1. Siehe die Beurteilung von Pilarski: „Friedländer war Mitglied der SED, steht aber nicht auf dem Boden des Marxismus. Koll. Friedländer hatte als jüdischer Mischling pol. Schwierigkeiten vor 1945. Politische Einstellung einwandfrei fortschrittlich. Zeigt nicht genügend Aktivität in der Parteiarbeit. Mitglied der Revisionskommission." [undatiert, 1948].

98 ACDP VI-052-0141, Protokoll PV, 3. 12. 1948.

99 Dieses Sitzungsprotokoll wurde nachträglich als Protokoll der ersten Sekretariatssitzung der DBD - also für die gesamte SBZ - bezeichnet, vgl. ACDP VI-052-0519, Protokoll der ersten Sitzung, 3.5. 1948. Demnach bestanden in Mecklenburg bereits 21 Kreisgründungsausschüsse (mit 118 Mitgliedern, 4 hatten noch keine Mitglieder). Indizien legen den Schluß nahe, daß dieses Protokoll nachträglich eingefügt wurde. Das Protokoll der nächsten überlieferten Sitzung vom 11.7.1948 nimmt nämlich Wort- und Formulierungsänderungen zu einem als 1. Protokoll bezeichneten Text vor, die im überlieferten 1. Protokoll nicht auftauchen. Höchstwahrscheinlich fehlen also Protokolle von Sitzungen, die dazwischen stattfanden. 
den. Am 6. Mai bewilligte Trufanow als Chef der Verwaltung der SMA die Tätigkeit des Organisationskomitees in Mecklenburg ${ }^{100}$. Die DBD erhielt damit die Genehmigung zur Mitgliedereinschreibung, nicht jedoch zu ihrer Aufnahme ${ }^{101}$. Diese sollte erst nach einer Überprüfung der Interessenten erfolgen; allerdings durften auch nominelle NSDAP-Mitglieder akzeptiert werden. Bereits am 30. Juli 1948 wurde die DBD Mecklenburgs in den Landesblock aufgenommen ${ }^{102}$. Auch in den anderen Ländern der SBZ kam es von Mai bis Juli zu Gründungsversammlungen der Bauernpartei. In Thüringen wurde der Landesverband am 18. Juni 1948 von Generalmajor Kolesnitschenko zugelassen. In Sachsen-Anhalt erfolgte die Genehmigung eines Landesverbands ebenfalls Mitte Juni ${ }^{103}$.

Von Mecklenburg aus gingen Gründungsimpulse ins benachbarte Brandenburg. Die Vorbereitungen der SED zur Gründung der DBD und der NDPD liefen in Brandenburg unter den Decknamen "Gesellschaft Y“ für DBD und „Gesellschaft X“ für die NDPD. Im Bestand des SED-Landesverbandes findet sich ein Aufruf von Vertretern der Bauernschaft aus einigen Kreisen des Landes ${ }^{104}$, die - so konnte man im Aufruf lesen - die Initiative der Bauern Mecklenburgs zur Gründung einer Bauernpartei nun für Brandenburg beschlossen hatten. Wenn dieser Aufruf nicht ohnehin im Landessekretariat der SED verfaßt worden ist - was anzunehmen ist -, so ist die unmittelbare Vorarbeit der SED für die „Gesellschaft Y“ erwiesen. SED-Mitglieder in den Kreisen wurden vom Landesverband angewiesen, aus der SED auszutreten, um sich für die DBD bereitzuhalten ${ }^{105}$. Ein Aktenvermerk der SED vom 26. Mai 1948 belegt die personelle Steuerung der DBDGründung. Über den Personenkreis, der an der Gründungsversammlung am 25. Mai im Volkstheater Potsdam teilnahm, war der SED-Landesverband bestens informiert ${ }^{106}$. Durch Verbindungsleute zur LDP sollte die Bauernpartei besonders in jenen Dörfern aufgebaut werden, in denen der Einfluß bürgerlicher Parteien hoch und der der SED gering war. Wie in Mecklenburg suchte man vor allem in der VdgB nach potentiellen Mitgliedern. Rudolf Albrecht (SED), zunächst 1. Vorsitzender der VdgB Brandenburgs, später Landesvorsitzender der DBD und 2. Vorsitzender der Partei, wurde zur Führungsfigur in Brandenburg.

100 ACDP VI-052-0001/a, deutsche Übersetzung eines sowjetischen Dokumentes vom 6. 5. 1948.

101 MLHA BPA Schwerin IV/2/1/27, Protokoll Landesvorstandssitzung SED, 24. 5. 1948, Bl. 30.

102 MLHA BPA Schwerin IV/L/2/13/617, Protokoll Blocksitzung am 30. 7. 1948, Bl. $53 \mathrm{ff}$.

103 Wernet-Tietz, Bauernverband, S. 105.

104 BLHA Rep. 332, Nr. 786, An die Bauern und Bäuerinnen des Landes Brandenburg, Resolution (2 Seiten). Das Dokument enthält im wesentlichen die gleichen Punkte wie der Aufruf vom 17. 4. 1948. Zusätzlich wird betont, daß die Bauernpartei eine aktivere VdgB für notwendig hält.

105 Vgl. z. B. BLHA Rep. 332, Nr. 786, Aktenvermerk 25. 5. 1948: Gottlieb M., Landwirt, 180 Morgen, Ortsvorsitzender der VdgB, „tritt auf Vorschlag des Gen. Pernitz, 1. Vorsitzender, Kreis Seelow aus der Partei aus. M. ist fortschrittlich und linientreu. Intelligent.“ [Schreibfehler korrigiert].

106 BLHA Rep. 332, Nr. 786, Aktenvermerk 26. 5. 1948. Vgl. auch Reinert, Parteien, S. 125; Wernet-Tietz, Bauernverband, S. 105. 


\section{Schauplatz Sachsen}

Die Gründung der DBD in Sachsen ist schwieriger zu rekonstruieren als in Mecklenburg, da die interne Überlieferung sehr fragmentarisch ist. Die Bedingungen für die Parteigründung unterschieden sich in vielerlei Hinsicht von denen in Mecklenburg. Das Land Sachsen war von anderen agrarstrukturellen Merkmalen geprägt. Im Juni 1948 war jeder vierte Einwohner Sachsens, also weniger als in Mecklenburg, ein sogenannter Umsiedler ${ }^{107}$.

Die Landesverbände der SED waren 1948 noch nicht völlig gleichgeschaltet ${ }^{108}$, sondern wiesen deutliche Eigenheiten auf. Auch in Sachsen war es der SED nicht gelungen, sich fest in der bäuerlichen Bevölkerung zu verankern. Der SED-Mitgliederstatistik für August 1948 zufolge waren insgesamt 14369 selbständige Bauern in der SED, darunter nur 1146 Frauen, sowie 10809 Arbeiter in der Landund Forstwirtschaft, darunter wiederum 1427 Frauen ${ }^{109}$. Die SED-Fraktion der VdgB-Kreistagsabgeordneten bedauerte Ende April 1948, daß nur jeder achte Bauer Mitglied der SED sei, 2500 gehörten der CDU an, 1700 der LDP und 70000 seien parteilos. Unter den Parteilosen vermutete man rund 22000 ehemalige Mitglieder der NSDAP 110 .

Nach Einschätzung des SED-Landesvorstands war die VdgB in Sachsen immerhin stärker in der Bauernschaft etabliert als in Mecklenburg. 90000 Bauern Sachsens, „fast alle" wie man in der SED feststellte, gehörten danach der VdgB an. Zum 1. Oktober 1948 zählte die VdgB Sachsens 108189 Mitglieder, davon waren nur rund $20 \%$ in der SED organisiert, $1,7 \%$ in der LDP, $2,9 \%$ in der CDU und knapp drei Viertel $(74,5 \%)$ waren als parteilos gemeldet ${ }^{111}$. In der sozialen $\mathrm{Zu}$ sammensetzung der VdgB-Mitglieder dominierte die Gruppe der Altbauern mit $46 \%$, sogenannte aufgestockte Altbauern mit $14 \%$ - also Altbauern, die Bodenreformland erhalten hatten -, gefolgt von $19,5 \%$ Neubauern und $5,7 \%$ Siedlern mit weniger als 2 ha Land ${ }^{112}$. Auffällig ist die hohe Verankerung der VdgB Sachsens unter den Altbauern.

Eingehender als in Mecklenburg beleuchtet der Weg zur Gründung der DBD in Sachsen die tatsächlichen Einstellungen der SED und der VdgB zu diesem Vorgang. Deutlich schält sich heraus, in welch hohem Maße die SMA die bestim-

107 SStAD BPA SED LL A/783, Sekretariatssitzung, 11. 6. 1948, Bl. 25. Im - hier exemplarisch herausgegriffenen - agrarisch geprägten Erzgebirgskreis Dippoldiswalde lebten 1948 insgesamt 20367 „Umsiedler“ (darunter rund 5900 Kinder), von denen nur 344 Männer und 156 Frauen bis Januar 1948 der SED beigetreten waren; SStAD BPA SED LL A/1406, Abt. Org. Statistik: Stand 25. 1. 1948.

108 Vgl. Malycha, Partei, S. 71 f.

109 SAPMO DY 30 IV 2/7/62, Mitgliederstatistik für August 1948, Bl. 144.

110 SStAD BPA SED LL A/864, Protokoll der Sitzung der SED-Fraktion der VdgBKreistagsabgeordneten vom 27. 4. 1948, auch zum folgenden.

111 SAPMO DY 30 IV 2/7/62, Zusammenstellung der Mitglieder der VdgB Sachsen nach Besitzgröße und Parteizugehörigkeit, 1. 10. 1948, Bl. 142f. DBD-Mitglieder wurden hier noch nicht erfaßt.

112 Ebd., Bl. 143. Desweiteren sogenannte Neusiedler mit 3,9\%, Gärtner mit 3\%, sonstige mit 2,9\%, aufgestockte Siedler 2,3\%, die restlichen rund 3\% verteilten sich auf Angehörige, Gehilfen, Neugärtner, aufgestockte Gärtner sowie Staatsgüter und Genossenschaften. 
mende Kraft hinter der Parteibildung war. Die SED-Führungskräfte im Landesverband der VdgB waren über den Stellenwert der Ereignisse vom 29. April 1948 informiert. Anton Jadasch reiste als inoffizieller Beobachter nach Mecklenburg und berichtete von dem Aktivistentreffen ${ }^{113}$.

Am 22. April 1948 informierte Wilhelm Koenen das Sekretariat des SED-Landesvorstands über die Aktivitäten zur Gründung einer Bauernpartei in Mecklenburg. Er habe in Berlin erfahren, daß die Gründung von dort aus angeschoben worden sei. Die Partei solle eine klare „Kleinbauernorientierung“ aufweisen und sei auch für Pächter, Siedler und Neubauern bestimmt. Es habe sich gezeigt, daß die VdgB keine eigentliche Linie geben könne, zumal Großbauern zu $80-90 \%$ in der VdgB organisiert seien, Kleinbauern aber kaum. Die Parteibildung müsse so ablaufen, daß von vornherein ein Zusammenwirken mit der SED gewährleistet sei. Das hatte organisatorische, vor allem jedoch politische Implikationen. Die SED solle sich darauf einstellen, daß einige ihrer besten Bauernkräfte von Anfang an in die neue Partei übertreten. Außerdem müßten die ersten organisatorischen Schritte, die die VdgB nun einleite, sorgfältig beobachtet werden. Die Genehmigung der Partei liege bei der SMA, die für die „demokratische“ Entwicklung sorgen werde. Im SED-Landesvorstand wurden durchaus Bedenken gegen die Bauernpartei geäußert; man fürchtete, daß zahlreiche Bauern der SED den Rücken kehren und in der neuen Partei eine Interessenpolitik für die eigene Klientel betreiben könnten. Außerdem wies Koenen auf den Charakter der Bauernparteien in den osteuropäischen Staaten hin und bezog sich damit offensichtlich auf deren oppositionelle Rolle gegenüber den Kommunisten. Auffälligerweise wurden Koenens kurzfristige Überlegungen nicht durch entsprechende Beschlüsse unterstützt ${ }^{114}$. Auch auf der Sekretariatssitzung eine Woche später, am 29. April 1948, verschob man die Beschlußfassung mit der Bemerkung, erst konkrete Hinweise aus Berlin abzuwarten. Am selben Tag fand bereits die Versammlung zur Wahl eines Landesgründungsausschusses statt, wohin die VdgB Sachsens schon drei Beobachter entsandt hatte ${ }^{115}$.

Einige Indizien zeigen, daß die Planungen für die Bauernpartei in Sachsen zunächst bewußt von seiten der SED verschleppt wurden. Ende April hatte das Landessekretariat der SED noch keine konkreten Vorstellungen darüber, welcher Personenkreis die sächsische Bauernpartei führen solle ${ }^{116}$. Am 11. Juni berichtete Otto Buchwitz dem Sekretariat über eine ausführliche Besprechung zu aktuellen

113 SStAD LV VdgB Sachsen 88, Abschrift des Protokolls der 5. Vorstandssitzung der ZVdgB am 21.5. 1948. Im Dokument ist von einer Reise nach Wismar die Rede. Es ist unwahrscheinlich, daß Jadasch am 17.4. in Wismar dabei war, zumal die weiteren Informationen über die Sitzung, der er beiwohnte - danach hörte er Vertreter aus 17 Kreisen nachweislich nur auf die Landesgründungsversammlung in Schwerin vom 29. 4. zutreffen. Unter Umständen reiste er nach Wismar, um sich nachträglich zu informieren, und nahm an der Sitzung vom 29. 4. in Schwerin teil

114 SStAD BPA SED LL A/782, Sekretariatssitzung, 22. 4. 1948, Bl. 80-86.

115 Ebd., Sekretariatssitzung, 29. 4. 1948, Bl. 109-122.

116 Ebd., hier Bl. 121, Anfrage Genosse Götzelt. 
Themen mit der SMA Sachsen ${ }^{117}$. Diese gab dem SED-Landesverband offenbar den notwendigen „Rat“, der neuen Partei mehr Aufmerksamkeit zu widmen.

Für Sachsen ist mittelbar überliefert, wie sehr die SMA die Parteigründung vorantrieb und mitorganisierte. Der Gründer der dortigen Bauernpartei, Friedrich Martin, floh später in den Westen und sagte vor dem Untersuchungsausschuß freiheitlicher Juristen folgendes aus ${ }^{118}$ : Im Frühjahr 1948 wurde er von der SMA Leipzig vorgeladen. Man befragte ihn, warum sich Bauern so wenig politisch betätigten, und ob er denke, diese Gruppe würde eine eigene Partei gründen wollen. Bald darauf folgte in Dresden ein Treffen mit Wilhelm Koenen und der sowjetischen Führung des Landes. Nachdem er das Projekt einer Bauernpartei in der neuerlichen Befragung durchaus begrüßt hatte, erhielt er wenige Wochen später eine Einladung Kurt Viewegs zu einer „konstituierenden Sitzung“ der DBD in Brandenburg. Martin gab zu Protokoll, daß bei dieser Sitzung, die rund 30 Teilnehmer zählte, ausschließlich SED-Genossen anwesend waren. Goldenbaum, Paul Scholz und Richard Richter habe er schon vorher gekannt. Nachdem Goldenbaum ein Grundsatzreferat über die Notwendigkeit einer Bauernpartei gehalten hatte, seien die Vorsitzenden der Landesverbände "bestimmt“ worden. Goldenbaum habe angekündigt, daß die erforderlichen Genehmigungen der SMA zur Gründung bald eingehen würden. Als Vertreter der SMA Sachsens Martin eine Woche später bei einem einbestellten Treffen zur Gründung einer Bauernpartei gratulierten, sei ihm zugleich ein Geschäftsführer für die Partei präsentiert worden. Die Personen, die erst nach dieser Genehmigung der Parteibildung zur konstituierenden Sitzung des Landesverbandes zusammentraten, waren von der SED und den sowjetischen Militärkommandanten in den jeweiligen Kreisen ausgesucht und hingeschickt worden. Die endgültige Genehmigung über den Einsatz von Personen in den neuen Parteiämtern erteilte Major Nikodenkow; ebenso finanzierte er den Aufbau der Partei in Sachsen.

Die SED-Mitglieder unter den VdgB-Kreistagsabgeordneten übernahmen eine aktive Rolle beim Vollzug der sowjetischen Vorgaben. Die Gründungsinitiative wurde durch die Abteilung Landwirtschaft des SED-Landesvorstandes in Zusammenarbeit mit Wilhelm Koenen und Ronneburger sorgfältig vorbereitet. Am 27. April 1948 trafen sich auf ihre Einladung hin ungefähr 40 VdgB-Kreistagsabgeordnete aus der SED und einige Agrarsekretäre der Partei im Gebäude des Landesvorstands ${ }^{119}$. Der Leiter der Abteilung Landwirtschaft Schenk begrüßte sie zu einer Aussprache von "historischer Bedeutung “120. Denn Zweck der Versammlung sei es, „die Bauernpolitik in Sachsen und [im] Zonenmaßstab zu ändern, nicht grundsätzlich, sondern in taktischer und strategischer Hinsicht." Die Bauernpartei sollte sich danach nahtlos in die politischen Konzeptionen von SMAD und SED einfügen. Zwar sei man in der Vergangenheit den „Vorgängen unter den

117 SStAD BPA SED LL A/783, Sekretariatssitzung, 11. 6. 1948, Bl. 23-28, hier Bl. 24.

118 Aussage Martins abgedruckt in: Unrecht als System, Teil II, S. $32 \mathrm{f}$.

119 Vgl. Bericht der Abt. LW der SED, gez. von Gen. Schenk, SStAD BPA SED LL A/864, 3. 11. 1948, Bl. $31 \mathrm{f}$. und den Bericht Schenks vom 27. 4. 1948, ebenda, Bl. 38.

120 SStAD BPA SED LL A/864, Protokoll der Sitzung der VdgB-Kreistagsabgeordneten am 27. 4.1948 vormittags im Gebäude des SED-Landesvorstands. 
Bauern" öfter kritisch gegenübergestanden, man habe sich aber in engeren Aussprachen entschieden, diese „Bewegung“ zu fördern.

Trotz der Grundentscheidung für die Bauernpartei bemühte sich Schenk nicht darum, seine Animositäten gegen die bäuerliche Bevölkerung und die Vorgänge in Mecklenburg zu verbergen. Er bedauerte, daß sogar Bauern aus der SED die neue Partei begrüßten, in der Hoffnung, nun das lästige Diktat der Einheitssozialisten abschütteln zu können. Es sei kein Zufall, daß die Partei in Mecklenburg gegründet worden sei. Während dort die Landwirtschaft vorherrsche und die „Reaktion“ vergleichsweise stark sei, läge in Sachsen die Hauptverantwortung bei den Werktätigen in den Betrieben. Mecklenburg erfülle die Vorgaben der DWK-Pläne nur ungenügend, Sachsens Bauern hingegen würden alle Anstrengungen unternehmen.

Die neue Partei müsse durch eine klare Bündnispolitik eingebunden werden. Sie sei von unten her zu organisieren. Keinesfalls dürfe die SED offiziell den Gründungsvorgang bestimmen; daher könnten nur einzelne, in der SED weniger bekannte Genossen daran mitwirken, die jedoch nicht den Part von Organisatoren übernehmen dürften. Notfalls würden sie nachträglich in die Partei eingebaut. Die SED müsse sich darauf konzentrieren, parteilose, angesehene und politisch konforme Bauern der Partei zuzuführen. Auch fortschrittliche bäuerliche Mitglieder von CDU und LDP kämen für die Bauernpartei in Frage. Diese Weisung war auch in Brandenburg und Mecklenburg ausgegeben worden, was für eine zentrale Steuerung der SED-Landesverbände spricht. Schenk beruhigte die anwesenden Mandatsträger der VdgB mit dem Hinweis, daß keinesfalls die VdgB durch die Bauernpartei geschädigt werden solle.

Ungeachtet der unmißverständlichen Weisung überwogen in der Aussprache die Bedenken gegen die Bauernpartei. Mehrere Redner sahen das Kernproblem darin, die bisher zu $70 \%$ politisch abstinente bäuerliche Bevölkerung überhaupt für eine politische Tätigkeit zu gewinnen. Man befürchtete, daß die „Bauernpolitik“ der SED infolge der Parteineubildung noch stärker einbreche. Denn das Bündnis der Arbeiter mit den Bauern stoße in den Ortsgruppen ohnehin auf erhebliche ideologische Vorbehalte; solche seien für langjährige Kämpfer der Arbeiterbewegung geradezu selbstverständlich und letztlich nur ein Beweis für ihr sozialistisches Bekenntnis, wie ein Teilnehmer einwarf. Konflikte mit der Bauernpartei waren aufgrund dieser Disposition einer Reihe von SED-Genossen bereits vorprogrammiert. Kader für die Bauernpartei hoffte man unter den einstigen Mitgliedern und Funktionären des Bundes der Schaffenden Landwirte finden zu können. Mindestens ein Teilnehmer dieser Debatte, Richard Köhler aus dem Kreis Oschatz, wirkte danach bei der Gründung in Sachsen mit.

Nachdem die SED-Kreistagsabgeordneten der VdgB vormittags instruiert worden waren, versammelten sich am Nachmittag im Landesbauernsekretariat der VdgB offenbar alle ihre Kreistagsabgeordneten, also auch die Parteilosen und Mitglieder anderer Parteien ${ }^{121}$. Zweck der Zusammenkunft sei es, wie der 1. Vorsit-

121 SStAD LV VdgB Sachsen 88, Sitzung der Kreistagsabgeordneten am 27. 4. 1948 nachmittags. Aus dem Dokument geht nicht hervor, ob parteilose Abgeordnete und Mitglieder 
zende der VdgB Bunzel einleitete, mit den Kreistagsabgeordneten über „parlamentarische Fragen" anläßlich der Pressenotizen zur Bildung einer Bauernpartei zu diskutieren ${ }^{122}$. Um den anwesenden etwaigen Gegnern der Bauernpartei den Wind aus den Segeln zu nehmen, wog man Vor- und Nachteile einer solchen Partei für die VdgB ab. Nachteilig wirke sich aus, daß eine neue Partei den ohnehin schmächtigen „Funktionärskörper" der VdgB noch mehr dezimiere und der Massenorganisation drohe, ihre parlamentarische Tätigkeit einstellen zu müssen. In den Stellungnahmen kristallisierten sich trotz SED-Regie zwei Gruppen heraus. Eine trat vorbehaltlos für die Gründung ein - so äußerten sich überwiegend die am Vormittag eingewiesenen SED-Vertreter der VdgB -, die zweite brachte massive Bedenken gegen die Bauernpartei vor. Dabei wird es sich um parteilose Vertreter und Mitglieder von bürgerlichen Blockparteien gehandelt haben. Von diesen wurde die zutreffende Vermutung geäußert, daß die Besatzungsmacht hinter der Bauernpartei stehe, sonst wäre die Entwicklung in Mecklenburg nicht so weit gediehen. Ungeachtet der Divergenzen beschloß die Versammlung, die Bauernpartei zu unterstützen. Diejenigen VdgB-Delegierten, die sich besonders für die neue Partei interessierten, erfaßte man umgehend namentlich. Drei von ihnen, Alfred Hantsche, Alfred Meier und Paul Weigelt, entsandte man auf Berliner Weisung zur Landesgründungsversammlung der DBD in Schwerin am 29. April $1948^{123}$.

Die sächsische VdgB-Versammlung vom 27. April war der Beginn für konzentrierte Vorbereitungen zur Gründung der DBD im Land. Die internen Aktivitäten der SED hielten sich offensichtlich in Grenzen. Nur am 13. Mai 1948 fand nachweislich eine Arbeitstagung mit den Kreissekretären der VdgB statt ${ }^{124}$, die zur Sondierung geeigneten Personals für die Bauernpartei gedient haben wird. Zur ersten Versammlung der DBD auf Zonenebene am 28. Mai in Brandenburg an der Havel reisten vier sächsische Vertreter an, die überwiegend aus dem Kreis Leipzig stammten ${ }^{125}$.

Erst nach dieser überregionalen Gründungsveranstaltung fand am 21. Juni 1948 die Gründungsversammlung der DBD Sachsens im Landesbauernsekretariat

bürgerlicher Parteien anwesend waren; dies ist aber wahrscheinlich, da es sonst keiner separaten SED-Sitzung am Vormittag bedurft hätte.

122 Pressenotizen zur Gründung einer Bauernpartei wurden seit 14 Tagen über Rundfunk, im „Sächsischen Tagblatt" der LDP, der „Neuen Zeit“ der CDU und in der „Sächsischen Zeitung“, dem Blatt der SED-Landesleitung, publiziert, Wernet-Tietz, Bauernverband, S. 105. ACDP VI-052-0001/a, Kopien von Zeitungsartikeln zur Gründung der DBD, z.B. „Thüringer Volk“, Organ der Landesleitung der SED Thüringen, 20. 4. und 24. 4. 1948.

123 Lt. Bericht der Abt. LW der SED am 3. 11. 1948 nahmen dann nur 2 sächsische Vertreter an der Schweriner Versammlung vom 29.4. 1948 teil. SStAD BPA SED LL A/864, Bl. $31 \mathrm{f}$.

124 SStAD LV VdgB Sachsen 88, Niederschrift über die Arbeitstagung mit den Kreissekretären, 13. 5. 1948.

125 Friedrich Martin aus Merkwitz, Julius Lehnen aus Seegeritz, Otto Steves aus Lindenthal sowie Richard Köhler aus Oschatz. ACDP VI-052-0001/b, Abschrift des Protokolls über die am 28.5. 1948 stattgefundene Tagung in Brandenburg über die Gründung der Bauernpartei. 
Dresden statt ${ }^{126}$. Sachsen war damit das Schlußlicht der Ländergründungen. Friedrich Martin, inzwischen Mitglied des provisorischen Zonengründungsausschusses, wiederholte die Motive zur Parteigründung. Ins Auge fällt, daß von den sonst gängigen Parolen weder die „Freundschaft mit der Sowjetunion“ noch die Anerkennung der Ostgrenze als „Friedensgrenze“ bemüht wurde. Die Diskussion zeigt vielfältige, mit der Parteigründung verbundene Hoffnungen auf. Fritz Weißhaupt ${ }^{127}, 1948$ Kreisvorsitzender in Ölsnitz und ab 1949 in wichtigen Positionen auf Länder- und Regierungsebene, wies der DBD als alleinige Vertreterin der bäuerlichen Belange eine eigenständige Rolle neben den bürgerlichen Parteien und der SED zu. In höherem Maße als in Mecklenburg wurden auf dieser Versammlung Vorbehalte gegen eine DBD als Neubauernpartei geäußert.

Über die personelle Zusammensetzung des Landesgründungsausschusses und der Geschäftsstelle entschied die SMA, Ausführung und Kontrolle übernahm die SED ${ }^{128}$. Den gewünschten Proporz im Gründungsausschuß setzte die SED trotz konträrer Diskussionen im Plenum durch ${ }^{129}$. Altbauern waren auf dieser Liste unterrepräsentiert ${ }^{130}$, was den sowjetischen Vorgaben wie der SED-Linie, eine Partei der Neu-, Klein- und Mittelbauern zu gründen, entsprach. Martin räumte Bedenken gegen das Verfahren aus, indem er das später nie eingelöste Versprechen gab, daß der endgültige Landesvorstand in direkter Wahl bestimmt werden sollte ${ }^{131}$.

Der späte Zeitpunkt der Gründung führte dazu, daß die sächsische Bauernpartei im Jahr 1948 der Entwicklung in anderen Ländern hinterherhinkte. Zwar wurden bis August 1948 - oft aufgrund von Initiativen der VdgB-Vorsitzenden oder auf Anordnung der sowjetischen Kommandanturen - 18 Kreisverbände gegrün$\operatorname{det}^{132}$ und bis November gab es 44 DBD-Ortsgruppen mit ca. 740 Mitgliedern. Auch lobte die SED-Abteilung Landwirtschaft im November die "gute politische Linie" der Geschäftsführer Walter und Ernst Findeisen, die auf Schulungen politisch eher nach „links" als nach "rechts“ tendierten 133. Dennoch täuscht dieses vordergründige Lob nicht darüber hinweg, daß der Landesverband Sachsen auf tönernen Füßen stand. Die SED war kaum bereit, für Abhilfe zu sorgen. Im August 1948 hielten Teile des Landessekretariates der SED die DBD für eine rein wirtschaftliche Organisation zur Vertretung bäuerlicher Interessen. Obwohl

126 SStAD BPA SED LL A/864, Protokoll der Gründung am 21. 6. 1948. Ein weiteres Protokoll befindet sich im Bestand des LV der VdgB, ebd., Akt 88.

127 BStU MfS AP 82/58, Fritz Weißhaupt, Bl. 2f., Lebenslauf, 15. 12. 1951.

128 Siehe oben, Aussage Martins. Vgl. Bericht der Abt. LW an das Sekretariat der Landesleitung, 3. 11. 1948. SStAD BPA SED LL A/864, Bl. $31 \mathrm{f}$.

129 Im Ausschuß: Martin, Leipzig; Kaiser, Leipzig; Köhler, Oschatz; Walther, Döbeln; Seidel, Ölsnitz; Michel, Zwickau; Hager, Dresden; Jungnickel, Dippoldiswalde und Uhlig, Chemnitz. SStAD BPA SED LL A/864, Protokoll der Gründung am 21. 6. 1948.

130 Pikanterweise ist dies dem Protokoll nicht zu entnehmen, das nur berichtet, daß Martin bekanntgab, wer Alt- und Neubauer war.

131 SStAD BPA SED LL A/864, Protokoll der Gründung am 21. 6. 1948.

132 SStAD BPA SED LL A/783, Sekretariatssitzung, 16.8. 1948, B1. 223. SStAD BPA SED LL A/864, Auszüge aus Kreismonatsberichten September über die Gründung der Bauernpartei, Bl. 36.

133 SStAD BPA SED LL A/864, Bericht der Abt. LW der SED, 3. 11. 1948, Bl. $31 \mathrm{f}$. 
Schenk und Ellrodt darauf drängten, die DBD personell zu verstärken, rang man sich nicht zu entsprechenden Beschlüssen durch ${ }^{134}$. Die SED griff weder die im November 1948 vom DBD-Landesverband eingereichten Vorschläge zur Verbesserung der Lage in der Partei auf noch behob sie mit anderen Mitteln den desolaten Zustand. Aus den Vorschlägen ging hervor, daß ein erheblicher Teil des Landesvorstandes seit Monaten nicht aktiv mitarbeitete ${ }^{135}$ und daher ersetzt werden müsse. Der engere Landesvorstand solle sich künftig zweimal im Monat treffen ${ }^{136}$ und wenigstens einer der beiden Vorsitzenden müsse seinen Wohnsitz nach Dresden verlegen. Der DBD fehlten Vertreter für Ausschüsse und vor allem ein Wirtschaftsfachmann. Die DBD baute auf eine Abgabe von Funktionären aus der SED, wozu diese nicht im erforderlichen Maße bereit war.

\section{Konstituierung der zentralen Ebene}

Die Konstituierung der zentralen Parteiebene 1948 ist nur fragmentarisch in den Quellen zu fassen. Anscheinend unpräzise informiert, meldete die Zeitung der SED Thüringens, „Thüringer Volk“, bereits am 24. April 1948, ein Organisationsausschuß einer neuen Partei sei in Berlin gebildet worden ${ }^{137}$. Daß zu diesem frühen Zeitpunkt ein von der Bauernpartei getragener Organisationsausschuß bestand, läßt sich weder belegen noch ist dies aufgrund des nachweislichen Gründungshergangs wahrscheinlich. Gemeint sein könnte allenfalls ein Zirkel eingeweihter Mitarbeiter der Abteilung Landwirtschaft des SED-Zentralsekretariates und informierte Kreise der VdgB. Vielmehr ist davon auszugehen, daß die Organisierung der Parteigründung von Ende April bis Mitte Mai hauptsächlich von Mecklenburg ausging, was nicht bedeutet, daß keine zentralen Weisungen vorlagen. Erst ab diesem Zeitpunkt wurde die Koordinierung aller Landesgründungsausschüsse in Berlin vorgenommen. Das deckt sich mit der Entwicklung, wie sie eine Niederschrift Piecks über ein Gespräch mit Tjulpanow, Nasarow, Grotewohl und Dahlem am 14. Mai 1948 dokumentiert. Die Notizen Piecks beleuchten den Einfluß und die Steuerung der Gründung durch die SMAD in Zusammenarbeit mit der SED ${ }^{138}$. Zuvor hatte das Zentralsekretariat am 8. Mai über die beiden neu zu gründenden Parteien beraten. Diese müßten ganz eng in die Westarbeit einbezogen und in der Blockpolitik wie Volkskongreßbewegung aktiv werden ${ }^{139}$.

Pieck schrieb eine Woche später am 14. Mai, daß die Bauernpartei „nahe der SED“ geplant sei. Nicht alle Personalentscheidungen hatte man zu diesem Zeit-

$134 \mathrm{Vgl}$. SStAD BPA SED LL A/783, Sekretariatssitzung, 16. 8. 1948, Bl. 223. Im August gab es in Dresden noch keine Leitung der DBD, Martin und andere operierten von Leipzig aus.

135 Darunter waren ausgerechnet die SED-Personalvorschläge: Lorek, Döbeln, Jungnickel, Dippoldiswalde, Rast, Freiberg, Uhlig, Chemnitz, Michel, Zwickau und Kreutzer, Auerbach. SStAD BPA SED LL A/864, DBD-Vorschläge zur Verbesserung der Lage der DBD im Lande Sachsen, 2. 11. 1948.

136 Er bestand aus Friedrich Martin, Richard Köhler, Fritz Weißhaupt, Erich Zöbisch, Kille, evt. auch Wolf und Uhlmann, sowie Walter und Findeisen.

137 ACDP VI-052-0001/a, Artikel aus "Thüringer Volk“, 24. 4. 1948.

138 Badstübner/Loth (Hg.), Wilhelm Pieck-Aufzeichnungen, hier S. 228.

139 SAPMO DY 30 IV/2/2.1/196, Protokoll ZS, 8. 5. 1948, Bl. 1. 
punkt schon gefällt; Goldenbaum war jedoch bereits als „Präsident“ eingeplant. Auch Robert Neddermeyer, seit 1947 Landessekretär, später Vorsitzender der VdgB Brandenburg ${ }^{140}$, war für einen leitenden Posten im Gespräch; das prominente SPD-Mitglied während der Weimarer Republik blieb in der SED. Als erste organisatorische Schritte waren Ländergründungsausschüsse vorgesehen. Der Landesverband Brandenburg sollte zwischen dem 20. und 23. Mai aus der Taufe gehoben werden; tatsächlich wurde die Bauernpartei dort wenig später am 27. Mai gegründet ${ }^{141}$. Gründungsausschüsse in Sachsen-Anhalt, Sachsen und Thüringen sollten Ende Mai und im Juni aktiv werden; diese Gründungen liefen termingemäß ab. Ende Mai sollte ein „Zonenausschuß" tagen und die Zulassung für die Landesverbände Mecklenburg und Brandenburg erreicht werden. Unklar war Mitte Mai, wann die Lizenzierung für die SBZ ergehen sollte. Außerdem besprach man die Parteipresse der Bauernpartei - sie sollte mit einer Wochenzeitung ausgestattet werden - sowie den künftigen „Sitz in Berlin“142. Piecks Notizen zur Gründung der Nationaldemokratischen Partei im gleichen Gespräch sind vergleichsweise ausführlicher und enthalten präzisere Vorgaben. Das deutet darauf hin, daß die Besatzungsmacht die Bildung der NDPD als Auffangbecken ehemaliger Nationalsozialisten für politisch brisanter als die DBD hielt und daher unter sorgfältiger Beobachtung halten wollte ${ }^{143}$.

An Planung und Durchführung der Parteigründung beteiligten sich die Abteilung Landwirtschaft des Zentralsekretariats, Teile des Zentralvorstands der VdgB und das Deutsche Bauernsekretariat. Kurt Vieweg drängte auf den Vorstandssitzungen der ZVdgB darauf, die Bauernpartei unbedingt zu fördern ${ }^{144}$. Nur einzelne Mitglieder der VdgB-Führung wie Anton Jadasch, Mitglied des Zentralvorstandes aus Sachsen, waren genauer informiert worden - dies waren sicherlich jene, die einer Gründung nicht im Wege standen. Andererseits herrschte in den Sitzungen des ZVdgB noch im Mai 1948 eine mißmutige Stimmung darüber, beim Entscheidungsprozeß zur Gründung übergangen worden zu sein. Nun sei man gezwungen, schleunigst eine einheitliche Stellungnahme und Vorgehensweise gegenüber der Bauernpartei herbeizuführen, da man in Mecklenburg für die Gründerin "gehalten werde" 145 .

Wie im Fahrplan der Niederschrift Piecks vorgegeben, trafen sich die Landesgründungsausschüsse der Bauernpartei am 28. Mai 1948 in Brandenburg an der Havel. Diese Zusammenkunft rangierte parteiintern als „Zonentreffen“ oder als

140 Vgl. Barth u. a. (Hg.), DDR, S. 1433. Neddermeyer saß aber für die KPD von 1924-28 im Reichstag.

141 BLHA Rep. 332, Nr. 786, Aktenvermerk zur Gründung der „Gesellschaft Y“ am 27. 5. 1948 in Potsdam, Zusammenstellung von Personallisten, ebenda, 25. 5. 1948; vgl. auch Reinert, Parteien, S. 124f., 158f., dort Verwechslung von „Gesellschaft X“, so die Bezeichnung für die NDPD, und „Gesellschaft $Y^{\prime}$.

142 Badstübner/Loth (Hg.), Wilhelm Pieck-Aufzeichnungen, S. $227 \mathrm{f}$.

143 Tjulpanow, Deutschland, S. $268 \mathrm{ff}$.

${ }^{144}$ SStAD LV VdgB Sachsen A/88, Abschrift des Protokolls der 5. Vorstandssitzung der ZVdgB am 21. 5. 1948. Als Berichterstatter zur Gründung der Bauernpartei trat Hansch vom DBS auf.

145 Ebd., Beitrag Hans Mirau. 
„konstituierende Sitzung“ der Bauernpartei und diente tatsächlich der Koordinierung der Landesparteibildungsausschüsse ${ }^{146}$. Mit ziemlicher Sicherheit fand bei dieser Gelegenheit auch die geplante Aussprache mit der Führung der VdgB statt. Denn dies war eine gute Gelegenheit, die Gründungen der DBD-Landesverbände, die von den VdgB-Landesverbänden mitgetragen oder sogar mitinitiiert wurden, mit dem ZVdgB abzustimmen ${ }^{147}$. Die Sitzung wurde als geheim deklariert; entsprechend freimütig gerieten dann einige Wortbeiträge. In einer längeren Rede informierte Goldenbaum die Anwesenden über Ziel und Zweck der DBD. Die Verabschiedung eines vorläufigen Programms und eines Statuts sollte jedoch noch einige Zeit in Anspruch nehmen, bis zur 1. Parteikonferenz bzw. Zonengründungskonferenz am 16./17. Juli 1948. Organisatorisch hatte die Sitzung am 28. Mai die Aufgabe, einen Zonengründungsausschuß zu wählen, der bei Marschall Sokolowski den Antrag auf Zulassung in der SBZ stellen sollte. Dieser Ausschuß konstituierte sich nur aus Repräsentanten der einzelnen Länder, ihm gehörten noch keine Vertreter eines zentralen Gremiums in Berlin an. Dies kann auch als Vertuschungsstrategie interpretiert werden; denn die Mitglieder der einzelnen Länder konnten so daheim berichten, daß noch kein zentrales, dann vermutlich von der SED gesteuertes Sekretariat bestehe. Dem Gründungsausschuß gehörten für Mecklenburg Goldenbaum und Franz Pilarski ${ }^{148}$ an, für Sachsen Friedrich Martin und Otto Steves, für Sachsen-Anhalt Richard Richter und Otto Voss, für Brandenburg Rudolf Albrecht und Frau Bettac und für Thüringen Herbert Hoffmann und Katharina Walther. Nachdem Goldenbaum am 2. Juni bei der SMAD die Zulassung der Partei für die ganze Zone beantragt hatte, wurde einer Delegation des Gründungsausschusses am 16. Juni durch Tjulpanow die Genehmigung zum Parteiaufbau und zur Publikation einer Zeitung erteilt ${ }^{149}$.

Rund einen Monat später, am 25. Juni, fand die erste Zonenvorstandssitzung der DBD in den Geschäftsräumen des VdgB-Zentralvorstandes in Berlin statt ${ }^{150}$. Anwesend waren Goldenbaum, der zu diesem Zeitpunkt schon als erster Vorsitzender rangierte, Albrecht als stellvertretender Vorsitzender, Pilarski für Mecklenburg, Hoffmann und Käthe Walter für Thüringen sowie der damalige Leiter der Zonen-Geschäftsstelle, Bernhard Griebel; Funktionäre aus Sachsen und Sachsen-Anhalt fehlten. Das Gremium besprach nochmals Fragen des Programms und der Statuten. Thüringens Vertreter schlugen vor, im Statut jene Passage zu streichen, die die besondere Bedeutung der Bauernpartei für die Neubauern hervorhob. Außerdem klärte man einige organisatorische Fragen ${ }^{151}$.

146 Vgl. Aussage Friedrich Martins, Unrecht als System, Teil II, S. 32 f.

147 MLHA LV VdgB 48, Korrigierte Pressenotiz des DBS anläßlich der ordentlichen Tagung des Hauptausschusses der ZVdgB vom 31.5. 1948 berichtet von einer vorherigen Aussprache mit namhaften Vertretern der Gründungsausschüsse der DBD in Brandenburg.

148 Pilarski, der spätere Landesvorsitzende Mecklenburgs, trat hier erstmals - aktenmäßig belegt - auf.

149 Wernet-Tietz, Bauernverband, S. 105.

150 ACDP VI-052-0141, Protokoll der ersten Zonenvorstandssitzung am 25. 6. 1948.

151 Das Sekretariat des Vorstandes sollte sich künftig zusammensetzen aus dem ersten Vorsitzenden und seinem Stellvertreter, dem Leiter der Abt. Organisation, dem Leiter der 
Die dringend notwendigen personellen Entscheidungen fällte die SED auf Drängen der SMAD und in Absprache mit ihr erst im Laufe des Juli 1948. Zwar nahmen der von Pieck als Hauptgeschäftsführer vorgesehene Paul Scholz sowie Leonhard Helmschrott bereits an der sogenannten Zonentagung und ersten Parteikonferenz der DBD am 16./17. Juli 1948 als "Gäste" teil. Offiziell entband sie das Zentralsekretariat der SED jedoch erst am 19. Juli von ihren bisherigen Funktionen: im Fall von Scholz als stellvertretenden Chefredakteur der VdgB-Zeitung „Der Freie Bauer" und Helmschrott, der gerade die Parteihochschule der SED absolviert hatte, als Redakteur der "Landeszeitung“ Mecklenburgs ${ }^{152}$. Trotz dieser Bemühungen hatte die DBD bis in den Sommer 1948 hinein kein funktionierendes Sekretariat ${ }^{153}$. Dieses wurde Ende August offiziell mit Felix Scheffler als Abteilungsleiter Organisation und Wilhelm Adam für die Abteilungsleitung Werbung verstärkt ${ }^{154}$. Damit bestand das Sekretariat 1948 aus Goldenbaum, Albrecht, Scholz, Scheffler, Griebel, Adam und Helmschrott.

Den offiziellen Auftakt gab die Bauernpartei auf der sogenannten „Zonengründungskonferenz" am 16./17. Juli 1948 in Schwerin ${ }^{155}$. Als Fahrplan für das weitere Vorgehen in den Ländern beschloß man dort, die bestehenden Landesgründungsausschüsse bis zum 25. Juli zu Landesparteibildungsvorständen umzuformen. Diese Gremien konnten mindestens je 21 Mitglieder umfassen. Bis 5. August sollten alle Landesvorstände konstituiert sein. Bislang gab es in knapp 1000 Ortschaften und in 80 von insgesamt 128 Verwaltungskreisen Parteibildungsausschüsse.

Die programmatischen Beschlüsse der Konferenz verfolgten eine dilatorische Taktik. Um den Parteidokumenten eine quasi basisdemokratische Legitimation $\mathrm{zu}$ verleihen, debattierte man über eine Vorlage des Landesverbandes Thüringen ${ }^{156}$. Diese forderte, so wie zuvor am 22. Juni auch von der NDPD angeregt worden war ${ }^{157}$, die Verschiebung der für Herbst 1948 geplanten Kommunalwahlen, da sich die Bauernpartei erst organisatorisch festigen wolle. Die Versammlung verabschiedete eine entsprechende Resolution an die SMAD, ganz im Sinne der

Abt. Presse, Bildung und Werbung und dem Leiter der Abt. Personal. Die geplanten Abteilungen "Frauen" und "Jugend" sollten dem Sekretariat nebengeordnet werden.

152 SAPMO DY 30 IV 2/2.1/217, Protokoll ZS, 19. 7. 1948, Bl. 4. Vgl. SAPMO NY 4026/ 724, Bl. 13, Pieck an Bichowski, 8. 7. 1948.

153 Scholz auf der ersten Sitzung des Parteivorstandes am 7. 8. 1948, ACDP VI-052-0141.

154 Ebd., Mitteilung von Scholz auf der Parteivorstandssitzung am 26. 8. 1948.

155 ACDP VI-052-0002, Anwesenheitsliste der 1. Parteikonferenz am 16./17. 7. 1948. Insgesamt waren am ersten Konferenztag mindestens 127 mit der DBD verbundene Personen anwesend, einschließlich Gastdelegierter und anderer Gäste. Die Gäste wurden bei dieser Zählung nicht abgezogen, weil z. B. auch Goldenbaum als "Gast“ geführt wurde. Auch ein Teil der mitreisenden Ehefrauen, die ebenfalls als Gäste geführt wurden, hatte Interesse an der Bauernpartei. Unter den 127 waren mindestens 4 Fahrer und ein Stenograph. Anwesend waren außerdem Vertreter der SMA, der Mecklenburger Verwaltungsbehörden sowie 11 Journalisten.

156 Ebd., Antrag des LV Thüringen, 15. 7. 1948, die Entschließung des Kreisgründungsausschusses Eisenach vom 1. 7. 1948 zur Beschlußfassung vorzulegen.

157 Staritz, National-Demokratische Partei Deutschlands (NDPD), in: SBZ-Handbuch, S. 577. 
sowjetischen Besatzer und der SED. Dieser Text floß in einen Brief Goldenbaums an Sokolowski ein ${ }^{158}$.

Das vorläufige Programm und Statut der Partei standen nicht ausdrücklich zur Diskussion, eine Abstimmung darüber fand nicht statt. Dies sollte einem späteren Parteitag vorbehalten bleiben. Das Statut lag nach Merkers Informationen den Delegierten nicht einmal vor ${ }^{159}$, es wurde dennoch „vorerst“ in Kraft gesetzt. Dieses Manko in der Programmatik und Verfaßtheit der Partei war beabsichtigt. Es eröffnete Handlungsspielräume für die Parteientwicklung und Mitgliederwerbung. Erweckte die DBD doch den Eindruck, als könne sie tatsächlich selbst an ihrem programmatischen Inhalt arbeiten. Auf die Mitgliederrekrutierung mochte sich diese inhaltliche Unbestimmtheit insofern positiv auswirken, als man Zielgruppen ansprechen konnte, die sich angesichts des späteren Programms nicht für die DBD interessiert hätten oder umgekehrt für die Partei als Mitglieder ausschieden ${ }^{160}$. Diese Beobachtung deckt sich mit Goldenbaums geradezu moderater Position gegenüber den bürgerlichen Blockparteien auf dieser Konferenz $z^{161}$ - das änderte sich bis zum 1. Parteitag 1949 grundlegend. Vorerst sollte der Kritik bürgerlicher Kräfte an der neuen Partei der Wind aus den Segeln genommen werden. Schon auf einer Zonenvorstandssitzung in Weimar am 10. Juli 1948 hatte man sich erstmals mit einer Entschließung zum Zweijahrplan ${ }^{162}$ öffentlich zu innenpolitischen Fragen geäußert. Die Versammlung verabschiedete darüber hinaus eine von Helmschrott vorgetragene Resolution „Bauernpartei gegen Separatstaat “163.

Goldenbaum wurde einstimmig zum Parteivorsitzenden gewählt und Rudolf Albrecht zu seinem Stellvertreter. In den damals noch so genannten „engeren Vorstand" wurden neben Goldenbaum nur Scholz und Helmschrott geschickt. Als geschulte und eigens abgestellte SED-Genossen sollten diese drei den politisch vorgezeichneten Weg der Partei auf zentraler Ebene gewährleisten. Dem Parteivorstand gehörten daneben Ländervertreter an ${ }^{164}$. Die Programmkommission

158 Die Bitte, die Kommunalwahlen auf 1949 zu verschieben, wurde von Goldenbaum u.a. damit begründet, daß die DBD in der verbleibenden kurzen Zeit den organisatorischen Aufbau nicht bewältigen könne, andererseits aber damit zu rechnen sei, daß sie im Ergebnis der Wahlen in vielen Dörfern die "Hauptverantwortung “ übernehmen müsse. ACDP VI-052-0001/c, Goldenbaum an Obersten Chef der SMAD, Marschall Sokolowski, 20. 7. 1948.

159 SAPMO DY 30 IV 2/2022/18, Bl. 62, Aktenvermerk für Merker, 22. 7. 1948.

160 Goldenbaum sprach dieses Faktum vor dem Hintergrund an, daß die LDP der DBD vorwerfe, die Bauernschaft spalten zu wollen. Er hielt entgegen, daß lt. Statut - das der Versammlung jedoch nicht vorlag - die DBD „nur aus eigentlichen Bauern bestehen soll. Diese Frage ist ganz offen gelassen worden.“ ACDP VI-052-0002, Protokoll der 1. Parteikonferenz 16./17. 7. 1948, S. 60.

161 Hingegen wies Goldenbaum darauf hin, daß sich der DBD trotz der bestehenden Parteien ein großes Arbeitsfeld eröffne. Es sei verständlich, daß die anderen Parteien die Konkurrenz fürchteten. Ebd., S. $57 \mathrm{f}$.

162 Abgedruckt in Bauern-Echo, 18. 7. 1948. Vgl. auch Goldenbaums Rede ACDP VI-0520002, Protokoll der 1. Parteikonferenz 16./17. 7. 1948, S. 9.

163 ACDP VI-052-0002, Protokoll der 1. Parteikonferenz 16./17. 7. 1948, laut Goldenbaum würde der Marshallplan eine extensive Landwirtschaft bewirken und so die Auslandsabhängigkeit Deutschlands verstärken, S. 6.

164 Für Mecklenburg Pilarski, Czymoniak und Reder, für Brandenburg Martha Krähe, Willi 
setzte sich zusammen aus Herbert Hoffmann (Thüringen), Pratsch (Sachsen-Anhalt), Frau Walter ${ }^{165}$ (Sachsen), Albrecht (Brandenburg), Waldemar Schulz - der quasi den Wismarer Gründerkreis vertrat - sowie Ernst Goldenbaum für den Parteivorstand.

Außer Katharina Walter aus Thüringen war keine der in die Gremien gewählten Frauen nachweislich auf der Parteikonferenz anwesend ${ }^{166}$. Sie dürften alle in Abwesenheit aufgrund der vorher von den Landesverbänden eingereichten Vorschlagslisten gewählt oder höchstwahrscheinlich erst nachträglich eingebaut worden sein, wie im Fall von Martha Krähe. So sollte zumindest ein kleines Frauenquorum hergestellt werden. Da die Vertreter der SMA die Personalauswahl für die DBD sorgfältig überwachten, dürfte ihr Einfluß auch eine Frauenbeteiligung zumindest in den repräsentativen Parteigremien bewirkt haben ${ }^{167}$.

Die inhaltlichen Vorgaben für die Zonenkonferenz waren vorher genau mit den zuständigen Personen der SED, in diesem Falle Paul Merker, abgesprochen worden. Daher lief die Versammlung nach dem Bericht der Informationsverwaltung der SMAD nach Moskau „in Übereinstimmung mit der politischen Linie, die im Laufe ihrer Vorbereitung von uns festgelegt worden war" ${ }^{168}$. Auch Merker war mit dem Verlauf zufrieden: Bei Referaten, Resolutionen und Parteivorstandswahlen gab es keine unangenehmen Überraschungen. Daß die Delegierten zum Statut nicht Stellung nehmen konnten, weil es ihnen schlichtweg nicht vorlag, wurde be-

Tausend und Rudolf Albrecht, für Sachsen Ilse Neumann, Richard Köhler und Friedrich Martin, für Thüringen Katharina Walter, Herbert Hoffmann und Walter Thiem sowie für Sachsen-Anhalt Otto Voss, Ernst Beer, Richard Richter und Frau Pilz. Laut Protokoll wurden Personen namens Deluski [offenbar Pilarski] und Schimonis [offenbar Czymoniak] gewählt. Dabei dürfte es sich um Hör- und Schreibfehler des Stenographen handeln, die Namen stehen nicht auf der Anwesenheitsliste. Der Name Krähe wurde nachträglich handschriftlich ins Protokoll eingefügt.

165 Auffällig ist, daß auf einer dem Protokoll im Akt vorangestellten Zusammenfassung des Wahlvorganges Frau Walter aus Sachsen in die Programmkommission gewählt wurde, dem Protokoll zufolge jedoch nur Männer in der Programmkommission saßen und eine Frau Walter aus Dresden auch in der Anwesenheitsliste fehlt. Höchstwahrscheinlich wurde sie nachträglich anstelle ihres Mannes plaziert, um wenigstens nominell eine Frau aufzuführen. Sie dürfte vermutlich ohnehin der Sicht ihres Mannes gefolgt sein, denn den hatte die SMA Sachsen dem späteren Landesvorsitzenden Martin als Geschäftsführer an die Seite gestelit. Auf der Suche nach einer Frau wäre für die Programmkommission auch Katharina Walter aus Thüringen in Frage gekommen. Doch da gab man Herbert Hoffmann den Vorzug, der 1949 als DDR-Landwirtschaftsminister gehandelt wurde. Vgl. ACDP VI-052-0002 Protokoll 1. Parteikonferenz 16./17. 7. 1948, S. 63.

166 Außer Katharina Walter fehlten alle gewählten Frauen sowohl in der Anwesenheitsliste als auch in der ursprünglichen, unretouchierten Fassung des Fotos des gewählten Parteivorstandes. ACDP VI-052, Fotosammlung.

$167 \mathrm{Vgl}$. z.B. die überlieferten detaillierten Auflistungen der Kreissekretäre und -vorstände Mecklenburgs. ACDP VI, unverz. Best. LV Mecklenburg; vgl. auch das Memorandum der Informationsverwaltung der SMAD für L. Baranow über die Zonenkonferenz der Demokratischen Bauernpartei, Juli 1948, in: Bonwetsch u.a. (Hg.), Politik, S. 167 f., das ausdrücklich vermerkt, daß vier (!) Frauen gewählt worden seien.

168 Memorandum der Informationsverwaltung der SMAD für L. Baranow über die Zonenkonferenz der Demokratischen Bauernpartei, Juli 1948, in: Bonwetsch u.a. (Hg.), Politik, S. $167 \mathrm{f}$. 
ruhigt zur Kenntnis genommen; insbesondere deshalb, weil dann bis zur Verabschiedung auf einem späteren Parteitag noch genügend Zeit verbleibe, einige Verbesserungen bezüglich der Abgrenzung der aufzunehmenden Mitglieder anzubringen ${ }^{169}$. Hierbei handelte es sich höchstwahrscheinlich um eine Festlegung in der sogenannten "Großbauernfrage“. Den Diskussionen in den Landesverbänden zufolge gab es durchaus Tendenzen, sogenannten Großbauern nicht grundsätzlich aus ideologischen Gründen eine Aufnahme zu verweigern ${ }^{170}$.

Der SED war auch der personelle Einbau von Scholz und Helmschrott in das entscheidende Parteigremium geglückt, den engeren Parteivorstand bzw. das Sekretariat, wie es wenig später hieß. Außerdem verständigte man sich auf erste politische Aufgaben, die die deutschlandpolitischen Positionen von SMAD und SED stärken sollten:

„Mit dem Gen. Scholz wurde vereinbart, daß der Vorstand noch vor der nächsten Volksratssitzung in einem Schreiben den Beschluß der Konferenz mitteilt, daß die Partei bereit ist, an der Volkskongreßbewegung und an dem Deutschen Volksrat teilzunehmen und daß die vorläufigen Vertreter der Partei, die bereits dem Volksrat angehörten, Mitglied sind. Die [!] Gen. Goldenbaum wurde beauftragt, an der Sitzung des Volksrates eine entsprechende Erklärung abzugeben." 171

Nach der Konstituierung der DBD auf zonaler Ebene wurde die Partei auf ihren Antrag hin am 5. August 1948 in den Block aufgenommen. Goldenbaum, Albrecht und in deren Vertretung Scholz sollten für die DBD regelmäßig daran teilnehmen ${ }^{172}$. Die Zeitung der SMAD, Tägliche Rundschau schrieb am 7. August angesichts der Wiederbelebung des Einheitsfrontausschusses von einem „Sieg des Blockgedankens"173.

\section{Die Gründergruppen 1948}

\section{Grundzüge der organisatorischen Entwicklung 1948}

Eine genaue Beleuchtung der organisatorischen Entwicklung der DBD 1948 steht auch nach Öffnung der Archive vor unlösbaren Quellenproblemen. Für diesen Zeitraum liegt keine zeitgenössische Organisationsstatistik der DBD vor. Zwar wurden in Parteivorstandssitzungen 1948 Mitgliederzahlen genannt, die jedoch aus Gründen der Geheimhaltung ab Herbst des Jahres nicht mehr im Protokoll niedergeschrieben wurden.

169 SAPMO DY 30 IV 2/2022/18, Bl. 62, Aktenvermerk, 22. 7. 1948.

170 ACDP VI-052-0141, Protokoll PV, 26. 8. 1948; dazu Goldenbaum: „Daraus ergibt sich, daß unsere Partei sich im wesentlichen stützen muß, [auf solche] die praktisch fortschrittlich sind, denen es politisch aber noch nicht zum Bewußtsein gekommen ist."

171 SAPMO DY 30 IV 2/2022/18, Bl. 62, Aktenvermerk, 22. 7. 1948.

172 SAPMO NY 4036/716, Aufstellung der Blocksitzungen, BI. 2 f.: DBD auf der 33. Sitzung aufgenommen, NDPD am 7. 9. 1948, 34. Sitzung. Ebd., BI. $89 \mathrm{ff}$. Protokoll der Blocksitzung vom 5. 8. 1948. Suckut, Blockpolitik, S. 257-282.

173 Suckut, Blockpolitik, S. 284f. Zum Zusammenhang von Parteineugründungen und Blockkrise 1947/1948 siehe Bauer, Krise. 
Trotz massiver Unterstützung der SMAD, der Länder-SMA und der Organe der SED litt der Parteiaufbau unter zahlreichen Erschwernissen und war 1948 insgesamt mangelhaft. Für das organisatorische wie politische Gelingen der Neugründung war daher der Einfluß von Personen, die strukturierend eingriffen und Kristallisationspunkte der weiteren Organisation bildeten, enorm wichtig. Die unzureichenden Organisationsstrukturen verursachten Informationsdefizite. Die wenigen vorliegenden Daten versuchte die Parteiführung geheimzuhalten. Denn die zunächst geringen Mitgliederzahlen spiegelten den anfänglichen Mißerfolg wider und galten als "gefundenes Fressen“ für politische Gegner. Bis Ende 1948 verfügte die DBD lediglich über 10456 Mitglieder ${ }^{174}$. Da keine Gesamtstatistik mit Angaben zur sozialstrukturellen Zusammensetzung der DBD bis 1950 überliefert ist, beschränken sich die Angaben hierzu im folgenden auf qualitative Aussagen.

Nach den Vorstellungen von SMAD, SED und dem Führungskern um Goldenbaum und Scholz sollte der Parteiaufbau und die Mitgliederrekrutierung möglichst gesteuert verlaufen. Um von Beginn an auszuschließen, daß sich die DBD zu einem „Sammelbecken der Reaktion“ entwickelt, vollzog sich der Parteiaufbau von oben nach unten. Nachdem sich bis Juli 1948 alle Landesverbände konstituiert hatten, folgte - je nach Landesverband früher oder später - die Gründung von Kreisverbänden. Nach welchen Kriterien sich die Personalauswahl für die Besetzung der Kreisvorstände und -sekretariate richtete, kann aufgrund der Überlieferung nur für Mecklenburg analysiert werden.

Bis Oktober 1948 waren erst zwei Drittel der mecklenburgischen Kreisverbände mit Kreissekretären versorgt. Der Erfolg in den Kreisen war sehr unterschiedlich und hing in hohem Maße von der Fähigkeit des leitenden Funktionärs vor Ort $a b^{175}$. Höchstwahrscheinlich reglementierte die SMAD von vornherein die Anzahl der erlaubten Ortsgruppen, um deren Kontrolle zu gewährleisten. Für Mecklenburg waren 250 vorgesehen ${ }^{176}$. Die Gründung von Ortsgruppen durfte nicht überhastet geschehen. Sogenannte Vertrauensleute der DBD sollten in den Ortschaften das Interesse der bäuerlichen Bevölkerung sondieren; dann waren Kontakte zur örtlichen sowjetischen Kommandantur und zum Kreisverband der DBD herzustellen. Auf direktem Weg wollte die höhere DBD-Ebene, teils in Kontakt mit SED und sowjetischen Stellen, die politisch korrekte Zusammensetzung der Grundeinheiten überwachen.

Die Gesamtzahl der Ortsgruppen in der SBZ betrug Mitte Oktober 1948 laut Angaben der DBD 280. Bis dahin hatte man über 5000 Mitgliedsbücher ausgehändigt; außerdem waren rund 7500 Aspiranten vorläufig registriert, ihre endgültige Aufnahme hing noch vom Ergebnis des Überprüfungsvorganges ab ${ }^{177}$.

174 ACDP VI-052-194/4, Entwicklung der Partei, Stand 31. 12. 1948. Diese Angaben stammen aus einer nachträglich, Mitte der achtziger Jahre zusammengestellten Handakte des damaligen Leiters der Organisationsabteilung Ermisch.

175 ACDP VI-052-0141, Protokoll PV, 8. 10. und 3. 12. 1948, Redebeiträge Goldenbaums.

176 Ebd., Sitzung Zonenvorstand, 25. 6. 1948.

177 Die offensichtlich erste Organisationsübersicht nennt im Oktober 1948282 Ortsgruppen, SAPMO NY 4036/724, Bl. 20, Organisationsstand, 15. 10. 1948, gez. Schnitzler. 
Dieser Umstand hat dazu geführt, daß die Bauernpartei gelegentlich als Partei ohne nennenswerte Zahl an Ortsgruppen und Mitgliedern angesehen wurde ${ }^{178}$.

Der organisatorische Aufbau der Partei litt auf allen Ebenen massiv unter Personalmangel. Das Dilemma für potentielle DBD-Funktionäre bestand häufig darin, eine professionelle Parteitätigkeit mit den betriebswirtschaftlichen Anforderungen der Höfe in Einklang zu bringen ${ }^{179}$. Den Neubauern fehlte oftmals Fachkompetenz und landwirtschaftliche Berufserfahrung. Es sollte jedoch vermieden werden, daß mißwirtschaftende Mitglieder und fachlich inkompetente Funktionäre das Image der DBD untergruben. Erfahrene Mittelbauern schreckten vor allem wegen der zunehmenden Propagierung des Klassenkampfes auf dem Lande vor der Übernahme von Funktionärsposten zurück. Denn falls sie zur Arbeitsentlastung auf ihren Höfen nicht auf mithelfende Familienangehörige zurückgreifen konnten, sondern familienfremde Arbeitskräfte anstellen mußten, gerieten sie unter Umständen schnell in den Verdacht, der angefeindeten Gruppe der „Großbauern" anzugehören.

Das zentrale Problem der frühen Parteiorganisation bestand in der hohen Fluktuation der Funktionäre auf der Ebene der Kreise und in den Landessekretariaten. Da geeignete Kader bis weit in die fünfziger Jahre hinein eigentlich ständig fehlten, entschieden die Funktionäre häufig, wenigstens zeitweilig auf solche zurückzugreifen, die man zwar fachlich und persönlich für ungeeignet hielt, die aber politisch verläßlich oder zumindest entwicklungsfähig erschienen. Fand ein Kreisfunktionär in der Gründungsphase keinen Kontakt zur bäuerlichen Bevölkerung, so mußte er einer besseren Kraft weichen, sobald eine solche zur Verfügung stand ${ }^{180}$. Im Vergleich zu den Landessekretariaten war die Fluktuation auf der Kreisebene und vor allem in den Ortsleitungen in der Frühphase geringer. Der Grund hierfür lag in den Kreisverbänden darin, daß politisch als brauchbar eingeschätzte Personen äußerst rar waren, für einen systematischen Kaderaustausch in der Regel kein Ersatz zur Verfügung stand. Außerdem war die DBD noch keine durchorganisierte Kaderpartei, die über ausreichende Disziplinierungsmechanismen verfügte, etwa um Parteisäuberungen in den Kreisen durchzuführen. Die für Organisation Zuständigen unterschieden zwischen der Besetzung von Kreissekretariaten und Kreisvorständen. Während man in den Sekretariaten und auch noch bei der Besetzung des 1 . Kreisvorsitzenden eine größere Vorsicht und Kon-

178 Richter, Ost-CDU, S. 94 ff; ders., Entstehung und Transformation, S. 2540-2545. Quellenkritisch ist hierbei anzumerken, daß diese Angaben nur auf qualitativen Beobachtungen des politischen Gegners beruhen. Andere Uberlieferungen belegen, daß die DBD bereits über Mitglieder verfügte. Diese informatorische Schieflage mag auch darin begründet liegen, daß die Mitgliederwerbung der DBD 1948 unter den Altbauern nur wenig erfolgreich verlief. Diese Gruppe ist hingegen eher zur Klientel der CDU zu zählen und dürfte auch als Informationsquelle fungiert haben.

179 ACDP VI-052-0141, Protokoll PV, 3. 12. 1948, wonach die Lage in Sachsen davon geprägt sei, daß "gute“ Bauern nicht in die Politik wollten.

180 Vgl. z. B. ebenda, Protokoll PV, 3. 12. 1948, Bericht über den Kreis Hagenow. 
trolle obwalten ließ ${ }^{181}$, war die Zusammensetzung der Kreisvorstände von nachrangiger Bedeutung. Im Gegenteil, hier wurden häufig bewußt Vertreter der Mittel- und sogar Großbauern ehrenamtlich eingebunden, um so weitere ländliche Schichten anzusprechen. Im Vergleich zu den Kreissekretariaten wiesen die Kreisvorstände eine kontinuierlichere Besetzung auf.

In den Ländersekretariaten gestaltete sich die Situation insofern anders, als trotz Kadermangel versucht wurde, nur politisch zuverlässige Kräfte in die Sekretariate einzubauen ${ }^{182}$. Dies geschah auf dem Weg der Kooptation von ehemaligen SED-Mitgliedern. In Sachsen-Anhalt wurden bis Dezember 1948 Pratsch und Sejna kooptiert, in Brandenburg verstärkte Walter Haberland das Sekretariat. Für Mecklenburgs Sekretariat suchte man nach einer weiteren Person; der Vorschlag aus Schwerin, Hans-Joachim Friedländer einzubauen, war Goldenbaum zufolge nicht realisierbar. Das Thüringer Sekretariat unter der Leitung von Herbert Hoffmann, dem man „Überspitzung“ vorhielt, sollte mit einem auf Ausgleich bedachten Funktionär ergänzt werden.

Auch parteiinterne Reibungen blockierten die Arbeit der Ländersekretariate. Rivalitäten herrschten zum einen zwischen dem ursprünglichen Gründungspersonal und den neu hereingenommenen Sekretariatsmitgliedern. Richard Richter wandte gegen Pratsch ein, daß dieser sich unmöglich verhalte, weil er die Schreibkräfte der Landesgeschäftsstelle von der SMA kontrollieren lasse. Offenbar zählte Richter anfangs zu den Funktionären, die zu direkte Eingriffe der SMA in die innere Struktur abwehren wollten ${ }^{183}$. Andererseits gab es auch Spannungen unter dem ursprünglichen Personal. Pilarski berichtete von Zwistigkeiten im Schweriner Sekretariat und meinte damit seine Streitereien mit Paul Reder ${ }^{184}$. Sachsens Sekretariat war ohne straffe Führung, da der Landesvorsitzende Friedrich Martin nicht in Dresden, sondern weiterhin in Leipzig wohnte und sich überhaupt weigerte, hauptamtlich für die DBD zu arbeiten. Das Manko von Ernst Findeisen und Walter, die Martin von der SMA für den organisatorischen Aufbau zur Verfügung gestellt worden waren, läge darin - so Martin -, daß sie keine Bauern seien $^{185}$. Insgesamt ist für das frühe Führungspersonal in den Ländern festzustellen, daß es im Unterschied zu später über einen erheblichen Handlungsspielraum verfügte. Manche agierten eigenmächtig, voller Selbstbewußtsein und waren sich ihrer Sache im Vergleich zu den beginnenden fünfzig Jahren allzu sicher. Rudolf Albrecht und Richard Richter führten ihre Sekretariate praktisch allein ${ }^{186}$. Zu dieser Zeit funktionierte der Organisationsaufbau der DBD noch keineswegs reibungslos nach den Prinzipien des "demokratischen Zentralismus“.

\footnotetext{
181 Für Mecklenburg siehe eingehender Bauer, Gründung, S. 305-311.

182 Das folgende nach ACDP VI-052-0141, Protokoll PV, 3. 12. 1948.

183 Ebd.

184 Ebd.

185 Ebd., Protokoll PV, 8. 10. 1948.

186 Ebd., Protokoll PV, 3. 12. 1948.
} 


\section{Profil der Parteigründer}

Beschäftigt man sich mit der Sozialstruktur und anderen Merkmalen der Gründergruppen der Partei, so ergeben sich folgende Fragen: Welche Personen ließen sich als politische Funktionsträger anwerben und aus welchen Motiven? Welchen Beruf übten sie aus, welcher ländlichen Schicht gehörten sie an? Wie hoch war der Anteil an Vertriebenen und Flüchtlingen? War die Bauernpartei für Neubauern und Altbauern gleichermaßen attraktiv? Welche Generation mit welchen politischen Vorprägungen interessierte sich für ein Engagement in der Bauernpartei, und in welchem Maße stießen Frauen und Jugendliche zur Gründergruppe? Untersucht man die laufenden Eingriffe in die Besetzung der Kreisvorstände 1948, so sind Rückschlüsse darüber möglich, in welche Richtung sich die DBD laut Vorgaben ihres engeren Parteivorstandes bzw. des zentralen Sekretariates und letztlich von SMAD und SED entwickeln sollte.

Die Analyse stützt sich in der Hauptsache auf Daten des Landesverbandes Mecklenburg, da nur für diesen eine dichtere Überlieferung zur Besetzung der Kreisvorstände 1948 vorliegt ${ }^{187}$. Nach sozialstrukturellen Gesichtspunkten können zwei mecklenburgische Gründergruppen vorgestellt werden, zum ersten die ganz frühen DBD-Mitglieder, die auf der Landesgründungsversammlung in Schwerin am 29. April 1948 (73 Personen) anwesend waren, und zum zweiten die Kreisvorstandsmitglieder (214 Personen). Die Analyse der letzteren basiert auf einer Aufstellung, die im Herbst 1948 entstand und 1949 fortgeführt wurde188.

Unter den 200 Kreisvorstandsmitgliedern waren nur elf Frauen und zwölf jugendliche Männer bis zum Alter von 25 Jahren. Das Durchschnittsalter der Kreisvorstandsmitglieder 1948 lag gerundet bei 38 Jahren. Durch Streichungen und gezielte Rekrutierung von jungem Personal im Alter von Anfang 20 versuchte man, den Altersdurchschnitt zu senken. 53 Personen oder rund 27\% waren 1948 48 Jahre und älter. Wählt man als Stichdatum das Geburtsjahr 1902, so umfaßt diese Gruppe der mindestens 46 Jahre alten sogar 39\%. 37 Personen oder knapp $19 \%$ waren 1948 bis zu 30 Jahre alt. Nur zehn Personen (rd. 5\%) waren maximal 23 Jahre alt und kannten aus eigener Erfahrung nur die Zeit des Nationalsozialismus. Über ein Viertel hatte noch im Kaiserreich und während des Ersten Welt-

187 Die Materiallücken bei anderen Landesverbänden sind m.E. darauf zurückzuführen, daß dort die Gründungsinitiativen später erfolgten und keine ähnlich organisierte Gründergruppe auf Landesebene existierte wie in Mecklenburg.

188 Für diese Datierung spricht, daß der Aufbau sämtlicher Kreisvorstände Mecklenburgs bis Herbst weitgehend vollzogen war, so auch für Parchim und Hagenow, wo im Sommer 1948 noch keine bestanden. In den Besetzungen wurden Streichungen politisch untragbarer Mitglieder vorgenommen, den Dokumenten ist zu entnehmen, wer wem weichen mußte. Noch für Sommer 1948 nachweisbare großbäuerliche Mitglieder sind in der späteren Aufstellung gestrichen. ACDP VI, unverz. Best. LV Mecklenburg, Akt Besetzung der Kreisvorstände 1949- (enthält auch Stand von 1948). Insgesamt sind 200 Personen erfaßt, wobei für verschiedene Erhebungen Angaben fehlen und daher teils von einer geringeren Basis auszugehen ist. Der folgenden Auswertung liegen die Daten der Personen der ursprünglichen Besetzung zugrunde, weil sie stärker jenen Personenkreis beleuchten, der sich anfänglich für die Bauernpartei interessierte. Soweit nur die Daten der Nachrücker bekannt sind, wurde auf sie zurückgegriffen. 
krieges Kindheit und Adoleszenz verbracht und die Revolutionszeit von 1918 schon als Erwachsene miterlebt. Die revolutionären Ereignisse von 1918 dürften aber auch bei einer erweiterten Gruppe von 39\%, zu der auch die damals 16-Jährigen zählen, einschneidende politische Prägungen bewirkt haben. Die Weimarer Republik hatten 39\% als Erwachsene durchlebt. Für diese Gruppe dürfte sie die politisch und lebensgeschichtlich prägende Erfahrung gewesen sein. Da die überwiegende Zahl der Kreisvorstandsmitglieder schon länger im ländlichen mecklenburgischen Gebiet ansässig war, erlebte sie sowohl die in Mecklenburg besonders tiefe Zäsur zwischen Monarchie und Republik ${ }^{189}$ als auch in unmittelbarer Nähe die politischen Wirren des Kapp-Putsches ${ }^{190}$. Ein Viertel der Kreisvorstände kannte aus eigener Erfahrung drei politische Herrschaftsformen: Kaiserreich, Weimarer Republik und Nationalsozialismus.

Zahlenmäßig fällt bei der Verteilung Altbauern - Neubauern ein deutliches Übergewicht letzterer auf. Der ursprünglichen Besetzung zufolge betrug ihre Zahl 136 von 200. Drei Neubauern mußten ihren Platz für Altbauern räumen, die auch dann nur 35 Personen oder rund $17 \%$ stellten, gegenüber 133 oder rund $66 \%$ Neubauern. Diese Altbauern wurden ganz offensichtlich anstelle von Neubauern mit Spitzenämtern in den Kreisverbänden betraut.

Nur für 168 Personen liegen Angaben zur Größe des Grundbesitzes vor ${ }^{191}$. Diese Aufstellung zeigt zum einen ein erhebliches Übergewicht der Kleinbauern und unteren Mittelbauern bis 15 ha. Die Gruppe der Bauern bis 14 ha umfaßte vier Fünftel (81\%). Gering vertreten war die Gruppe der wirtschaftlich stärkeren Mittelbauern von 15 bis 19 ha. Ihr Anteil von 7\% wird sogar knapp übertroffen von den später als großbäuerlich klassifizierten Wirtschaftsbetrieben. Nimmt man die Gruppe der über 20 ha großen Betriebe zusammen, so stellten sie 7,7\%.

$\mathrm{Da}$ die Aufstellungen der Kreisvorstände 1948 keine Angaben zu einer Mitgliedschaft in der VdgB enthalten, sollen dazu Übersichten von drei Kreisvorständen von April/Mai 1949 herangezogen werden ${ }^{192}$. Vergleicht man diese Auflistun-

189 In beiden Großherzogtümern Mecklenburg-Schwerin und Mecklenburg-Strelitz galten bis 1918/1919 feudal-ständische Verfassungen. Da die Revolution die wirtschaftliche Vormachtstellung der Großagrarier unangetastet ließ, zog der politische Umbruch nicht unbedingt eine Anderung der überwiegend agrarisch geprägten Lebensverhältnisse nach sich. Vgl. Karge u.a., Geschichte; Fait, Mecklenburg, in: SBZ-Handbuch, S. 104-108; Bentzien/Neumann (Hg.), Volkskunde, S. $161 \mathrm{ff}$. (zu Landarbeitern), S. $131 \mathrm{ff}$. (zu Bauern).

190 Polzin, Kapp-Putsch, S. $37 \mathrm{ff}$; in beiden Mecklenburg standen die Bauernräte z.T. unter dem Einfluß des Großgrundbesitzes. Vgl. die Beteiligung von Gründungsmitgliedern der DBD an den revolutionären Vorgängen im Mecklenburgischen, etwa Goldenbaums Erinnerungsbericht, SAPMO SgY 30/1423 Ernst Goldenbaum.

191 Eine Personengruppe, die sowohl als Pächter und Altbauern zugleich klassifiziert wurde, berechnete man nicht mit ein. Bis 5 ha besaßen demnach 3 Personen $(1,8 \%)$, zwischen 5 ha und 9 ha 87 oder $51,8 \%$, zwischen 10 und 14 ha hatten 46 Personen oder $27,4 \%$, zwischen 15 ha und 19 ha 12 Personen oder 7,1\%, zwischen 20 und 29 ha kamen auf 7 Bauern oder $4,2 \%$ und mehr als 30 ha besaßen 8 Personen oder $4,8 \%$, so die Angaben in den Statistiken. Lt. telefonischer Auskunft Friedländers vom Januar und Februar 2000 sind die Angaben zu Hahn und Dietz fehlerhaft, beide besaßen nur unter 20 ha.

192 ACDP VI, unverz. Best. LV Mecklenburg, Akt Besetzung der Kreisvorstände 1949- (enthält auch Stand von 1948), Aufstellungen DBD-Kreisvorstände April/Mai 1949 der DBD. 
gen der Kreisvorstände von Ludwigslust, Parchim und Schwerin mit der Besetzungsliste von 1948, so sind folgende Unterschiede feststellbar: 1949 gehörten sämtliche Kreisvorstandsmitglieder der DBD zugleich dem VdgB-Kreisvorstand an. Der DBD-Kreisvorsitzende und sein Stellvertreter hatten auch eine leitende Aufgabe in der VdgB inne. Lediglich für den Kreis Schwerin enthalten diese zuletzt genannten Aufstellungen von 1949 über die Aufgliederung in Alt- und Neubauern hinausreichende Berufsangaben. Unter den 17 Mitgliedern befanden sich zehn Neubauern, nur zwei Altbauern, ein Landarbeiter, ein Maschinenschlosser, ein Student, sowie - auf den Leitungspositionen - zwei festangestellte Parteifunktionäre.

Doch kehren wir zurück zur ursprünglichen Besetzung der Kreisvorstände nach dem Stand vom Herbst 1948. Auf der Basis von $196^{193}$ Mitgliedern können Angaben zur früheren Parteizugehörigkeit und damit zu politischen Bindungen und Prägungen gemacht werden. Über die Hälfte der Kreisvorstandsmitglieder (111 oder 56,6\%) war vor 1948 parteilos, knapp 43\% (84) hatten zuvor der SED angehört, nur zwei Personen der CDU und niemand der LDP. Vor 1933 gehörte ein Fünftel der Kreisvorstände (39) der KPD an, 15 der SPD (7,7\%), zwei der DDP und einer der NSDAP. Etwas weniger als ein Fünftel (37 Personen) war zugleich vor 1933 und nach 1945 Mitglied der KPD gewesen, 11 Personen (5\%) gehörten vor 1933 der SPD und nach 1945 der SED an. Die zwei ehemaligen DDPMitglieder besaßen deutlich über 30 ha Grundbesitz und stießen nach 1945 vermutlich zum eigenen Schutz zur SED. Einer von ihnen wurde 1948 aus dem Kreisvorstand entfernt. Die Häufung altgedienter KPD-Mitglieder versuchte man anscheinend zu vermindern, denn drei davon wurden aus dem Vorstand wieder gestrichen.

\section{Die politische Sozialisation von Führungskräften der Gründungszeit}

Beim Gründungsprozeß der Bauernpartei verfolgten die SED-Parteistellen und die SMA der Länder das Ziel, die Personalauswahl für DBD-Parteigremien um so sorgfältiger zu steuern, je mehr Entscheidungsbefugnisse das Gremium besaß und je höher es in der Parteihierarchie, angefangen von den Ortsgruppen bis hinauf zum Sekretariat des Parteivorstandes, angesiedelt war. Da die Gründung von oben nach unten vollzogen wurde, sind auch jene Personen zu berücksichtigen, die mit zeitlicher Verzögerung nach der Bildung der zentralen Parteigremien und der Landesverbände erst von Herbst bis Frühjahr 1948/49 als Parteigründer vor Ort auftraten.

Im folgenden wird ein Personenkreis untersucht, der sowohl am Gründungsvorgang 1948/1949 Anteil hatte als auch danach in wichtige Partei- und/oder Staatsämter einzog. Zwei Merkmale treffen a priori auf diese Führungskräfte zu: Sie hatten ihre politische Zuverlässigkeit im Sinne der SED und SMA durch eine Tätigkeit in den Genossenschaften, der VdgB, als Bürgermeister oder als haupt-

193 Ebd., Aufstellungen DBD-Kreisvorstände Herbst 1948. Nach dortiger Auflistung sind nur 194 nachweisbar. Waldemar Schulz, Gründungsgruppe in Wismar, und Otto Block gehörten ebenfalls vorher der SED an. 
amtliche Funktionäre der SED bereits vor 1948 bewiesen und brachten fast durchgängig ein besonderes Interesse für die Landwirtschaft und davon abgeleitet für eine Bauernpartei als Interessenvertretung der ländlichen Bevölkerung mit.

Die zentrale Ebene repräsentieren Ernst Goldenbaum, Paul Scholz, Leonhard Helmschrott und Felix Scheffler ${ }^{194}$. Bis auf Scheffler hatten alle über den Untersuchungszeitraum hinaus Schlüsselfunktionen inne. Für die Ebene der Landesverbände wurden profilierte Führungspersönlichkeiten ausgewählt ${ }^{195}$. Als Personen aus dem zweiten Glied boten sich Hans-Joachim Friedländer, Stefan Zagrodnik, Adolf Giese und Else und Helmut Merke an. Diese fünf gründeten Ortsgruppen und/oder organisierten die Partei in den Kreisen.

Ernst Goldenbaum wurde 1898 als sechstes von acht Kindern einer Parchimer Arbeiterfamilie in bescheidenen Verhältnissen geboren. Sein Elternhaus war offenbar nicht einschlägig parteipolitisch vorgeprägt. Goldenbaum verfügte über eine gewisse religiöse Erziehung, verdiente er sich doch erste Groschen als Kurrendaner im höchstwahrscheinlich evangelischen Kirchenchor. Nach dem Besuch einer siebenklassigen Elementarschule verdingte er sich ab 1913 erst als Kuhhirte, dann als Knecht in der Landwirtschaft, eine für die Region typische Lohnarbeit. Erlebnisse während des Ersten Weltkrieges interpretierte er später als politisch prägend. Der Tod seines Bruders Willi, zu dem er ein vertrautes Verhältnis hatte, führte ihm nach eigenen Aussagen die gesellschaftlichen Gegensätze vor Augen, denn zur gleichen Zeit lebten die zwar in Uniformen gekleideten Gutsbesitzer vom Krieg ungefährdet auf ihren Gütern ${ }^{196}$. Als vermutlich erst 18jähriger versuchte er sich durch Flucht einer Einberufung an die Front zu entziehen. Man faßte ihn, und er landete im Gefängnis, wo er erste Kontakte mit politisch "Gleichgesinnten" knüpfte. Das Kriegsgeschehen erlebte er nur drei Tage lang an der Westfront. Verwundet kehrte er in ein Schweriner Lazarett zurück, wo es unter den Soldaten seiner Kompanie bereits gärte.

Goldenbaum ging im Frühjahr 1919 nach Parchim zurück. Dort war er als Wachmann im Zivildienst eines Kriegsgefangenenlagers für Russen eingesetzt. Er

194 Weggelassen wurden Griebel und Adam, die in den folgenden Jahren keine Führungsfunktionen einnahmen.

195 Die Landesvorsitzenden Rudolf Albrecht (Brandenburg), Ernst-Walter Beer (Mecklenburg 1949), Hermann Gräfe (Sachsen-Anhalt), Herbert Hoffmann (Thüringen), Friedrich Martin (Sachsen), Richard Richter (Sachsen-Anhalt), Arthur Pech (Brandenburg 1951/52), Fritz Petersohn (Sachsen 1951/52), Franz Pilarski (Mecklenburg) und Albert Rödiger (Thüringen 1951/52), sowie Fritz Weißhaupt (Mitbegründer in Sachsen, dort politischer Geschäftsführer 1950 und Minister für Land- und Forstwirtschaft 1950-1952), Dietrich Besler (Mitbegründer in Brandenburg und 1951/1952 Minister für Landwirtschaft in Brandenburg). Mangels Datenmaterial konnten nicht minder interessante Gründungspersönlichkeiten nicht einbezogen werden; so etwa Katharina Walter, die einzige Frau, die aktiv an der Gründung beteiligt war und nicht nur kooptiert wurde, und Paul Reder, Gründungsfigur mit SED-Vergangenheit aus dem Kreis Wismar, der 1950 aus der DBD ausgeschlossen wurde. Vgl. ACDP VI, unverz. Aufstellung von Mitgliedern des auf der Konferenz vom 16./17. 7. 1948 gewählten Parteivorstandes und besonders aktiver Mitbegründer in den Landesverbänden: Josef Czymoniak, Herbert Hoffmann, Richard Köhler, Helmut Merke, Ilse Neumann, Arthur Pech, Fritz Petersohn, Ursula Sawall, Walter Thiem, Fritz Weißhaupt.

196 SAPMO SgY 30/1423 Ernst Goldenbaum. 
beteiligte sich an der Gründung einer Ortsgruppe der USPD in Parchim ${ }^{197}$, deren politischer Kopf Hans Kollwitz ${ }^{198}$ war. In den zwanziger Jahren arbeitete er nicht mehr in der Landwirtschaft, sondern in verschiedenen handwerklich-gewerblichen Anstellungen. Dieser Weg war nicht untypisch für ein USPD-Mitglied, dominierte doch die MSPD den Deutschen Landarbeiterverband. So war Goldenbaum auch nicht in die Auseinandersetzungen zwischen dem Pommerschen Landbund und den freigewerkschaftlichen Landarbeitern in Ostelbien 1919 verwickelt ${ }^{199}$. Der Pommersche Landbund stützte sich auf die gleichen konservativen Kräfte, die ein Jahr später auch den Kapp-Lüttwitz-Putsch in Ostelbien unterstützten. Goldenbaum wandte sich ab 1919 gewerkschaftlicher Arbeit zu. Er trat dem Fabrikarbeiterverband bei, wurde 1920 in dessen örtlichen Vorstand gewählt und war Delegierter des Gewerkschaftskartells. 1922 wählte man ihn zum Vorsitzenden des Ortsausschusses des ADGB und des Fabrikarbeiterverban$\operatorname{des}^{200}$.

Nach dem Kapp-Lüttwitz-Putsch vom 13. März 1920 kam es auch in Parchim zum Generalstreik. Die Landesregierung von Mecklenburg-Strelitz hatte als erste die Putschisten anerkannt, die Regierung Mecklenburg-Schwerins war überrumpelt worden und verhielt sich passiv ${ }^{201}$. Am Streik in Parchim beteiligten sich SPD und USPD, trotz des gespannten Verhältnisses zwischen den beiden konkurrierenden Parteien. Dieses entzündete sich etwa daran, daß der frühere bürgerliche Bürgermeister auch nach $1918 \mathrm{im}$ Amt verblieben war, obwohl die SPD über die absolute Stimmenmehrheit verfügte 202 . Nach der Verhaftung von Kollwitz führte Goldenbaum die USPD-Streikleitung, daneben agierte ein gleichberechtigter SPD-Vertreter. Ausschlaggebend für diese Haltung dürfte sein Engagement in den örtlichen Gremien des ADGB gewesen sein, hatte doch die Gewerkschaftszentrale in Berlin die Führung in der Abwehr der Putschisten übernommen ${ }^{203}$.

Erst nach diesen Ereignissen muß es zum Wechsel der USPD-Mitglieder Parchims in die KPD, damit auch Goldenbaums Eintritt, gekommen sein. Goldenbaum war sicher nicht vor Oktober 1920204 KPD-Mitglied, aber spätestens ab

197 Hier wirkten zumindest die Genossen Fleischmann aus Westfalen und Goldenbaums Bruder Karl mit.

198 Zur Biographie von Hans Kollwitz (1893-1948): Für die Arbeiter- und Bauernmacht, S. 112.

199 Vgl. dazu Kölling, Familienwirtschaft; Winkler, Revolution, S. 249, 296f.; Kohler, Pomerania, S. 363 passim.

200 Der Hauptvorstand des Fabrikarbeiterverbandes in Hannover bestätigte diese Wahl jedoch nicht. SAPMO SgY 30/1423 Ernst Goldenbaum. Für die Arbeiter- und Bauernmacht, S. 114.

201 Ausführlich dazu Polzin, Kapp-Putsch.

202 SAPMO SgY 30/1423 Ernst Goldenbaum.

203 Winkler, Revolution, S. 305.

$204 \mathrm{Zu}$ diesem Punkt liegen unterschiedliche biographische Angaben vor. Goldenbaum erwähnt rückblickend in seinem Erinnerungsbericht von 1978 als Ergebnis des Streiks für die USPD die Gründung der USPD-Tageszeitung „Die Volkswacht“, was nahelegt, daß er zu diesem Zeitpunkt noch USPD-Mitglied war. Laut SBZ-Handbuch, S. 912, und den Angaben in Buch, Namen (1973), S. 90, trat Goldenbaum 1919 der KPD bei, laut Herbst u.a., DDR, Bd. 3, S. 108, erst 1920. Nach Für die Arbeiter- und Bauernmacht, S. 114, 
Januar 1921. Dann gehörte er der erweiterten, ab 1923 der engeren Bezirksleitung der KPD an ${ }^{205}$. Hatte er 1921 noch sein Mandat in der Parchimer Stadtverordnetenversammlung einem kommunistischen Genossen überlassen, so wurde er nach einer Neuwahl von 1923 bis 1925 stellvertretender Stadtvorsteher ${ }^{206}$. Von 1924 bis 1926 und von 1929 bis 1932 gehörte er dem Landtag von Mecklenburg-Schwerin an. Beruflich war er von 1927 bis 1932 als verantwortlicher Redakteur der Zeitung „Volkswacht“ tätig, dem Organ der Bezirksleitung der KPD. Goldenbaum wirkte außerdem als Lehrgangsleiter an der Bezirksparteischule 207 . Wenngleich er früh über Kontakte zu Spitzenfunktionären der KPD Mecklenburgs verfügte, darunter Hans Kollwitz, Hans Warnke und Willi Schultz, zählte er doch nicht zur engeren Führungsriege der KPD Mecklenburg-Schwerins. Diese Position im zweiten Glied begünstigte nach 1945 eine Führungsrolle in der Bauernpartei. Trotz dieser Details bleibt seine Haltung zur innerparteilichen Radikalisierung der KPD in den zwanziger Jahren unklar. Es gibt zumindest Indizien dafür, daß er eher einer so titulierten "rechten Opposition" zuneigte, die gegen den strikten Stalinisierungskurs ab 1925 Vorbehalte hegte 208 .

Goldenbaum wurde in den zwanziger Jahren mehrmals verhaftet, vor der nationalsozialistischen Machtergreifung zuletzt 1932. Ab 1935 zog sich Goldenbaum als Landwirt nach Parchim zurück. Im August 1944 wurde er in Zusammenhang mit der Gestapo-Aktion "Gewitter" nach der Zerschlagung der Widerstandsgruppen des 20. Juli erneut inhaftiert und mit anderen KPD-Funktionären Mecklenburgs in das KZ Neuengamme eingeliefert ${ }^{209}$. Goldenbaum überlebte als einziges Mitglied der KPD-Gruppe Mecklenburg-Schwerin den Todesmarsch der Häftlinge und das Bombardement mit folgender Versenkung des Schiffs „Cap Arkona" in der Lübecker Bucht ${ }^{210}$.

nahm Goldenbaum noch im Oktober 1920 am Landesparteitag der USPD teil und fungierte ab 1921 als Mitglied der KPD-Bezirksleitung.

205 Arbeiter- und Bauernmacht, S. 114.

206 SAPMO SgY 30/1423 Ernst Goldenbaum.

207 Arbeiter- und Bauernmacht, S. $114 \mathrm{f}$.

208 Vgl. dazu allgemein: Winkler, Schein, S. 417-448. Weber, Wandlung des deutschen Kommunismus, S. $104 \mathrm{ff}$., $137 \mathrm{ff}$. Zu Goldenbaum die Informationen von IM „Bernd“ (Helmschrott) im Treffbericht vom 19.1. 1958, BStU MfS AP 661/92, Ernst Goldenbaum, Bl. 42f., Treffbericht, 19. 1. 1958, die allerdings fehlerhaft und daher mit Vorsicht zu genießen sind: Demnach sei Goldenbaum 1933 Chefredakteur der „Roten Fahne“ Mecklenburgs gewesen, von dieser Funktion aber im Zusammenhang mit der Entlarvung der "parteifeindlichen Gruppe Fischer, Dahlheim, Maßlo“ [sic] durch das ZK abgesetzt worden. Tatsächlich war Goldenbaum bis 1932 Chefredakteur des KPD-Organs „Volkswacht" in Mecklenburg-Schwerin und schied dann aus. Einige Daten seines biographischen Werdegangs decken sich mit Zäsuren in den KPD-Richtungsstreitigkeiten. Die Stimmenthaltung der KPD-Landtagsfraktion in Mecklenburg-Schwerin, die zu einer sozialdemokratischen Minderheitsregierung führte, war auf dem Essener PT der KPD im März 1927 scharf kritisiert worden. Thälmann forderte damals einen harten Kampf gegen die Sozialdemokratie (Winkler, Schein, S. 436).

209 Für die Arbeiter- und Bauernmacht, S. 115.

210 Ebd.; SAPMO SgY 30/1423 Ernst Goldenbaum. Goldenbaum gedenkt darin Walter Block aus Malchin, der ihm den lebensrettenden Posten in der Effektenkammer des Schiffes verschafft hatte. Vermutlich ein Verwandter Blocks baute später die DBD im Kreis Malchin auf. ACDP VI, unverz. Best. LV Mecklenburg, Aufstellungen und Über- 
Nach seiner Rückkehr wurde er von der sowjetischen Stadtkommandantur umgehend als Bürgermeister in Parchim eingesetzt. Im Herbst 1945 wechselte er auf den Posten des Geschäftsführers der Landeskommission für Bodenreform, die Hans Warnke leitete ${ }^{211}$. Bis 1949 war Goldenbaum leitend in den Abteilungen Landwirtschaft des entsprechenden mecklenburgischen Ministeriums tätig212. Während dieser Zeit arbeitete er eng mit Warnke zusammen.

Paul Scholz, obwohl in seinem politischen Einfluß nicht weniger bedeutend als Goldenbaum, brachte es nie zum Parteivorsitz. Er vertrat die DBD jedoch in staatlichen wichtigen Ämtern. Innerhalb des engeren Führungszirkels der DBD in den fünfziger Jahren umgab Scholz nie der Nimbus des „autonom“ agierenden Parteigründers ${ }^{213}$; vielmehr war im kleineren Kreis bekannt, daß er erst auf der 1. Parteikonferenz im Juli 1948 zur Gründergruppe gestoßen war. Auf Veranlassung der SED wurde er als Hauptgeschäftsführer präsentiert. Er brachte einige dafür hilfreiche biographische Voraussetzungen mit und genoß - im Unterschied zu Goldenbaum - 1948 das Vertrauen der SED-Führungsriege um Grotewohl, Pieck und Ulbricht.

Scholz wurde am 2. Oktober 1902 als Sohn eines Kleinbauern in Braunau im schlesischen Kreis Löwen geboren ${ }^{214}$. Von Kind an war er mit der Not der Kleinbauern seiner Heimat vertraut. Er besuchte die Volksschule und später die Landwirtschaftsschule in Cottbus. Obwohl gelernter Landwirt, war er nie selbständig tätig, wie er in seinem Lebenslauf unterstrich, sondern als Land- und Fabrikarbeiter beschäftigt. Mit 21 Jahren trat er 1923 in die KPD ein, daneben war er im Landarbeiter- und Fabrikarbeiterverband organisiert. 1932 ging er nach Berlin, ab 1933 war er illegaler Gebietsberater der KPD. Zuvor schon mehrfach inhaftiert, wurde er 1935 in einem Prozeß vor dem Volksgerichtshof wegen Vorbereitung zum Hochverrat zu vier Jahren Zuchthaus verurteilt ${ }^{215}$. Zeitweise saß er im selben Gefängnis wie Ernst Thälmann ein ${ }^{216}$. Während des Krieges mußte Scholz im Strafbataillon 999 Dienst leisten 217.

1945 trat er erneut der KPD bei. Er war bei verschiedenen Zeitungen als Redakteur tätig, darunter auch beim KPD-Vorläufer des „Neuen Deutschland“, der

sichten von 1948, demnach war ein Otto Block Kreisvorsitzender in Malchin und vor 1933 in der KPD organisiert gewesen. Otto Block gehörte 1951 auch der Volkskammer an; MLHA BPA Schwerin IV/L/2/13/624, Bl. 27, Aktenvermerk.

211 Zu Hans bzw. Johannes Warnke vgl. van Melis, Entnazifizierung, passim.

212 So leitete er unter dem Minister für Landwirtschaft Otto Möller (parteilos/CDU) bis spätestens Oktober 1948 die Abt. Landwirtschaft, nach einer Namensänderung die Abt. I Landwirtschaft sowie die Abt. Bodenreform im gleichen Ministerium. Ab 1.8. 1949 leitete er erneut eine Abt., die Abt. II Agrar- und Bauernpolitik. Fait, Mecklenburg, in: SBZ-Handbuch, S. 122.

213 Vgl. dazu ACDP VI, unverz. Handakten Rose, Protokoll Sekretariat, 29. 11. 1950.

214 Biographische Daten nach Herbst u.a., DDR, Bd. 3, S. 306; Buch, Namen (1979), S. 286; SBZ-Handbuch, S. 1021; Barth u. a. (Hg.), DDR, S. 1769. Darüber hinausreichende Angaben nach BStU MfS AP 4387/92.

215 Dies nach den eigenen Angaben von Scholz und nicht nach den davon abweichenden Angaben in den genannten Nachschlagewerken.

216 Vgl. dazu den Erinnerungsbericht von Scholz in SAPMO SgY 1/2165.

217 Vgl. hierzu allg. Klausch, 999er; aus DDR-Sicht: Burkhardt u.a., Schein. 
„Deutschen Volkszeitung“218. 1947 wirkte Scholz als verantwortlicher Redakteur der Berliner Ausgabe des „Neuen Deutschland“, ab Dezember des Jahres in der Chefredaktion des VdgB-Blattes „Der Freie Bauer"219. Als in der SED Anfang 1948 die Suche nach geeignetem Personal für die Parteineugründungen begann, empfahl der damalige Leiter der Kaderabteilung des Parteivorstandes, Philipp Daub, gegenüber Pieck Paul Scholz als Geschäftsführer der Bauernpartei220. Unmittelbar nach der 1. Parteikonferenz der DBD am 16./17. Juli 1948 verfügte das Zentralsekretariat der SED dann Scholz' Ausscheiden als stellvertretender Chefredakteur bei der Zeitung „Der freie Bauer“221.

Zeitgleich mit Scholz stieß auf der 1. Parteikonferenz auch Leonhard Helmschrott zur DBD. Er wurde von der SED als Chefredakteur des „Bauern-Echo“ eingesetzt. Scholz und Helmschrott waren seit ihrer gemeinsamen Tätigkeit bei der „Deutschen Volkszeitung“, wo auch Helmschrott von 1945 bis 1946 als Redakteur beschäftigt war, miteinander bekannt ${ }^{222}$. Anschließend arbeitete er beim SED-Organ für Mecklenburg, der "Landeszeitung“ in Schwerin ${ }^{223}$. Er war dort Sekretär der Betriebsparteiorganisation und gehörte ab 1947 der SED-Kreisleitung Rostock an ${ }^{224}$. Unmittelbar bevor er von der SED für eine Funktion in der DBD abgestellt wurde, entließ man ihn per Beschluß des Zentralsekretariats vorzeitig aus einem Zweijahreslehrgang der Parteihochschule „Karl Marx“, den er 1947 begonnen hatte 225 . Auch Helmschrott zählt nicht zu den Mitbegründern der DBD von April bis Juni 1948, sondern wurde von der SED als Führungskader der Zentralebene Ende Juli in die DBD delegiert. Was prädestinierte Helmschrott für eine Karriere in der DBD? Schließlich war er dann von 1948 bis 1986 nicht nur Chefredakteur der DBD-Parteizeitung „Bauern-Echo“, und damit der dienstälteste Chefredakteur einer deutschen Wochenzeitung ${ }^{226}$, sondern er gehörte im Untersuchungszeitraum stets zum engen Führungszirkel der Partei und genoß über weite Strecken das besondere Vertrauen Goldenbaums ${ }^{227}$.

218 SAPMO NY 4182/901, Bl. 1, Schreiben Sepp Schwabs an die Mitglieder des Sekretariats im Hause, 9. 3. 1946.

219 Siehe die entsprechenden Beschlüsse des ZS der SED in: SAPMO DY 30 IV 2/2.1/137, Protokoll ZS, 6. 10. 1947, Bl. 1; SAPMO DY 30 IV 2/2.1/158, Protokoll ZS, 18. 12. 1947, Bl. 5. Fehlerhaft Angaben in Herbst u. a., DDR, Bd. 3, S. 306.

220 SAPMO NY 4036/724, Bl. 13, Pieck an Bichowski, 8. 7. 1948.

221 SAPMO DY 30 IV 2/2.1/217, Protokoll ZS, 19. 7. 1948, Bl. 4.

$222 \mathrm{Vgl}$. die Angaben in: BStU MfS AIM 357/88, Bd. I/1, Helmschrott, Bl. 14ff. Vorschlag zur Anwerbung, 10.10. 1950, mit Angaben zum Lebenslauf; ebd., Bl. 22ff., Abschrift Personal-Fragebogen, 19. 7. 1948, Bl. $30 \mathrm{ff}$., Lebenslauf, 9. 10. 1950.

223 Auch hier ergeben sich wieder Ungenauigkeiten, lt. einer Kurzbiographie, BStU MfS AIM 357/88, Bd. I/1, Helmschrott, Bl. 14ff., Vorschlag zur Anwerbung, 10. 10. 1950, hielt er sich bis 1947 in Rostock auf, auch ab 1947 sei er Student der Parteihochschule "Karl Marx“ gewesen.

224 BStU MfS AP 75835/92, Helmschrott, Bl. 1, Kurzbiographie 14. 11. 1984.

225 SAPMO DY 30 IV 2/2.1/217, Protokoll ZS, 19. 7. 1948, Bl. 4.

226 Barth u.a. (Hg.), DDR, S. 804.

227 Der Chefredakteur des „Bauern-Echo“ gehörte zwar in dieser Funktion nicht immer automatisch, aber die meiste Zeit dem Sekretariat an und war seit der Anfangszeit eng mit den inneren Partei-Angelegenheiten vertraut. 
Wie fast alle Funktionäre der ersten Generation war auch Helmschrott bäuerlicher Herkunft. Seine Eltern bewirtschafteten einen kleineren Hof im schwäbischen Untertürkheim. Dort wurde er 1921 geboren und wuchs mit mehreren Geschwistern auf228. Er besuchte ab 1927 die siebenklassige Volksschule und die sogenannte "Sonntagsschule“, was auf eine übliche religiöse Erziehung in der Kindheit hindeutet. Ab seinem 14. Lebensjahr bis zur Einberufung zur Wehrmacht 1941 half er seinen Eltern auf dem Hof. Vermutlich hatte er keine Chance, den Hof zu erben, weil das in der Gegend übliche und von den Nationalsozialisten propagierte Anerbenrecht dazu keine Möglichkeit ließ229. Seine Eltern waren politisch nicht aktiv gewesen. Ohne die Kriegserfahrung hätte er sich wohl nie dem Kommunismus zugewandt. Nach einem Jahr Kriegsdienst geriet er 1942 in sowjetische Kriegsgefangenschaft. 1943 durchlief er an der Antifaschistischen Zentralschule in Krasnogorsk eine politische Schulung, im gleichen Jahr wurde er Gründungsmitglied des Nationalkomitees „Freies Deutschland“ und Frontagitator. 1945 kehrte er nach Rostock zurück und trat in Berlin der KPD bei230.

Auch Felix Scheffler wurde weder durch sein bürgerliches Elternhaus noch durch spezifische Jugenderlebnisse sozialistisch beeinfluß $\mathrm{t}^{231}$. Scheffler kam am 10. Februar 1915 in Hamburg als Sohn eines leitenden Angestellten zur Welt. Nach der Mittelschule begann er eine Lehre als Drogist. Dem schloß sich eine Ausbildung zum Matrosen der Handelsmarine und Steward auf der „HamburgSüd-Linie“ an. Scheffler wurde vom RAD verpflichtet und leistete ab 1937 Wehrdienst. 1941 geriet er als Unteroffizier in sowjetische Gefangenschaft. Wie Helmschrott gehörte er nach Aufenthalten in Antifa-Lagern zu den Teilnehmern der Gründungsversammlung des NKFD und besuchte ebenfalls die Antifa-Schule in Krasnogorsk. 1944 schloß er sich mit der Gruppe 117 des NKFD sowjetischen

228 BStU MfS AP 75835/92, Helmschrott, Bl. 1, Kurzbiographie 14. 11. 1984, demnach hatte er zu diesem Zeitpunkt noch drei Geschwister in der Bundesrepublik.

$229 \mathrm{Da}$ er sich selbst als mithelfenden Angehörigen bezeichnet, nicht als Bauer und nicht ukgestellt wurde, ist mit hoher Wahrscheinlichkeit anzunehmen, daß er nicht der älteste, also erbberechtigte Sohn war.

230 BStU MfS AIM 357/88, Bd. I/1, Helmschrott, Bl. 30f., Lebenslauf 9. 10. 1950; Barth u.a. (Hg.), DDR, S. 804; Morré, Kulissen, S. 54, 83, 163, 174, 214.

231 Herbst u.a., DDR, Bd. 3, S. 292, Barth u.a. (Hg.), DDR, S. 1704. Reichelt, Blockflöte, S. 33. Der Funktionär der DBD Felix Scheffler, der von Oktober 1948 bis ins Jahr 1950 die Abt. Organisation leitete, ist identisch mit jenem Felix Scheffler, der 1950 Volkspolizei-Inspekteur in der Hauptverwaltung für Ausbildung der Seepolizei wurde, es dort bis zum Chefinspekteur und 1956/57 zum Chef der Seestreitkräfte der NVA brachte. Folgende Indizien belegen diese Identität, die aus allen gängigen biographischen Nachschlagewerken nicht hervorgeht: Eine Geburtstagsliste des Parteivorstandes der DBD um 1949 nennt als Geburtsdatum von Felix Scheffler den 9. 2. 1915, der verdächtig nahe am genannten 10.2. ist. Außerdem notierte man im mecklenburgischen Landesverband der SED auf Personalgesuche Schefflers die Bemerkung „Partisan“, MLHA BPA Schwerin IV/L/2/13/624, Schreiben Schefflers an Bürger. Aus Gesprächen von Sekretariatsmitgliedern am 29. 11. 1950 geht zweifelsfrei hervor, daß nicht mehr Scheffler die Abt. Organisation leitete sondern Reichelt. Ulbricht schlug Scheffler der SKK als 2. Stellvertreter des Leiters der Hauptverwaltung für Küstenschutz für das Amt des Polit-Kulturleiters vor; SAPMO NY 4182/1195, Bl. 42, Ulbricht an den Vorsitzenden der SKK Tschujkow, 26. 5. 1950. 
Partisanen an ${ }^{232}$. Nach 1945 leitete er ein Antifa-Aktiv in einem sowjetischen Kriegsgefangenenlager. Erst 1947 kehrte er in die SBZ zurück und trat umgehend der SED bei. Dann verlieren sich seine Spuren zunächst, gesichert ist, daß er als Sekretär den Leiter der Parteihochschule der SED unterstützte. Aus dieser Zeit dürfte er den Parteihochschüler Helmschrott näher kennen, mit dem er dann ab August 1948 beim Parteivorstand der DBD in Berlin arbeitete ${ }^{233}$.

Scheffler brachte weder eine persönliche Bindung zur Landwirtschaft noch besonderes Interesse daran mit. So konzentrierten sich seine Aufgaben als Organisationsleiter darauf, die personelle Entwicklung der DBD im Sinne der SED sicherzustellen. Es ist nicht verwunderlich, daß er 1948 die DBD in den industriellen Fragen politisch vertreten sollte ${ }^{234}$. Scheffler war die kommunistische Rückversicherung im Organisationsapparat der DBD. Diese Aufgabe hat er bis 1950 offenbar zur vollen Zufriedenheit Ulbrichts erfüllt; sonst hätte der ihn nicht für den ideologisch verantwortungsvollen Posten des Politkulturleiters vorgesehen. Aus der Sicht der SED war Schefflers Weggang aus der DBD zu diesem Zeitpunkt vertretbar, weil inzwischen andere als politisch verläßlich eingeschätzte Kader für die DBD bereitstanden. So warben Scheffler und Scholz vereint noch Hans Reichelt als Schefflers Nachfolger an ${ }^{235}$.

Die Kader, die in die Berliner Zentrale der DBD ab Juli 1948 eingebaut wurden, hatten mit Ausnahme Goldenbaums kaum etwas mit dem Gründungsprozeß in den Ländern zu tun. Da verschiedentlich zu beobachten ist, daß sich zwischen Zentrale und einzelnen Landesverbänden Reibungen ergaben oder die politischen Geschäfte nicht genügend abgestimmt waren, lohnt es sich, der Frage nachzugehen, welche biographischen Merkmale und politischen Erfahrungswelten diese Länderfunktionäre prägten. Mit Ausnahme von Franz Pilarski - den man weglobte - wagte oder schaffte keiner davon den Sprung auf einen Funktionärsposten in Berlin. Bis 1952 räumten drei von fünf Landesvorsitzenden aus eigenem Entschluß oder zwangsweise den leitenden Stuhl in der DBD.

Die Landesvorsitzenden von 1948 waren Friedrich Martin (Sachsen), Richard Richter (Sachsen-Anhalt), Herbert Hoffmann (Thüringen), Rudolf Albrecht (Brandenburg) und Franz Pilarski, der unmittelbar auf Goldenbaum in Mecklenburg folgte. Alle waren 1948 Mitglieder, vereinzelt auch nachrangige Funktionäre der SED gewesen, und alle gehörten der VdgB an, wirkten dort teils in leitender Position. Nur Richard Richter war vor 1945 weder in der Arbeiterbewegung organisiert gewesen noch hatte er sich dafür einschlägige Beschäftigungen gewählt. Auch mit dem nationalsozialistischen Regime war er nicht in Konflikt geraten. Er

232 BStU MfS AKK 17257/85 B, Felix Scheffler. Reichelt, Blockflöte, S. 33, nennt ihn "Kundschafter" der Roten Armee.

233 ACDP VI-052-0141, Protokoll PV, 26. 8. 1948, Scholz stellte Scheffler als Leiter der Abt. Organisation vor.

$234 \mathrm{Vgl}$. SAPMO NY 4182/964, Materialien zu Sitzungen des Deutschen Volksrates im Sommer 1948, Bl. $219 \mathrm{f}$.

235 ACDP VI, unverz. Handakten Rose, Protokoll Sekretariat, 29. 11. 1950. Reichelt berichtete darin, daß Scheffler allein seine Bedenken gegen die Bauernpartei nicht hatte ausräumen können. Erst im Gespräch mit Scholz, dem er sich als VVN-Genossen verbunden fühlte, habe er sich für die DBD entschlossen. 
hatte 1945 im Zuge der Bodenreform eine Neubauernstelle erhalten und trat im gleichen Jahr der SPD bei. Erst seit dieser Zeit, die den einst reisefreudigen Varieté- und Zirkusbegeisterten zum Landeigentümer machte, engagierte er sich in gesellschaftlich-politischen Bereichen wie etwa in der Jugendarbeit und in der $\mathrm{VdgB}^{236}$. Somit gehörte Richter zu denjenigen, die erst in fortgeschrittenem Alter nach dem Krieg politisiert wurden.

Bis auf Herbert Hoffmann hatten alle anderen Landesvorsitzenden die meist achtklassige Volksschule absolviert ${ }^{237}$. Hoffmann hatte in seiner Heimatstadt Görlitz die Oberrealschule besucht ${ }^{238}$, danach eine Schriftsetzerlehre angetreten; er gehört zum verschwindend geringen Teil derjenigen Gründungsfunktionäre, die über eine höhere Schulbildung verfügten; erst später stieg der Bildungsgrad der DBD-Funktionäre durch die Rekrutierung von Antifa-Schülern und die Heranbildung einer jüngeren Funktionärsgeneration. In der Anfangszeit haftete den Oberschülern, vermutlich zu Recht, der Geruch des „Bürgerlichen“ an; für „bürgerliche Agrarfunktionäre “, die oft im weitgefächerten Apparat des nationalsozialistischen Reichsnährstandes beschäftigt gewesen waren, sollten die Leitungsebenen einer Partei, die vornehmlich auf Klein- und Mittelbauern zielte, verschlossen bleiben. Höchstwahrscheinlich kamen alle fünf Landesvorsitzenden, sicher vier von ihnen, aus Arbeiter- oder Landarbeiterfamilien ${ }^{239}$. Bei der Auswahl dieser Personen wurde streng auf das Kriterium der „adäquaten“ sozialen Herkunft geachtet. Fast alle standen schon vor 1933 in Kontakt mit der Arbeiterbewegung,

236 Auffälligerweise verschwieg Richter in einem handgeschriebenen Lebenslauf von 1952 seine Vergangenheit beim Zirkus; stattdessen nennt er politisch offenbar höher eingeschätzte Beschäftigungen, wie Tätigkeiten als Landarbeiter bei „Großbauern“ und Beschäftigungen in Industriebetrieben. BStU ASt Nbg. AIM 769, Personalakte, Bl. 10, undatierter Lebenslauf [März 1952]. Vgl. hingegen die Beurteilung in ebd., Arbeitsvorgang II, Bl. 72 [vor 1952] sowie Auszug aus Lebenslauf Richard Richter, Bl. 75. Danach gründete er in mehreren Orten FDJ-Gruppen und wurde von der SED als Treuhänder für landwirtschaftliche Betriebe eingesetzt. Die Schilderung trägt Züge eines politischen Erweckungserlebnisses.

237 Zu Franz Pilarski vgl. BStU ASt Rst. AIM 1897/86, Bd. I/I, Bl. 34-37, Personalfragebogen und Bl. 42, 54, 78, sowie BStU MfS AIM 127/54, Personalakte Reichelt. Zu Pilarski: 1931 KPD, illegale Tätigkeit während der NS-Zeit, 1947/1948 Kreisvorstand der SED Greifswald, 1949 Landesvorsitzender der DBD.

238 Herbst u. a., DDR, Bd. 3, S. 146.

239 BStU ASt Nbg. AIM 769/56, Personalakte Richter, Bl. 10, Lebenslauf [undatiert, März 1952], sein Vater war Arbeiter; zu Pilarski: BStU ASt Rst. AIM 1897/86, Bd. I/I, Bl. 3437, Personalbogen 20. 10. 1955, Bl. 78, Lebenslauf 16. 9. 1955, er stammte aus einer Landarbeiterfamilie; BStU MfS AIM 513/52, Personalakte Hoffmann, Bl. $11 \mathrm{f}$., Lebenslauf und Charakteristik, 27. 10. 1950. Hoffmanns Vater war Bergmann und gehörte damit zu einer Arbeiterschicht, die bereits über ein besseres Einkommen verfügte. Bislang ungeklärt ist die genaue soziale Herkunft von Friedrich Martin und Rudolf Albrecht. Beide gehörten schon vor 1933 der KPD an. Zu Albrecht: Herbst u. a., DDR, Bd. 3, S. 18, SBZ-Handbuch, S. 859 und Wernet-Tietz, Bauernverband, S. 221; zu Martin: ACDP VI, unverz. Best., Karton Sachsen, VdgB, 1948-1952 Schriftverkehr und Sekretariat, 1948 bis Juli 1952, Charakteristiken, Martin war demnach 1945 im Landkreis Leipzig Vorstandsmitglied der Kreisbodenkommission; bevor er eine Neubauernstelle übernahm, war er Treuhänder des ehemaligen Rittergutes Biagosch in Merkwitz. Er gehörte seit $1945 \mathrm{dem} \mathrm{Be}-$ zirksvorstand der KPD, später dem Kreisvorstand der SED an. 
Martin und Albrecht gehörten früh der KPD an, Hoffmann war zumindest gewerkschaftlich engagiert. Albrecht geriet nach 1933 kurzzeitig in KZ-Haft ${ }^{240}$. Franz Pilarski war offenbar am intensivsten politisch tätig. Wegen seiner Tätigkeit als Organisationsleiter und Mitglied einer Unterbezirksleitung der KPD seit 1931 verbrachte er in den Jahren 1933 und 1934 einige Zeit im Konzentrationslager Lichtenberg. 1929 hatte er für neun Wochen die Sowjetunion besucht. Er war Mitglied des Landarbeiterverbandes, der Roten Hilfe und in der Revolutionären Gewerkschaftsopposition (RGO) ${ }^{241}$. Daher war es naheliegend, daß die SED diesen als politisch zuverlässig geltenden ehemaligen Arbeitsgebietsleiter des SEDKreisvorstandes Greifswald und Organisationssekretär des dortigen Kreisverbandes der VdgB als Nachfolger Goldenbaums im wichtigen Gründungszentrum Mecklenburg installierte. Um so enttäuschender war es, daß er die an ihn gestellten Erwartungen aus der Sicht der DBD nicht erfüllte. Er ist nicht der einzige für die DBD abgestellte SED-Funktionär, der die Arbeit für die DBD in erster Linie als Parteiauftrag der SED verstand - ein Umstand, der den Erfolg für die Sache der DBD empfindlich behinderte.

Alle fünf Landesvorsitzenden waren Neubauern. Bis auf Albrecht, der schon vor 1933 Landwirt und Siedler gewesen war, arbeiteten alle vor 1945 zunächst in handwerklichen oder gewerblichen Sparten, bis Arbeitslosigkeit im gelernten Beruf sie höchstwahrscheinlich mit Tätigkeiten in der Land- oder Waldwirtschaft in Berührung brachte. Richter hatte keinen Beruf erlernt, Hoffmann war als Schriftsetzer dauerhaft beschäftigt. Pilarski, an sich ausgebildeter Bauschlosser, war als reisender Vertreter im Außendienst verschiedener Firmen unterwegs gewesen; nach Arbeitslosigkeit verdingte er sich als Wald- oder Landarbeiter. Auch während seiner Kriegsgefangenschaft im englischen Lager Wilton Park arbeitete er in der Landwirtschaft. Für die Vorsitzenden und eine Reihe noch vorzustellender weiterer Funktionäre war der berufliche Fortgang bis 1945 oft von Unsicherheit, Arbeitslosigkeit, einem häufigen Wechsel der Tätigkeiten und Existenznot gekennzeichnet. Bei keinem konnten Anhaltspunkte für eine nationalsozialistische Vergangenheit ermittelt werden. Keiner von ihnen war Flüchtling oder Vertriebener ${ }^{242}$. Pilarski und Albrecht stammten zwar aus damals polnischen Orten ${ }^{243}$, hatten diese aber bereits vor 1933 verlassen. Pilarski sprach fließend polnisch, da er, vermutlich zeitweise von seinen Eltern getrennt, die seit 1912 in Vorpommern auf Wanderschaft waren, die Volksschule teilweise noch in Polen besucht hatte.

Instruktiv ist ein Blick auf den Verbleib der ersten Landesvorsitzenden, die in ihrem jeweiligen Landesverband eine enge Bindung zum Funktionärsapparat und

240 SBZ-Handbuch, S. 859.

241 Zu Pilarski: BStU ASt Rst. AIM 1897/86, Bd. I/I, Pilarski, Bl. 34-37, Personalbogen, 20. 10. 1955. Lt. Auskunft eines Informanten „Saba“ vom 14. 2. 1958 wurde Pilarski 1948 von der SED beauftragt, in die DBD einzutreten, ebd., Bl. 45.

242 Hoffmann wird lediglich an einer Stelle als "Umsiedler" geführt. Diese Einordnung geht m.E. auf seinen Geburtsort Görlitz zurück, nicht auf eine tatsächliche Flucht oder Vertreibung im Zuge des Zweiten Weltkrieges; ACDP VI-052-0017, Zusammensetzung des PV 1960.

243 Pilarski kam in Miedznow zur Welt, Albrecht vermutlich am Arbeitsort seines Vaters im oberschlesischen Königshütte, das seit 1922 zu Polen gehörte. 
zu den Mitgliedern erreichten. Friedrich Martin wurde 1951 als Landesvorsitzender abgelöst und floh etwa 1953 in die Bundesrepublik. Er und Richard Richter galten in der Zentrale als "politisch schwach“. Richter wurde aus persönlichen Gründen 1951 als Landesvorsitzender und Minister zurückgezogen. Danach arbeitete er in verschiedenen LPG und spitzelte bald für das MfS in den Dörfern ${ }^{244}$. Rudolf Albrecht war ebenfalls bis 1951 Landesvorsitzender und bekleidete daneben zahlreiche andere Ämter. Er geriet 1952 als Staatssekretär im Ministerium für Handel und Versorgung in den Strudel des Prozesses gegen Minister Hamann (LDPD), wurde zeitweise inhaftiert, dann doch nur gerügt und schließlich rehabilitiert. Mitte der fünfziger Jahre trat er aus der DBD aus und ging zurück in die SED. Auch Franz Pilarski gestattete man 1957 den Wiedereintritt in die SED, nachdem er schon 1949 von Ernst-Walter Beer als Landesvorsitzender abgelöst worden war und man ihn innerhalb der DBD degradierte, zuletzt zum Bibliothekar einer Schulungsstätte. Da er keine Perspektive für sich sah, bemühte er sich um die Rückkehr zur SED. Trotz schwerwiegender gesundheitlicher Probleme arbeitete er nach seinem Eintritt in die SED ab Juni 1958 als Geheimer Hauptinformator (GHI) im Rahmen seiner Tätigkeit als Sekretär der Gesellschaft für Deutsch-Sowjetische Freundschaft an der Universität Greifswald ${ }^{245}$. Nur Hoffmann blieb der DBD dauerhaft treu. Er wechselte vom Amt des Landesvorsitzenden Ende 1949 für die DBD ins Ministerium für Land- und Forstwirtschaft der DDR als Hauptabteilungsleiter und gehörte der Volkskammerfraktion an. Von 1963 bis 1970 leitete er als Vorsitzender den Bezirksverband Potsdam, bis 1977 gehörte er dem Parteivorstand an ${ }^{246}$.

Landesvorsitzende bzw. leitende Funktionäre der zweiten Parteigeneration waren Ernst-Walter Beer - er begründete im Auftrag der SED die DBD in SachsenAnhalt und folgte im Januar 1949 auf Franz Pilarski im mecklenburgischen Landesvorsitz -, Albert Rödiger - Mitbegründer der ersten Stunde im thüringischen Landkreis Sondershausen, Landesvorsitzender 1951/52 in Thüringen -, Fritz Weißhaupt - Gründer im sächsischen Ölsnitz und Minister für Land- und Forstwirtschaft in Sachsen 1950-1952 -, Dietrich Besler - Mitbegründer im brandenburgischen Luckenwalde, ebenfalls Minister für Landwirtschaft in Brandenburg und zeitweise politischer Geschäftsführer der DBD Brandenburg, sowie Hermann Gräfe - Nachfolger von Richter als Landesvorsitzender in Sachsen-Anhalt -, Arthur Pech - ab 1951 Landesvorsitzender in Brandenburg, danach Bezirksvorsitzender in Frankfurt/Oder und Fritz Petersohn - 1951 Landesvorsitzender in Sachsen und bis 1953 Bezirksvorsitzender in Dresden. Dieser Personenkreis unterscheidet sich von den fünf Landesvorsitzenden des Jahres 1948 in einigen auf-

244 BStU ASt Nbg. AIM 769/56, Personalakte, Bl. 10, Verpflichtungserklärung, 10. 3. 1952; bis 1956 lieferte er Berichte, dann brach das MfS die Verbindung ab und ging dazu über, ihn selbst zu „bearbeiten“, weil er manche Dinge verschwiegen hatte; ebd., Bl. 24, Beschluß über Abbruch, 2. 10. 1956; seine Berichte in BStU ASt Nbg. AIM 769/56, Arbeitsvorgang.

245 Vgl. BStU ASt Rst. AIM 1897/86, Bd. I/I, Pilarski, u.a. Verpflichtung für die Überlassung eines Zimmers als KW am 14. 3. 1958. Pilarski starb 1985, Bl. 185.

246 Widersprüchliche Angaben im SBZ-Handbuch, S. 933 f., Herbst u. a., DDR, Bd. 3, S. 146; Reichelt, Blockflöte, passim. 
fälligen Punkten. Man trifft hier auf aktive und passive Mitglieder nationalsozialistischer Parteien, dekorierte Weltkriegsteilnehmer und sogenannte Umsiedler. Einige weisen eine sozialdemokratische Vergangenheit auf, manche stießen erst nach 1945 zur KPD/SED.

Ernst-Walter Beer kam 1910 im tschechischen Thein zur Welt ${ }^{247}$. Seine Eltern waren Sudetendeutsche ${ }^{248}$. Seine Mutter starb früh, und da er mit seiner Stiefmutter nicht zurechtkam, wuchs er bei Verwandten auf. Er absolvierte nach der Mittelschule einige Semester an der Acker-, Obst- und Weinbauschule, was ihn nicht vor Arbeitslosigkeit bewahrte. Er leistete ab 1938 Wehrdienst und wurde im Zweiten Weltkrieg verwundet ${ }^{249}$. Bevor Beer 1945 der KPD beitrat, hatte er einen wechselvollen Gang durch Parteien verschiedenster Ausrichtung hinter sich: 1927 gehörte er wenige Monate den Sozialdemokraten an, wechselte 1928 dann zur KPTsch ${ }^{250} .1956$ räumte Beer auf massiven parteiinternen Druck ein, daß er während des Krieges der sudetendeutschen, zunehmend nazifizierten Henleinpartei zumindest als Kandidat angehört hatte ${ }^{251}$. Nach dem Krieg siedelte er nach $\mathrm{He}-$ dersleben über, wo er eine Neubauernstelle übernahm. Die DBD verdankte es insbesondere seinem Einsatz - und dies hielt ihm Goldenbaum zugute, als er 1956 in die Schußlinie geriet -, daß er den Landesverband Mecklenburg nach Pilarskis mäßiger Leistung stabilisierte und die DBD dort 1950 zur zweitstärksten Partei aufbaute ${ }^{252}$. Doch diese Verdienste konnten sein "mangelndes Vertrauen“ zur Partei, das im Verschleiern von Henleinpartei und Wehrmacht im Lebenslauf offenbar geworden war, nicht aufwiegen. Nach einem Parteiverfahren im Ritual von Kritik und Selbstkritik kam er einem Parteiausschluß durch Austritt zuvor ${ }^{253}$.

Albert Rödiger gehörte zu den wenigen der hier vorgestellten Funktionäre die 1948 noch an ihrem Geburtsort lebten und dort politisch engagiert waren. Er kam 1903 im thüringischen Seega als Waldarbeiterkind zur Welt. Ungelernt wie seine

247 Das Folgende nach BStU ASt Nbg. AIM 602/71, (Handakte) Beer, Bl. 12f., Personalfragebogen 25. 8. 1950 (Abschrift), Bl. 14-16, Lebenslauf 13. 9. 1950 (Abschrift von Abschrift); Bl. 65-74, Aussagen Beers vor DBD, im Gespräch mit Rietz und Hoffmann, 8. 8. 1956. Siehe auch Herbst u. a., DDR, Bd. 3, S. 30; SBZ-Handbuch, S. 866.

248 BStU ASt Nbg. AIM 602/71, (Handakte) Beer, Bl. 51 f., Charakteristik aus DBD Schwerin, 27. 12.1951.

249 Ebd., Personalakte, Bl. 12f., Personalfragebogen 25. 8. 1950 (Abschrift), Bl. 14-16, Lebenslauf 13.09. 1950 (Abschrift von Abschrift).

250 In den Augen von DBD-Kaderleiter Rietz machte ihn diese sozialdemokratische Episode verdächtig.

251 BStU ASt Nbg. AIM 602/71, (Handakte) Beer, Bl. 65-74, Aussagen Beers vor DBD, 8. 8. 1956. Für die DBD-Personalunterlagen hatte er fälschlich angegeben, während des Krieges in der Illegalität gelebt und Widerstandsgruppen bei der Flucht geholfen zu haben; ACDP VI, unverz. Best. LV Mecklenburg, Akt LV Mecklenburg: PPA, Verwaltungsreform und Reorganisation der Partei Juli/August 1952, Angaben zu seiner Person.

252 BStU ASt Nbg. AIM 602/71, (Handakte) Beer, Bl. 51 f., Charakteristik aus DBD Schwerin.

253 Ebd., Bl. 102-122, Protokollauszug aus PV-Sitzung am 15. 9. 1956. ACDP VI-052-0159, Protokoll PV, 14./15. 12. 1956. Offensichtlich wollte ihn die DBD vor Bloßstellung schützen, wie die unterschiedlichen Varianten in den MfS-Unterlagen - die von offentlichem Ausschluß sprechen - bzw. den DBD-Akten - die von freiwilligem Austritt berichten - belegen. 
Eltern verdiente er seinen Lebensunterhalt als Holzfäller, Steinträger und dann als Feuerwehrmann in Berlin 254. Rödiger verkörpert den Typus des lokal verwurzelten Angehörigen der ländlichen Unterschicht, der, mit einer antifaschistischen Vergangenheit den sozialen Aufstieg über eine dauerhafte politische Karriere voll$\operatorname{zog}^{255}$. Seine „Schwerfälligkeit“, wie ihm der Leiter der Organisationsabteilung Körber 1950 bescheinigte 256 , dürfte dazu beigetragen haben. Rödiger, der schon vor 1933 zur KPD gestoßen war, übernahm nach dem Kriegsdienst 1945 sofort Parteiaufgaben im Bereich Schulung und Werbung. Die Bodenreform machte ihn zum Neubauern. Er begründete die VdgB in Seega, wurde 1946 dort auch zeitweise Bürgermeister für die SED. Von seiner Partei dürfte er 1948 zur Teilnahme an der Gründung der DBD aufgefordert worden sein, die er dann im Kreistag vertrat $^{257}$. Er folgte 1950 auf Herbert Hoffmann als thüringischer Landesvorsitzender und blieb als Bezirksvorsitzender in Erfurt erstaunlich lange bis $1965 \mathrm{im} \mathrm{Amt}{ }^{258}$.

Dietrich Beslers Kindheit war von sozialer Not und Existenzgefährdung geprägt ${ }^{259}$. Er kam 1919 als Kind deutscher Eltern in Buchenhain, Kreis Obernick, im damals wieder polnischen Bezirk Posen zur Welt. Tief verschuldet verloren die Eltern ihren 45 ha großen Hof 1926 durch eine Zwangsversteigerung, die die Großfamilie in Verarmung stürzte. Beslers Vater versuchte in Danzig als Hafenarbeiter den Lebensunterhalt für Frau und zwölf Kinder zu verdienen. Eine Lehre als kaufmännischer Angestellter mußte Dietrich aus finanziellen Gründen abbrechen. Mit 18 Jahren wurde er vom RAD verpflichtet, danach zur Wehrmacht eingezogen. Kurz vor Kriegsende wurde der inzwischen zum Oberfeldwebel Aufgestiegene schwer verwundet und dekoriert entlassen. Bis dahin ohne politisches oder gewerkschaftliches Engagement, trat er 1945 der SPD bei und wurde auf nur 3,7 ha Neubauer in Brandenburg. Wie viele andere Parteigründer war er in der Lokalpolitik aktiv, wurde 1946 SED-Bürgermeister in Fröhden, Kreis Jüterbog. Als Kreissekretär der VdgB Luckenwalde gründete er dort 1948 im Auftrag der SED die Bauernpartei und stieß später zum Landesgründungsausschuß Brandenburg 260 . Zunächst Geschäftsführer des Landesverbandes in Brandenburg, über-

254 ACDP VI-052-212/2, Personalbogen der Kreistagskandidaten 1948-1950, Personalia Albert Gustav Rödiger, verfaßt von Erwin Körber. Lt. Herbst u. a., DDR, Bd. 3, S. 278, war er auch Land- und Bergarbeiter.

255 Von 1951-1973 gehörte Rödiger dem PV der DBD an, 1955-1957 dessen Präsidium. Nur zeitweise war er Mitglied des Sekretariats des PV. Von 1954 bis zu seinem Todesjahr 1973 hatte er ein Mandat im Bezirkstag Erfurt, dort zeitweise auch Stadtrat, 1954-1958 war er Vizepräsident der Länderkammer. Herbst u.a., DDR, Bd. 3, S. 278.

256 ACDP VI-052-212/2, Personalbogen der Kreistagskandidaten 1948-1950, Personalia Albert Gustav Rödiger, verfaßt von Erwin Körber.

257 SAPMO DY 30 IV 2/15/18, Bericht der BL Erfurt über Rödiger am 14. 1. 1955, wonach er zu den „ehrlichen, fortschrittlichen" Mitgliedern gehöre, der in jeder Position immer engen Kontakt mit der SED gehalten habe, für den aber doch eine Fortbildung auf der zentralen Parteischule empfohlen wird.

258 Herbst u. a., DDR, Bd. 3, S. 278.

259 Das Folgende nach BStU MfS AIM 3562/59, Bd. 2, Personalakte, Bl. 8, Werbungsvorschlag der HA V, Abt. 3 vom 10. 5. 1954, Bl. 13 f., selbstverfaßter Lebenslauf (Abschrift).

260 Lt. ebd., Bl. 8, Werbungsvorschlag HA V, Abt. 3, 10. 5. 1954 gehörte er dem Landesgründungsausschuß an. Allerdings dürfte er erst nach dem 27. 5. $1948 \mathrm{zu}$ diesem Kreis gestoßen sein, da er nach SED-Unterlagen nicht an der Gründungsversammlung am 27. 5. 
nahm er dort 1951 den Posten des Landwirtschaftsministers. Aus diesem Amt zog ihn die Partei 1952 wegen angeblich fehlender Selbstkritik wieder zurück - offensichtlich reagierte die DBD damit auf Beschwerden der SED über ihn bei der $\mathrm{SKK}^{261}$. Von 1953 bis 1957 gehörte er zum organisatorischen Führungszirkel der Partei und wirkte als Sekretär des Parteivorstandes ${ }^{262}$. Von 1954 bis zu seiner Delegierung an die Akademie für Staats- und Rechtsfragen im Herbst 1955 lieferte er für die Staatssicherheit Berichte über die Interna der DBD. Danach arbeitete er auf eigenen Wunsch in einer LPG in Weißenberg 263 . Die nicht schlecht bezahlte Tätigkeit in einer LPG bedeutete dennoch eine politische Degradierung. Seit August 1958 forderte Besler die DBD intern auf, ihn aus der Partei zu entlassen ${ }^{264}$. 1959 trat er wieder in die SED ein und gehörte für sie der Volkskammer an ${ }^{265}$.

Fritz Weißhaupt ${ }^{266}$ stammte wie Helmschrott aus einer mittelbäuerlichen Landwirtsfamilie in Südwestdeutschland. $1910 \mathrm{kam}$ er im badischen Leitishofen zur Welt. Seine elf Geschwister lebten Ende 1951 in der Bundesrepublik. Nach der Realschule absolvierte er eine landwirtschaftliche Lehre ${ }^{267}$. Von Kindheit an arbeitete er auf dem 17 ha großen Hof seiner Eltern. Seit 1928 war er als Milchkontrolleur, von 1930 bis 1937 als Volontär und dann Verwalter auf mitteldeutschen Rittergütern beschäftigt ${ }^{268} .1933$ trat er in die NSDAP ein ${ }^{269}$. Aus ungeklärten Gründen schloß ihn deren Gaugericht Sachsen 1936 wieder aus. Nach kurzem Kriegsdienst und amerikanischer Kriegsgefangenschaft setzte ihn die Rote Armee

1948 teilnehmen sollte. BLHA Rep. 332, Nr. 786, Bericht zur Vorbereitung der Gründung der "Gesellschaft Y“, 26. 5. 1948.

261 BStU MfS AIM 3562/59, Bd. 2, Personalakte, Bl. 12, Charakteristik gez. Otto (Abschrift). Zu seinem Rückzug vgl. dagegen auch: BLHA Rep. 332, Nr. 786, Bericht der SED Brandenburg an SKK über die Arbeit der DBD Land Brandenburg, 2. 12. 1951. Besler sträube sich als Minister gegen eine Sekretärin, die SED-Mitglied sei. Er habe den Verdacht, man wolle ihn bespitzeln, und äußerte sich dahingehend, daß dann doch gleich sein Referent, Genosse Haberland, den Ministerposten übernehmen solle.

262 Reichelt, Blockflöte, S. 375.

263 BStU MfS AIM 3562/59, Bd. 2, Personalakte, Bl. 28, Schlußbericht der HA V/3, 22. 10. 1956.

264 Ebd., Bl. 37, Bericht von GI „Pankow“, eines Mitglieds der DBD, 30. 10. 1958.

265 Ebd., Bl. 41, am 5. 8. 1959 beschloß man den Abbruch der Verbindung, da Besler wieder in die SED eingetreten war. Als Volkskammer- und SED-Mitglied erfuhr er von DBDMitgliedern nichts Berichtenswertes mehr.

266 Das Folgende nach BStU MfS AP 82/58, Bl. 2, selbstverfaßter Lebenslauf, 15. 12. 1951.

267 Diese Schulbildung ist in Herbst u. a., DDR, Bd. 3, S. 363, in SBZ-Handbuch, S. 1054 und in Wernet-Tietz, Bauernverband, S. 225 aufgeführt, nicht aber im selbstverfaßten Lebenslauf.

268 Abweichend davon Herbst u.a., DDR, Bd. 3, S. 363, 1932-1935 Volontär, anschließend Verwalter landwirtschaftlicher Betriebe.

269 Dieses Faktum ist nur ebd. nicht aufgeführt. Das MfS legte aufgrund der West-Veröffentlichung „Braunbuch DDR“ einen Untersuchungsvorgang an, konnte die Angaben zu Weißhaupt anhand archivalischer Unterlagen in der DDR aber weder belegen noch entkräften. BStU MfS AP 82/58, Bl. 3, eine Charakteristik, verfaßt vom Personalreferenten des sächsischen Ministeriums für Land- und Forstwirtschaft, undatiert [bei Amtsantritt] erwähnt diese NSDAP-Mitgliedschaft. Sein selbstverfaßter Lebenslauf vom 15.12. 1951 enthält dazu nichts, ebd., Bl. 2. 
als Treuhänder 270 eines zu ihrer Versorgung dienenden Gutes im sächsischen Bosebrum, Kreis Ölsnitz, ein. Weißhaupt war mit der Aufteilung des Gutes beauftragt und erhielt eine Neubauernstelle. 1946 trat er in die SED ein und wurde im Januar 1948 Kreisparteisekretär in Ölsnitz. Er engagierte sich im landwirtschaftlichen Genossenschaftswesen, aber offenbar nicht in der VdgB. Seit 1945 war er zweiter Vorsitzender der landwirtschaftlichen Hauptgenossenschaft Sachsens und saß im Aufsichtsrat der landwirtschaftlichen Zentralgenossenschaft ${ }^{271}$. Weißhaupt war aufgrund seiner Ausbildung und Funktionen für die SED attraktiv, da er sich in seiner politischen Einstellung deutlich vom sonstigen Personal in den landwirtschaftlichen Genossenschaften unterschied, die im allgemeinen und besonders in Sachsen als „Hort der Reaktion“ galten ${ }^{272}$. Sowjetischen Stellen bestens bekannt, wechselte er im Sommer 1948 zur DBD und wurde erster Kreisvorsitzender in Ölsnitz. Ab Januar 1950 leitete er als politischer Geschäftsführer des Landesverbandes die Geschicke der DBD. Im Juni 1950 löste er den LDP-Landwirtschaftsminister Uhle in Sachsen ab. Weißhaupt war später langjähriger Mitarbeiter im Ministerium für Land- und Forstwirtschaft der DDR. Von 1962 bis 1975 leitete er den Bezirksverband Magdeburg der DBD, 1955 bis 1982 gehörte er dem Parteivorstand an ${ }^{273}$.

Über den einzigen mitteldeutschen Altbauern in dieser Gründergruppe ist wenig bekannt. Fritz Petersohn kam 1910 vermutlich im Kreis Großenhain zur Welt. Nach 1945 gehörte er der SED und aller Wahrscheinlichkeit nach auch der VdgB an. Vermutlich gründete er die Bauernpartei im Auftrag der SED in diesem Kreis, wo er auch 1. Kreisvorsitzender war. Petersohn gehörte zu den besonders aktiven Gründern auf Landesebene. Seine Funktionärslaufbahn in der DBD endete 1953 als Bezirksvorsitzender in Dresden, zuvor hatte er nach Friedrich Martins Ablösung ab 1951 den Landesvorsitz Sachsens geleitet ${ }^{274}$.

Dem Typus des altgedienten Funktionärs der Arbeiter- und Gewerkschaftsbewegung ist Hermann Gräfe ${ }^{275}$ zuzurechnen, der wie viele andere Gründungsmit-

270 Herbst u. a., DDR, Bd. 3, S. 363.

271 In diesen Funktionen bemühte er sich um ein gutes Verhältnis zur SED und zum Landwirtschaftsministerium. BStU MfS AP 82/58, Bl. 3, Charakteristik (Abschrift), undatiert [nach Amtsantritt im Ministerium]. Auskunft des Personalreferenten im Ministerium über den Minister.

272 SStAD BPA SED LL A/782, Bd. 2, Protokoll Sekretariat 21. 5. 1948.

273 Herbst u. a., DDR, Bd. 3, S. 363.

274 SStAD BPA SED LL A/833, Bl. 12-49, Analyse der Mitgliederbewegung, 14. 4. 1950, angefertigt vom LV der DBD Sachsen; SStAD BL SED IV 2. 15. 005, Bericht zur Lage in der DBD, 24. 6. 1953, angefertigt von Org.Abt. SED, danach wurde Petersohn krankheitsbedingt zurückgezogen und weil er nicht in der Lage war, das Sekretariat kollektiv zu führen. Vgl. auch SStAD BPA SED LL A/796, Protokoll Sekretariatssitzung SED, 2. 1. 1952, Bl. 1-24, hier Bl. 11 und ACDP VI, unverz. Aufstellung von Mitgliedern des auf der Konferenz vom 16./17. 7. 1948 gewählten Parteivorstandes und besonders aktiver Mitbegründer in den Landesverbänden.

275 Er kam am 10.6. 1900 in Beerendorf (Kreis Delitzsch) als Sohn eines Landarbeiters zur Welt. Nach der Volksschule arbeitete er auf dem Land, dann als Elektromonteur. 1924 schloß er sich der KPD an, 1928 dem Deutschen Metallarbeiterverband. In Lützen begründete er den Roten Frontkämpferbund. 1935 wurde er, angeblich wegen Widerstandstätigkeit, zu 3 Jahren Haft verurteilt, danach vom RAD verpflichtet. 1943 zur Wehrmacht 
glieder in den politischen Auseinandersetzungen der Weimarer Republik geprägt worden war. Er löste 1951 Richard Richter im Amt des Landesvorsitzenden ab und war bis Ende 1958 Bezirksvorsitzender in Magdeburg 276. Der letzte in dieser Reihe der zeitweiligen Landesvorsitzenden, Arthur Pech, entspricht aufgrund seiner Herkunft aus der Arbeiterbewegung und als Neubauer dem Standardtyp eines DBD-Funktionärs 277 ; 1912 geboren, trat er 1945 in die SPD ein. Er wechselte vom Landesvorsitz in Brandenburg, den er nach Rudolf Albrecht 1951 angetreten hatte, auf den Bezirksvorsitz in Frankfurt/Oder, den er bis 1963 innehatte. Seine bis dahin beachtliche Laufbahn in der DBD endete 1963 abrupt, sieht man von dem zwar ehrenvollen, aber nicht gewichtigen Amt im Parteischiedsgericht ab.

Als Personen aus der zweiten Reihe der Funktionäre seien hier Hans-Joachim Friedländer, Adolf Giese, Else und Helmut Merke sowie Stefan Zagrodnik ausgewählt. Alle genannten waren an der Gründung von Ortsgruppen und/oder beim Aufbau der Partei in den Kreisen beteiligt, gelangten aber bis 1952 und teils darüber hinaus nicht in Führungspositionen der Partei in den Ländern, sondern nahmen nachgeordnete Funktionen ein.

Am Beispiel Hans-Joachim Friedländers läßt sich exemplarisch aufzeigen, welche biographischen Prägungen und politischen Dispositionen 1948 mit einer Parteikarriere in der Führungsmannschaft unvereinbar waren, zumal mangelndes Interesse in seinem Fall als Hinderungsgrund ausscheidet. Friedländer war die Schlüsselfigur der Gründungsinitiative in Wismar, und er übernahm die

eingezogen, geriet er später in Kriegsgefangenschaft. Nach 1945 war er Betriebsleiter der Elektrowerke in Lützen, übernahm dann eine Neubauernstelle. Er war KPD/SED-Mitglied und VdgB-Kreisvorsitzender in Lützen. 1948 arbeitete er an der Gründung der DBD unterhalb der Landesebene mit. 1950-51 war er Leiter einer Hauptabt. im Ministerium für Land- und Forstwirtschaft in Sachsen-Anhalt, Herbst u.a., DDR, Bd. 3, S. 109 f., anders SBZ-Handbuch, S. 914. Evt. war Gräfe 1946 Landrat in Kamenz, dazu SAPMO DY 30 IV 2/7/61, Bl. 28 f, Schreiben des Landrats zu Kamenz, Hermann Grafe, an SED LV Sachsen, 26. 8. 1946 [Abschrift, Grafe evt. Schreibfehler]. Vermutlich ist er nicht identisch mit jenem H.G., den Goldenbaum aus der Mecklenburger Gewerkschaftsbewegung kannte, SAPMO SgY 30/1423 Ernst Goldenbaum.

276 Falsch sind Angaben, wonach er 1952-1960 Mitglied des PV der DBD und von 19521960 Vorsitzender des BV der DBD Magdeburg gewesen sein soll, so in Herbst u.a., DDR, Bd. 3, S. 110 und bei Reichelt, Blockflöte, S. 378. Ende 1958 legte Gräfe alle Parteiund öffentlichen Funktionen nieder. Die DBD verweigerte ihm die sonst übliche Hilfe bei einer Stellensuche, gewährte ihm nur Überbrückungsgeld. Der Grund für sein Ausscheiden und die harsche Behandlung ist unklar. ACDP VI-052-0321, Protokolle Sitzungen des Präs. des PV, 14.9. und 3. 12. 1958.

277 Pech (9. 4. 1912-20. 5. 1980), geb. in Schnogrow als Sohn einer Arbeiterfamilie. Sein Vater war Ziegler. Nach der Volksschule begann er eine Lehre als Melker. 1945 wurde er Neubauer, 1948 trat er der DBD bei; 1950-52 Landrat des Kreises Angermünde, 1952/53 stv. Vors. des RdB Frankfurt(O), 1951-63 Mitgl. des DBD-PV, 1955-63 Mitgl. seines Präsidiums, 1953-55 Mitgl. des Sekr. des DBD-PV, 1977 stv. Vors. des Parteischiedsgerichts, 1954-58 Mitgl. der Länderkammer, 1954-63 Abg. des Bezirkstages Frankfurt(O), Mitgl. des VdgB-ZV, zeitweise Präs. Mitglied, Leiter einer Inspektorengruppe in Frankfurt(O) und Mitarbeiter beim DBD-PV, Präs. Mitgl. der Volkssolidarität. Angaben nach ACDP VI-052-0017, Zusammensetzung des PV 1960; Herbst u.a., DDR, Bd. 3, S. 253. Reichelt, Blockflöte, S. 97. 
ersten Schritte zur landesweiten Gründung. Anfangs wurde er daher als Landesvorsitzender gehandelt, bald aber verschwieg man seinen Beitrag systematisch $^{278}$.

Friedländer kam am 17. Juni 1917 in der hinterpommerschen Stadt Kolberg zur Welt. Er wuchs im Dorf Schulzenhagen im Kreis Köslin auf279. Seine Eltern bewirtschafteten ein 130 ha großes Rittergut ${ }^{280}$. Die Familie war protestantischer Konfession, der väterliche Teil war in den 1830er Jahren vom jüdischen zum christlichen Glauben konvertiert ${ }^{281}$. Friedländer besuchte ab 1925 ein humanistisches Gymnasium in Kolberg, das er als Unterprimaner verließ, um im Oktober 1934 eine halbjährige Ausbildung auf einer Handelsschule aufzunehmen. Danach begann er eine landwirtschaftliche Lehre, die er 1937 mit der Gehilfenprüfung abschloß. Einer kurzen Dienstzeit beim RAD folgten Einsätze in der Wehrmacht, bis er 1940 aufgrund seiner in NS-Kategorien "rassischen “ Herkunft als Obergefreiter, ausgezeichnet mit dem Eisernen Kreuz II. Klasse, entlassen wurde ${ }^{282}$. Bis Ende 1944 lebte er auf dem väterlichen Rittergut ${ }^{283}$. Schließlich ereilte ihn die unmittelbare Verfolgung durch das nationalsozialistische Regime, das ihn in Zwangsarbeitslager preßte. Seine Eltern flohen vor der anrückenden Roten Armee; sie lebten nach 1945 im westlichen Norddeutschland. Am 16. April 1945 wurde er von amerikanischen Truppen befreit. Da eine Rückkehr ins weitgehend zerstörte Kolberg unmöglich war, meldete er sich beim Landratsamt Wismar. Dort wurde er seinen Kenntnissen entsprechend zur Erntearbeit eingeteilt und Anfang 1946 mit dem Posten eines landwirtschaftlichen Beraters in Neukloster betraut. 1947 weitete er seine berufliche Tätigkeit in der VdgB aus. Seit April 1947 war er Kreiswirtschaftsberater der VdgB in Wismar, im Juli des gleichen Jahres wurde er zum Kreisvorsitzenden der VdgB gewählt. Fachlich kompetent, regional

278 Reichelt, Blockflöte, S. 17-25, geht zwar auf seine entscheidende Rolle bei der Gründung ein, blendet jedoch die neuralgischen Punkte aus.

279 Das Folgende nach BStU ASt Swn. AIM 1170/64, Personalakte Friedländer, Bl. 11-14, Personalbogen (Abschrift), 3. 8. 1950; Bl. 15, Lebenslauf (Abschrift), 2. 8. 1950. Manches auch in SBZ-Handbuch, S. 903 und Herbst u.a., DDR, Bd. 3, S. 91. Lückenhafte Angaben, vermutlich um Friedländer zu decken, in ACDP VI, unverz. Best. LV Mecklenburg, Akt LV Mecklenburg: Personalpolitische Abt., Verwaltungsreform und Reorganisation der Partei Juli/August 1952.

280 Friedländer unterläßt in seinen Personalangaben 1950 die Präzisierung, daß sein Vater Rittergutsbesitzer war, bezeichnet ihn als "Landwirt"; er bestätigte dies telefonisch im Januar/Februar 2000. Da 1950 sogenannte Großbauern, unter die sein Vater nach SEDKategorien fiel, bekämpft wurden, dürfte er dieses Detail bewußt verborgen haben. Nur seine parteiinternen Gegner erwähnten eine "große Landwirtschaft" und ein angebliches Samen- und Viehhandelsgroßgeschäft gegenüber dem MfS, siehe BStU ASt Swn. AIM 1170/64, Personalakte Friedländer, Bl. 61 f., Bericht von IM „Mai“ (= Beer), 4. 1. 1961.

281 Telefonische Auskünfte Friedländers, Januar/Februar 2000. Demnach falsche Angaben in der Charakteristik des MfS, 21. 12. 1951, BStU ASt Swn. AIM 1170/64, Personalakte Friedländer, Bl. $17 \mathrm{f}$. Die auf einem Informantenbericht basierende Personenbeschreibung behauptet, Friedländers Vater sei Jude gewesen. Die Ausführungen in Bauer, Gründung, S. 297 f., sind daher zu korrigieren.

282 BStU ASt Swn. AIM 1170/64, Personalakte Friedländer, Bl. 11-14, Personalbogen (Abschrift), 3. 8. 1950.

283 Ebd., Bl. $15 \mathrm{f}$. 
geachtet und ohne eine Funktion in der SED, die den gesteuerten Charakter der Gründung allzusehr offenlegen würde, empfahl er sich als Funktionär für die neuzugründende Bauernpartei.

Die Biographie Friedländers ist durch zwei Elemente gekennzeichnet, die ihn aus Sicht der SED suspekt erscheinen ließen. Friedländers Vater gehörte während der Weimarer Republik dem nationalkonservativen Lager an, nach 1945 schloß er sich der SPD an und war Anhänger Kurt Schumachers ${ }^{284}$. Hans-Joachim Friedländer trat zunächst in keine Partei ein; als die Vereinigungskampagne schon lief, wurde er im November 1945 Mitglied der SPD285. Seine SPD-Mitgliedschaft in Kombination mit seiner, wie es vorwurfsvoll immer wieder hieß, „großbäuerlichen “ 286 sozialen Herkunft bewirkte, daß man ihn als Führungsfigur der DBD, kaum angeworben, schleunigst wieder fallenließ. Als ehemaliger Sozialdemokrat und Opfer nationalsozialistischer Verfolgung hatte der heimatvertriebene Sohn eines Rittergutsbesitzers keine Chance auf eine politische Führungsfunktion in der DBD.

Eine weitere Gründungsfigur in Mecklenburg, die die DBD aus dem zweiten Glied heraus aufbaute und dort blieb, war Adolf Giese (Jahrgang 1906), der in seiner Heimatstadt Neubrandenburg Kreisvorsitzender wurde 287 . Giese gehörte zum Netzwerk von frühen DBD-Funktionären, deren Verbindungen in die Zeit der Weimarer Republik zurückreichten. Er hatte die KPD im Landtag von Mecklenburg-Strelitz 1932/33 vertreten und kannte Goldenbaum aus dessen Funktionärstätigkeit für die KPD. Die aus seiner Sicht allzu erfolgreich verlaufende Werbeaktion für die DBD stürzte ihn in ein Dilemma, denn er verstand seinen Einsatz für die DBD 1948 in erster Linie als Parteiauftrag der SED, die er als seine eigentliche politische Heimat betrachtete.

Helmut Merke und seine Frau Else, 1919 bzw. 1920 geboren, gehören zur Generation der jüngsten Parteigründer ${ }^{288}$. Sie bauten den Kreisverband Stendal und die Partei in Sachsen-Anhalt mit auf. Mit einigen anderen Eheleuten nehmen sie in den fünfziger Jahren und danach die Stellung eines „Musterpaares“ in der DBD ein. Beide entstammten bäuerlichen Familien und arbeiteten in der Landwirtschaft; bis 1945 traten sie politisch nicht in Erscheinung, ihnen fehlte der Stallge-

284 Ebd., Bl. 47, Bericht GI „Paul“, 26. 9. 1957. Die Friedländer feindlich gesonnenen IM-Berichte kennzeichnen seinen Vater als immer schon überzeugten SPD-Anhänger. Über die nationalkonservative Ausrichtung informierte Friedländer telefonisch im Jan./Febr. 2000.

285 Vor der SED versuchte er seine politische Abstinenz bis dahin damit zu rechtfertigen, daß er angab, sich erst als Erwachsener parteipolitisch festlegen haben zu wollen; BStU ASt Swn. AIM 1170/64, Personalakte Friedländer, Bl. 15f., hier Bl. 15. In der DBD versuchte man diese SPD-Vergangenheit zu verschleiern, indem man in Personalbögen nur das Faktum einer SED-Mitgliedschaft nach 1945 anführte, das ja auch zutraf. ACDP VI, unverz. Best. LV Mecklenburg, Karton LV Mecklenburg, Akt LV Mecklenburg: PPA, Verwaltungsreform und Reorganisation der Partei Juli/August 1952, Angaben zu Friedländer.

286 Vor allem einige IMs hatten sich darauf eingeschossen, wie z. B. Ernst-Walter Beer.

${ }^{287} \mathrm{MdL}, \mathrm{S}$. 363. Ebenso in MLHA BPA Schwerin IV/L/2/13/624, Liste über die Kreisvorsitzenden der DBD Mecklenburg [1948]. Vgl. auch ACDP VI, unverz. Best. LV Mecklenburg, Karton LV Mecklenburg, Listen aus Landesvorständen, Stand 1950: Giese war 1950 im Parteischiedsgericht der DBD Mecklenburgs.

288 Die folgenden Daten nach Barth u.a. (Hg.), DDR, S. $1336 \mathrm{f}$. 
ruch der Arbeiterbewegung. Erst nachdem sie politische Schulungen durchlaufen hatten, schienen sie für Ämter qualifiziert. Helmut Merke, Unteroffizier der Wehrmacht, nahm während seiner Gefangenschaft in der Sowjetunion an AntifaSchulungen teil; Else Merke, die im hinterpommerschen Stargard zu Hause war, wurde 1945 vertrieben und gelangte nach Stendal. Als Vertriebene mußte sie politische Zuverlässigkeit nachweisen. Nach Schulungen wurde sie 1950 Landesinstrukteurin des Demokratischen Frauenbunds Deutschlands (DFD). Ihr Mann war zeitweise stellvertretender Landesvorsitzender der DBD. Helmut Merkes Einfluß in den Parteigremien stieg in den sechziger Jahren; erst ein Studium eröffnete ihm diesen politischen Karrieresprung. Um das Paar rankte sich der Mythos von LPG-Gründern, der ihnen einen gewissen Bekanntheitsgrad in der DDR ver$\operatorname{lieh}^{289}$.

Stefan Zagrodnik zählt zu den späten Gründern ${ }^{290}$. Erst im Januar 1949 wurde mit seiner Hilfe eine Ortsgruppe der DBD an seinem Wohnort Hirschfeld im sächsischen Kreis Freiberg ins Leben gerufen. Bis zu seinem Eintritt in die DBD war Zagrodnik nicht parteilich engagiert gewesen. Zagrodnik kam 1916 in Waldau bei Kassel zur Welt. Seine Eltern, ursprünglich in einem polnischen Dorf beheimatet, waren Landarbeiter auf Wanderschaft. Auf der Suche nach besseren Lebensbedingungen ständig unterwegs, arbeiteten sie 1916 auf einem Rittergut nahe Kassel ${ }^{291}$. Von den zehn Kindern überlebten nur acht. Immerhin versuchte das Paar, den Kindern eine geregelte Schulbildung zu ermöglichen ${ }^{292}$. Die Familie zog häufig um, so in den Kreis Wurzen, später in die Gegend von Meißen. 1932 kehrte die Familie nach Polen zurück und konnte sich dort offensichtlich Land kaufen. $\mathrm{Da}$ sie kein weiteres Auskommen für den wohl noch unter 20jährigen Stefan sah, wurde er von Verwandten in Oppeln aufgenommen. Dort trat er als Lehrling in die Verwaltung des Landratsamtes ein. 1937 wurde er vom Dienst entbunden und kehrte zu seinen Eltern zurück. 1939 rückten Wehrmachttruppen in das polnische Gebiet ein; Zagrodnik wurde vom RAD dienstverpflichtet, 1940 von der Wehrmacht eingezogen. Am Angriff auf die Sowjetunion nahm er noch teil, dann folgten Zeiten der Verletzung und Krankheit, die er meist in Berliner

289 Sie gehörten zu den Aktivisten der Kollektivierung im August 1952. Vgl. dazu Helmut Merkes autobiographische Notiz: Dorftanz mit den Genossenschaftsbauern von morgen, in: Wie wir angefangen haben, S. 169-172. Er war bis 1984 Vorsitzender der LPG „7. Oktober" in Schenkenberg. Seine Frau gelangte in prestigeträchtige politische Ämter; sie war von 1953 bis 1986 Volkskammerabgeordnete und zeitweise Mitglied des Staatsrates.

290 Biographische Daten aus Barth u.a. (Hg.), DDR, S. 2199, BStU MfS AIM 3189/63, Personalakte, Bl. 8 f., BV MfS Dresden Abt. V-Ref. III, 22. 4. 1954, Vorschlag zur Anwerbung eines GI; Bl. 10-12, Lebenslauf, 17. 5. 1954; Bl. 35 f., Auskunftsbericht HA V-Ref. III, 26. 9. 1961; Herbst u. a., DDR, Bd. 3, S. 381.

291 Zur prekären Situation der Landarbeiter vgl. Winkler, Weg, S. 40 f. Landwirtschaftliche Saisonarbeiter waren seit Juni 1929 von der Krisenfürsorge ausgeschlossen und damit meist auf Wohlfahrt angewiesen. Sie zählten zu den untersten Schichten des Proletariats. Ausdruck ihrer Notlage war eine überaus hohe Säuglingssterblichkeit unter den Landarbeiterkindern. Im Januar 1931 waren saisonbedingt allein 238358 arbeitslos, im Juli 102165.

292 Für Landarbeiterkinder war dies nicht selbstverständlich. Vgl. dazu Weiland, Lage. 
Lazaretten zubrachte. Am 1. Mai 1945 geriet er in Schwerin in amerikanische Kriegsgefangenschaft ${ }^{293}$.

Aus dem Bodenreformfond erhielten Zagrodnik und seine Frau rund 6 ha Land im sächsischen Hirschfeld im Kreis Freiberg. In seinem Verständnis spielten dieses Ereignis und die Erfahrung, daß er 1948 „mit Hilfe der Regierung“ einen Neubauernhof aufbauen konnte, eine zentrale Rolle. Zagrodnik arbeitete seit 1946 im Ortsvorstand der VdgB mit, seit 1948 war er stellvertretender Bürgermeister, ab Herbst 1950 erster Bürgermeister. Unter seiner Mithilfe gründete man im Januar 1949 eine Ortsgruppe der Bauernpartei. Die Bindung an den Hof blieb nicht eng. Zagrodniks Aufstieg in der DBD begann mit der Teilnahme an den Verwaltungslehrgängen in Forst-Zinna. Bis Juli 1952 war er Kreissekretär in Meißen, danach Kadersekretär im Bezirksverband Dresden. 1954 verpflichtete er sich zur Zusammenarbeit mit dem MfS. Nach weiteren Stationen in den Bezirken kam er im Februar 1960 zum Apparat des Parteivorstandes, wo er für das MfS wertvolle Dienste leistete. Zagrodnik ließ seine ärmliche Kindheit hinter $\operatorname{sich}^{294}$ und bemühte sich um sozialen Aufstieg, zunächst via Verwaltung und Partei, später auch über eine Verpflichtung ${ }^{295}$ und langjährige inoffizielle, dann auch offizielle Tätigkeit für das MfS.

\section{Das Parteiprogramm}

Zwischen den ersten programmatischen Überlegungen und der offiziellen Verabschiedung eines Parteiprogrammes auf dem 1. Parteitag der DBD in Mühlhausen 1949 verstrich ein Jahr. Unmittelbar nach der Landesgründungsversammlung der DBD in Mecklenburg am 29. April 1948 begann eine Gruppe mit der Ausarbeitung programmatischer Grundsätze. Zu ihr zählten nachweislich Ernst Goldenbaum und Paul Reder, höchstwahrscheinlich auch Hans-Joachim Friedländer 296.

Der Entwurf unterstrich eingangs den „demokratischen Weg“, den Deutschland künftig gehen müsse. Daran anschließend hob er die Bodenreform hervor, die „selbständige Bauern auf eigenem Grund und Boden“ anstelle von Junkern und Großgrundbesitz geschaffen habe. Auffälligerweise war als Klientel der Par-

293 Das Faktum der amerikanischen Kriegsgefangenschaft verschwieg er in seinem Lebenslauf; das MfS war dennoch darüber informiert. BStU MfS AIM 3189/63, Personalakte Zagrodnik, Auskunftsbericht HA V/3, 26. 9. 1961, Bl. 35-38, hier Bl. 35.

294 Auffälligerweise enthält sein Lebenslauf mehr Aussagen zur Zukunft seiner Schwiegereltern in Polen - die politisch angepaßt sehr rosig geschildert wird - als zum Verbleib seiner eigenen Familie. Eine seiner Schwestern war wie er in Hirschfeld ansässig und dort mit dem DBD-Ortsvorsitzenden verheiratet.

295 BStU MfS AIM 3189/63, Personalakte Zagrodnik, Bl. 16, Verpflichtungserklärung, 30.4. 1954.

296 Vgl. eine als „Entwurf“ überschriebene Fassung der „Grundsätze und Forderungen“ der Demokratischen Bauernpartei Deutschlands, undatiert, sicher vor 28. 5. 1948 verfaßt, MLHA BPA Schwerin IV/L/2/13/624, Bl. 62-65. Goldenbaum sprach am 28. 5. 1948 in Brandenburg/Havel von mehreren vorangegangenen Entwürfen. ACDP VI-052-0001/b, Protokoll Sitzung der Landesgründungsausschüsse, 28. 5. 1948, S. 9. 
tei weder von Alt- noch von Neubauern die Rede; die Partei gab sich vielmehr nach außen als „selbständige Partei der fortschrittlichen Bauern“ zu erkennen ${ }^{297}$. Wie diese nicht SED-konforme Formulierung fiel in späteren Fassungen auch die Forderung weg, die eine "gerechte Festlegung des Ablieferungssolls für jede einzelne Bauernwirtschaft nach ihrer Leistungsfähigkeit“ und eine „Differenzierung durch die Bauern im Dorfe selbst" vorsah. An diesem Punkt werden vor allem die sowjetischen Besatzungsbehörden Anstoß genommen haben. Sie wollten das landwirtschaftliche Erfassungswesen aufs genaueste regulieren und waren daher mit solchen autonomen Praktiken keinesfalls einverstanden. Der Entwurf schloß mit einem gesamtdeutschen Bekenntnis und lag damit ganz auf der Linie eines entsprechenden Beschlusses des Zentralsekretariats der SED298.

Auf der als „intern“ eingestuften Sitzung der Landesgründungsausschüsse in Brandenburg/Havel am 28. Mai 1948 hielt Goldenbaum ein Grundsatzreferat zu "Zweck und Ziel der deutschen [!] demokratischen Bauernpartei“299. Goldenbaum reklamierte für die DBD eine weitgefaßte politische Geltung, die über die Ziele einer berufsständischen Interessenpartei hinausging. Diese Reichweite der Partei unterschied sich erheblich von jener, die in später formulierten und von der SED redigierten offiziellen Dokumenten nachzulesen war ${ }^{300}$. Außerdem stellte er die vorgelegten „Grundsätze und Forderungen“ zur Diskussion. Angeblich sollte ein Meinungsbild darüber hergestellt werden, ob Vertreter anderer Länder mit dieser Grundlinie einverstanden seien. Es ist unwahrscheinlich, daß die Länderdelegationen über ein so weitgehendes Mitspracherecht verfügten, um programmatische Vorgaben von SMAD und SED zu verändern. Bei den Länderdelegationen konnte jedoch der Eindruck entstehen, als sei ihre Einschätzung tatsächlich gefragt. Diese frühe Fassung gelangte nie an die Öffentlichkeit. In höherem Maße als andere Fassungen war sie von den Vorstellungen der mecklenburgischen Parteigründer beeinflußt. Im folgenden sei vor allem ihre Differenz zur allerersten Fassung wie zum späteren offiziellen Programm herausgestellt.

Stärker als in der vorhergehenden Variante hob die Fassung vom 28. Mai darauf ab, den Anteil der Stadt, respektive der Arbeiterschaft an der Entmachtung der Junker und beim wirtschaftlichen Neuaufbau hervorzukehren. Nur wenn Arbeiter und Bauern „zusammen schreiten“ würden, sei Friede und Demokratie möglich. Diese Veränderung dürfte auf Eingriffe der SED zurückgehen. Offenbar gestalteten die für die Bauernpartei abgestellten SED-Funktionäre um Goldenbaum eine zu eigenständige Programmatik für ihr neues Projekt. Erst diese Fassung enthält das Stichwort „Umsiedler“, die im Zuge der Bodenreform Bodeneigentum erhalten hätten. Neben die Absicherung der Bodenreform in der SBZ trat die Forderung, diese auf ganz Deutschland auszudehnen. Ein Bekenntnis zum Programm des Deutschen Volkskongresses und damit zum gesamtdeutschen Staat fehlte auch

297 MLHA BPA Schwerin IV/L/2/13/624, Entwurf „Grundsätze und Forderungen“ der Demokratischen Bauernpartei Deutschlands, Bl. 62-65, hier Bl. 63.

298 Ebd., hier Bl. 65; SAPMO DY 30 IV 2/2.1/196, Protokoll ZS, 8. 5. 1948, Bl. 1.

299 ACDP VI-052-0001/b, Protokoll Sitzung der Landesgründungsausschüsse, 28. 5. 1948, S. $2 \mathrm{ff}$.

300 Ebd., S. 4. 
nicht. Eine neu eingefügte Passage betonte die Freundschaft mit der Sowjetunion und den anderen volksdemokratischen Ländern. Weiter unterstrich man die Zusammenarbeit mit allen antifaschistisch-demokratischen Parteien und versprach, die VdgB und die landwirtschaftlichen Genossenschaften zu unterstützen. Auf diese „Grundsätze“ aufbauend, erhob man eine Reihe von „Gegenwartsforderungen":

1. Bauern sollten stärker in allen Verwaltungsorganen und Parlamenten vertreten sein. Bürokratismus wolle man beseitigen und „für die Ausmerzung der oft als ,Fachleute، getarnten hemmenden Kräfte, insbesondere in den landwirtschaftlichen Abteilungen, sorgen “301.

2. Bauern sollten an der Erstellung einer gerechten Differenzierung und einem gerechten Ablieferungssoll mitwirken und bei der Aufstellung der Anbaupläne beteiligt werden - diese also nicht mehr selbst erarbeiten, wie in der früheren Fassung noch gefordert.

3. Man trat für einen schnelleren Aufbau der Landwirtschaft auf der Grundlage „produktiver Bauernwirtschaften“ ein, die im Privateigentum der Besitzer bleiben sollten. Darunter verstand man explizit den Einsatz von Technik via Ausbau der Maschinenausleihstationen, eine Förderung der Tierzucht und die Abgabe von Vieh an Neubauernwirtschaften, eine bessere Versorgung mit Düngemitteln und den Bau von Neubauernhäusern.

4. Die Kultur auf dem Dorfe sollte „gehoben“ werden. Daher plädierte man für eine Schulreform und den Ausbau des Berufs- und Fachschulwesens für bäuerliche Jugendliche. Ihnen sollten auch Universitäten offenstehen. Zusammen mit anderen Parteien und Organisationen wollte man sich für soziale und kulturelle Gemeinschaftseinrichtungen für Frauen und Jugendliche einsetzen.

5. Schließlich bekannte man sich dazu, werktätige Bauern und Landarbeiter vor „Ausbeutung“ und „Wucher“ zu schützen. Diese neue Forderung ging konform mit sowjetischen Bemühungen um ein Landarbeiterschutzgesetz, die ebenfalls im Sommer 1948 einsetzten. Bodenspekulation sollte durch ein staatliches Vorkaufsrecht zugunsten Landarmer und Umsiedler verhindert werden. Die alten, noch laufenden Siedlerverfahren sollten auf der Grundlage einer tragbaren Rente reguliert werden. Weiter trat man für ein einheitliches Erbrecht unter Gleichberechtigung der nachgeborenen Kinder, also für eine Realteilung, ein. Am Ende betonte auch diese Fassung, daß die DBD keine Partei der Berufsinteressen sei.

Neu im Vergleich zur früheren Fassung war eine präzisere Ausrichtung auf die Klientel der Neubauern. Die Partei stehe zwar „offen für alle aufbauwilligen Bauern, vor allem aber für die vielen Neubauern, die ehrlich und gewissenhaft, getragen vom Pflichtgefühl für den demokratischen Wiederaufbau Deutschlands eintreten. “ 302

301 Folgende wörtlichen Zitate ebd.

302 ACDP VI-052-0001/b, Grundsätze und Forderungen der Demokratischen Bauernpartei Deutschlands, rückdatiert auf April 1948. Für eine Rückdatierung nach der Diskussion sprechen folgende Indizien: Der Diskussion am 28. Mai 1948 zufolge erwähnte die vorgelegte Fassung die Frauen nicht eigens. Da dies bemängelt wurde, kam man überein, Frauen wie Jugend gesondert anzusprechen. Da die Frauenthematik in dieser überliefer- 
Die „Grundsätze und Forderungen“ standen auf der ersten Zonenvorstandssitzung am 25. Juni 1948 nochmals zur Debatte. Allerdings fehlten zu diesem Termin DBD-Vertreter aus Sachsen und Sachsen-Anhalt. Herbert Hoffmann nannte für den Landesverband Thüringen eine Reihe von Änderungsvorschlägen $^{303}$. Diese bezweckten, die Akzeptanz der Bauernpartei unter der altbäuerlich dominierten ländlichen Bevölkerung Thüringens zu erhöhen. Deshalb schlug er vor, das Wort "Sowjetunion“ im Absatz über die freundschaftlichen Beziehungen zu streichen und durch „demokratische Kräfte“ zu ersetzen. Vor allem aber kritisierte er die herausgehobene Rolle der Neubauern im Programm. Goldenbaum erläuterte in ausführlichen, nicht protokollierten Worten, warum eine Änderung ausgeschlossen sei. Nur für die thüringische Ausgabe der Grundsätze und Statuten billigte man jedoch eine Änderung, die der landwirtschaftlichen Struktur Thüringens angepaßt war ${ }^{304}$. Diese Variante dürfte auch der Stärke der bürgerlichen Parteien in Thüringen geschuldet gewesen sein, die einer dezidierten Neubauernpartei das Wasser abgegraben hätten.

Erstmals standen auch die Statuten zur Debatte ${ }^{305}$. Als Änderung wurde vorgeschlagen, daß jeder Staatsbürger Mitglied der DBD werden könne. Das hätte die politische Reichweite der Bauernpartei erheblich erweitert. Mit der Durchführung der ersten Zonenkonferenz wollte man abwarten, bis die Zeitung der Bauernpartei erschienen sei ${ }^{306}$.

Nach diesen Beschlüssen der sich konstituierenden Bauernpartei griff die SED nachweislich, die SMAD höchstwahrscheinlich erneut in das Programm der Bauernpartei ein ${ }^{307}$. Obwohl der geschäftsführende Ausschuß der Bauernpartei noch am 11. Juli 1948 festgelegt hatte, für die Zonenkonferenz eine Mappe vorzubereiten, die die erste Nummer der künftigen Zeitung, die Statuten und die Grundsätze und Forderungen enthalten solle ${ }^{308}$, wurde auf der Zonenkonferenz nicht darüber diskutiert oder abgestimmt ${ }^{309}$. Über diese Vorgehensweise berichteten Mitarbeiter der SED-Abteilung Landwirtschaft an Paul Merker sehr beruhigt; bis zur endgültigen Verabschiedung von Programm und Statut auf dem 1. Parteitag

ten Variante bereits auftaucht, muß es sich um eine Variante handeln, die nach der Sitzung vom 28. Mai überarbeitet wurde.

303 ACDP VI-052-0141, Protokoll Zonenvorstandssitzung, 25. 6. 1948.

304 Ebd.; statt „Die Demokratische Bauernpartei Deutschlands steht offen für alle aufbauwilligen Bauern, vor allem aber für die vielen Neubauern“ genehmigte man für Thüringen die Formulierung „Die Demokratische Bauernpartei Deutschlands steht offen für alle aufbauwilligen Bauern sowie Neubauern“.

305 Man gab vor, daß die Statuten vor Genehmigung auf Landes- und Kreiskonferenzen debattiert werden sollten. Eine Frühfassung des Textes der Statuten konnte in den Akten nicht nachgewiesen werden.

306 ACDP VI-052-0141, Protokoll Zonenvorstandssitzung, 25. 6. 1948. Ursprünglich war für die Zonen- oder Parteikonferenz der 10. 7. 1948 vorgesehen, als späterer Termin dann der 17. 7. 1948.

307 In Thüringen vermuteten VdgB-Kreise, daß die Besatzungsmacht den Schutz des bäuerlichen Eigentums aus dem Programm gestrichen habe, und das Programm in enger Abstimmung von SED und SMAD entstanden sei. SAPMO NY 4090/507, Bl. 1, Schreiben der Abt. Werbung, Presse, Rundfunk des ZS der SED an Grotewohl, 30. 6. 1948.

308 ACDP VI-052-0519, Sitzung geschäftsführender Ausschuß, 11.7. 1948.

309 ACDP VI-052-0002, Protokoll der ersten Parteikonferenz, 16./17. 7. 1948. 
1949 habe man nun ausreichend Gelegenheit, einige Verbesserungen vorzunehmen, insbesondere bezüglich der Abgrenzung der aufzunehmenden Mitglieder ${ }^{310}$. Schon am 7. August 1948 bestätigte der Parteivorstand die Statuten in neuer Fassung 311.

Die unmittelbar nach der ersten Parteikonferenz im „Bauern-Echo“312 veröffentlichte Fassung des Programmes zeichnet sich durch die Diskreditierung sogenannter „Fachkräfte in den Verwaltungen“ aus. Man zielte damit auf Angehörige bürgerlicher Parteien sowie jene, die während des Nationalsozialismus als Funktionäre des Reichsnährstandsapparates eine Entscheidungsposition innegehabt hatten, und die in der SBZ aufgrund ihrer Fachkompetenz nicht ohne weiteres zu ersetzen waren. Dahinter stand auch das Motiv, das Selbstvertrauen der Neubauern gegenüber den eingesessenen altbäuerlichen Kreisen zu heben. Vehement polemisierte man auf DBD-Versammlungen gegen die professionell ausgebildete Gruppe ehemaliger Gutsverwalter oder Lehrherren ${ }^{313}$. Der berufliche Ausbildungsstand auf den großen landwirtschaftlichen Gütern Ostelbiens war höher als andernorts, auch die Arbeitsabläufe folgten betriebswirtschaftlich moderneren Gesichtspunkten ${ }^{314}$. Die SED verfolgte hier, gestützt auf die SMAD, eine Politik der teilweisen Entprofessionalisierung mit dem Ziel des Elitenaustauschs ${ }^{315}$. Die fachlich gebildete Führungsschicht sollte einer neuen Elite weichen, die sich vorrangig durch Nähe zu den Vorgaben von SED und SMAD und weniger durch Berufskompetenz auszeichnen mußte. Die antinazistische Stoßrichtung wurde dazu benutzt, die wirtschaftlich kontraproduktiven Folgen des Elitenaustauschs zu legitimieren.

Berücksichtigt man, daß die Grundsätze und Forderungen überhaupt nur einmal, am 18. Juli 1948, im „Bauern-Echo“ veröffentlicht wurden, ansonsten offenbar nicht als Massendruckware zugänglich waren, so präsentierte sich die DBD 1948 kaum als dezidierte Programmpartei ${ }^{316}$. Dies hat die Chancen zur Mitgliederrekrutierung eher verbessert als verschlechtert. Da der Mitgliederwerbung im Dorf meist ein Gespräch vorausging, konnte ein Parteiredner unabhängig vom Programm flexibel auf die jeweilige Situation vor Ort eingehen. Je nach Bedarf bot sich die Chance, stärker die Garantie des Privateigentums bis 100 ha landwirtschaftliche Nutzfläche zu betonen ${ }^{317}$, die in altbäuerlichen Gegenden mit Zuspruch rechnen durfte, oder in Neubauerndörfern die Hilfe für ebensolche hervorzukehren. Die Ausformulierung eines Programmes ist 1948 höchstwahr-

310 SAPMO DY 30 IV 2/2022/18, Bl. 62, Aktenvermerk für Paul Merker, 22. 7. 1948.

311 ACDP VI-052-0141, Protokoll PV, 7. 8. 1948.

312 „Bauern-Echo“, 18. 7. 1948.

313 Vgl. Wortbeiträge auf der Konferenz der Landesgründungsausschüsse in Brandenburg/ Havel, 28. 5. 1948, ACDP VI-052-0001/b, oder auf der ersten Parteikonferenz am 16./ 17. 7. 1948 in Schwerin, ACDP VI, unverz. Best. LV Mecklenburg.

$314 \mathrm{Vgl}$. Klemm, Agrarwissenschaften; Heß, Junker.

315 Vgl. mit Beispielen aus Brandenburg Bauerkämper, Loyale „Kade““.

316 MLHA LV VdgB Mecklenburg, 5, Sitzung des engeren Vorstandes des LV VdgB, 20. 9. 1948.

317 Über diese Größenordnung sprach Goldenbaum auf der ersten Parteikonferenz am 16./ 17. 7. 1948, ACDP VI-052-0002. 
scheinlich von der SED mit Unterstützung der SMAD verhindert worden. In der DBD arbeitete man allerdings auch nach der ersten Parteikonferenz an programmatischen Vorschlägen zu den Forderungen und Grundsätzen ${ }^{318}$.

Gegenüber der Zielgruppe der ehemaligen NSDAP-Mitglieder unter den Bauern legte die DBD besonderes Fingerspitzengefühl an den Tag. Einfache ehemalige Parteigenossen wollte man nicht durch penetrante Fragebögen von einem Parteieintritt abschrecken. Von Funktionsträgern in Landes- und Kreisvorständen verlangte man hingegen detaillierte Angaben zu vorherigen Parteimitgliedschaften; dabei dürften Informationen zum Engagement in der NSDAP und ihren Gliederungen im Mittelpunkt gestanden haben ${ }^{319}$.

In der Anfangszeit überschätzte man in der DBD die Reichweite der eigenen Forderungen maßlos. So äußerte Goldenbaum im August 1948, daß sich die Landwirtschaft in der SBZ durch ihr Festhalten am Ausbau des Anbauplanes und eine allmähliche Abkehr vom Ablieferungszwang auf einen freien Markt hin entwickle. In den Westzonen hingegen herrsche eine $Z$ wangswirtschaft, der immer mehr eine Agrarkrise drohe, da man sich vom Plananbau abkehre, aber einen Ablieferungszwang beibehalte ${ }^{320}$.

Neben diesen veröffentlichten Grundsätzen stehen programmatische Äußerungen der Gründergruppen. Sie zeigen die Motive derjenigen auf, die frühzeitig zur Bauernpartei stießen. Die verschiedenen Landesgründungsversammlungen griffen die nationalsozialistische Agrarpolitik und den Reichsnährstand an. Im Sinne dieses antifaschistischen Selbstverständnisses forderten Funktionäre wie Delegierte eine Fortführung der Entnazifizierung in den Verwaltungen und ein Realteilungsrecht. In Verkennung der eigenen Position wunderten sich viele darüber, warum die Bauernpartei noch nicht sämtliche Gebäude des Reichsnährstandes erhalten habe. Außerdem verlangte man gegen die Praxis der Handwerker vorzugehen, nur gegen naturale Kompensationen bei Bauern arbeiten zu wollen ${ }^{321}$. Welch überzogene Hoffnungen viele Gründungsmitglieder mit der neuen Partei verknüpften, und wie sehr sie das politische Gewicht der DBD verkannten, geht aus dem Sammelsurium an Forderungen hervor, die auf der ersten Parteikonferenz am 16./17. Juli 1948 vorgebracht wurden ${ }^{322}$. Ernst Rummel und Paul Reder reklamierten politische Schulungen für die Bauernschaft, der fachliche Part sollte der $\mathrm{VdgB}$ vorbehalten bleiben. Friedrich Martin mahnte eine Steuerreform und die Anpassung der Sozialabgaben an. Hoffmann kündigte für den LV Thüringen an, bald weitere Ergänzungen zu den „Forderungen und Grundsätzen“ einzureichen.

318 Vgl. Redebeitrag Hoffmanns, Thüringen, auf der 1. Parteikonferenz, ACDP VI, unverz. Best. LV Mecklenburg.

319 ACDP VI-052-0141, Protokoll Zonenvorstandssitzung, 25. 6. 1948. Ein entsprechender Fragebogen („Sind Sie in der Ausführung ihrer staatsbürgerlichen Rechte beschränkt?“) war offensichtlich nur für Funktionsträger gedacht.

320 ACDP VI, unverz. Best. LV Mecklenburg, Zonenvorstandssitzung (d.i. Parteivorstandssitzung) am 26. 8. 1948.

321 So Reder am 29.4. 1948 auf der Landesgründungsversammlung der DBD in Schwerin ACDP VI-052-0001/a.

322 Folgende Beispiele aus der Diskussion auf der 1. Parteikonferenz am 16./17. 7. 1948, ACDP VI, unverz. Best. LV Mecklenburg. 
Die programmatische Formierung war 1948 nach außen hin noch flexibel. Nur mit großer Mühe und unter direkter Einflußnahme von SED und höchstwahrscheinlich auch der SMAD verständigte man sich auf ein Minimalprogramm. Bei den Funktionären und Mitgliedern blieb jedoch der Eindruck zurück, das Programm mitgestalten zu können. Diese programmatische Offenheit hat die Attraktivität der DBD 1948 gesteigert.

\section{Reaktionen in SED, VdgB und den bürgerlichen Blockparteien}

Die Gründung von zwei neuen Blockparteien stärkte insgesamt die Position der SED, besonders im seit Anfang 1948 verschärften Vorgehen gegen die bürgerlichen Parteien. Eine Arena der Auseinandersetzung war der zentrale Block, der zu dieser Zeit paralysiert war. Dort kollidierten die Parteien wegen der zunehmenden Aushöhlung der verfassungsrechtlich garantierten Kompetenzen der Landtage durch zusätzliche legislative Rechte der DWK, die die Landesparlamente zu ausführenden Organen degradierten. Kommunal- und VdgB-Wahlen waren ursprünglich für das Jahr 1948 vorgesehen. Daher stritt man um die Wählergunst und um die Besetzung von Ministerposten ${ }^{323}$.

Auf der anderen Seite führte die Gründung der Bauernpartei der SED deutlich vor Augen, wie sehr sie in der Parteiarbeit auf dem Land bisher versagt hatte. Dies einzugestehen, fiel einer Reihe von SED-Funktionären schwer. Besonders in den SED-Landesverbänden waren die Reaktionen auf die DBD-Gründung keineswegs einhellig positiv. Es verwundert daher nicht, daß die SMAD mit der von der SED eingeforderten Unterstützung für die DBD unzufrieden war. Tjulpanow warf der SED im Herbst 1948 vor, sie fördere die neuen Parteien zu wenig324.

Die unmittelbaren Reaktionen in der SED auf die Gründung der DBD waren widersprüchlich. Zum einen mußte die SED auf Geheiß der SMAD die Gründung und Entwicklung personell und organisatorisch stützen, oft erst in Gang bringen $^{325}$. Häufig war es nötig, grundsätzliche Bedenken von Funktionären im Dorf auszuräumen und die auf lange Sicht erheblichen Vorteile zu erklären. $\mathrm{Zu}$ Beginn neigten Genossen auf dem Land oftmals dazu, die offiziellen Verlautbarungen zur Bauernpartei allzu wörtlich auszulegen und gingen dazu über, SED-Ortsgruppen kurzerhand aufzulösen und dafür eine DBD-Gruppe zu gründen ${ }^{326}$. Andererseits mußte die SED der Tendenz entgegenwirken, daß die neuen DBD-Mitglieder, ins-

323 Vgl. Rede Kurt Bürgers zur Parteiarbeit der SED, MLHA BPA Schwerin IV/2/1/27, Protokoll Landesvorstandssitzung SED, 24. 5. 1948, Bl. 29-32.

324 So berichtete Otto Buchwitz im Sekretariat der LL Sachsen. SStAD BPA SED LL A/784, Protokoll Sekretariatssitzung, 10.11.1948, Bl. 33.

325 Vgl. SStAD BPA SED LL A/864, Bl. 36, Auszug aus den Kreismonatsberichten September über die Gründung der Demokratischen Bauernpartei. MLHA BPA Schwerin IV/L/ 2/13/624, Bl. 26, Aktenvermerk 18. 6. 1948 über Bericht Adolf Gieses.

326 Über solche Vorgänge in Mecklenburg berichtet wiederholt Kurt Bürger. MLHA BPA Schwerin IV/2/1/27, Protokoll Landesvorstandssitzung SED, 24. 5. 1948, Bl. 29-32. 
besondere die Überwechsler aus den eigenen Reihen, zu Renegaten gestempelt wurden und eine Zusammenarbeit mit dem neuen Bündnispartner kaum möglich war ${ }^{327}$. Für die Verhältnisse in den Dörfern war es dabei nicht unerheblich, daß diese gestörte Beziehung oft über Jahrzehnte hinweg trotz Mahnungen der Parteileitungen unverändert blieb. Ungeachtet eines Programmes, das zweifellos die Ziele und Vorherrschaft der SED stützte, galt der Wechsel zur DBD als bewußte Entscheidung gegen die SED. Wenn SED-Funktionäre spürten, daß die Neulinge an den Machtverhältnissen vor Ort zum eigenen Nachteil rüttelten, schritten sie umgehend gegen die Gründung ein ${ }^{328}$.

Ulbricht äußerte sich kurz nach der Wismarer Aktivistentagung am 21. April 1948 vor den Innenministern zur Forderung nach einer Bauernpartei. Der Tenor seiner Ausführungen bewegte sich zwischen leichter Abschätzigkeit und der Zuversicht, die SED werde es schaffen, diese Bewegung so zu instruieren, daß sie sich „fortschrittlich“ entwickle; denn davon könnten die Sozialisten nur profitieren $^{329}$ :

„Diese Bauern wollen politisch auftreten. Bisher war ein Teil von ihnen in der SED, ein Teil in der CDU und wenige in der LDP organisiert. Wenn diese Bauern politisch auftreten wollen, um ihre Interessen besser vertreten zu können, können wir garnichts dagegen haben. Jedenfalls ist es besser, als wenn sie für die CDU stimmen. Aber ob im Ergebnis dieser Entwicklung diese Bauern wirklich fortschrittliche Interessen vertreten, hängt von Euch ab. Die objektiven Voraussetzungen sind vorhanden, daß wir die Bauern auf diesen Weg bringen können. Es gibt keine objektiven Hindernisse. Die Mecklenburger haben recht, wenn sie unterstrichen haben, daß es sich nur um eine Organisation handeln kann [zuerst: handelt], die unter Führung der kleinen Bauern steht."

Auf der Landesvorstandssitzung der SED Mecklenburg äußerte sich Kurt Bürger zur Bauernpartei: „Wir können und wollen nicht dagegen auftreten, weil wir die Verfassung hochhalten und uns nicht dem Vorwurf aussetzen wollen: Also doch SED-Diktatur, doch ein [Ein-]Parteiensystem. Wenn wir nicht gegen die Bauernpartei sind, so bedeutet das aber nicht, daß wir sie auf Kosten unserer Partei fördern. " ${ }^{330}$ Er bekräftigte diese Einschätzung für das weitere Vorgehen anläßlich der 10. Tagung des SED-Parteivorstandes am 12./13. Mai 1948331. Bürger gab als Strategie vor, gerade jetzt eine verstärkte Werbung für die SED auf dem Land durchzuführen. Dort wo die Bauernpartei aber im Ort bestehe und parteilose Mitglieder werbe, „haben unsere Genossen die verdammte Pflicht und Schuldig-

327 Ebd. So auch in Sachsen, SStAD BPA SED LL A/864, Bl. 31 f., Mitteilung Abt. LW an Sekretariat, 3. 11. 1948, und in Thüringen, ACDP VI-052-0141, Protokoll PV, 3. 12. 1948, Redebeitrag Hoffmann. MLHA BPA Schwerin IV/L/2/13/624, Bl. 42f., Beschwerde über das Verhalten der SED-Orts- und Betriebsgruppe Sternberg, 7. 7. 1950.

328 Ebd., Bl. 15, undatiert, aufgrund des Aktenzusammenhangs wahrscheinlich Juni/Juli 1948. Berichtauszüge zur Überprüfung der OG Neu-Penzlin.

329 SAPMO DY 30 IV 2/13/109, Rede Ulbrichts auf Innenministerkonferenz, 21. 4. 1948, Bl. 213-238, hier Bl. $234 \mathrm{f}$.

330 MLHA BPA Schwerin IV/2/1/27, Protokoll Landesvorstandssitzung SED, 24. 5. 1948, Rede Bürgers Bl. 29-32, Zitat Bl. 30.

331 Entscheidungen, S. 105-107. 
keit von vornherein in ein gutes Verhältnis zu diesen Leuten zu kommen" 332 . Im Idealfall sollte man nach Bürgers Worten die Gründung der Bauernpartei in erster Linie in solchen Dörfern durchführen, wo CDU und LDP noch nicht Fuß gefaßt hatten, zumal die bürgerlichen Parteien aufgrund eines neuen Befehls von Marschall Sokolowski zur Gründung eigener Ortsgruppen keine besondere Genehmigung mehr brauchten. Erst in zweiter Linie solle man DBD-Ortsgruppen in Dörfern mit hohem Anteil bürgerlicher Parteien ins Leben rufen, um ihnen Mitglieder abzujagen. Diese Taktik schlug oft fehl, weil die DBD-Werbung gerade unter den SED-Mitgliedern sehr erfolgreich war ${ }^{333}$. Deshalb ging man dazu über, die Gründung der DBD dort zu forcieren, wo bereits Grundeinheiten der bürgerlichen Parteien bestanden ${ }^{334}$. Gewisse persönliche Ressentiments gegenüber der Bauernpartei konnte Bürger trotz aller Bemühungen nicht verbergen. Diese rührten daher, daß er die Gründung der neuen Parteien in Kontinuität zu dem fehlgeschlagenen und von der SED wenig geliebten Ansinnen der SMAD sah, die SPD in der SBZ wieder zuzulassen ${ }^{335}$.

Erst am Tag nach der offiziellen Zulassung der DBD am 16. Juni 1948 veröffentlichte die SED im „Neuen Deutschland“ eine parteiamtliche Stellungnahme ${ }^{336}$. Die dort formulierte abwartende Haltung ist nicht verwunderlich, denn die SED mußte die Neuschöpfungen von dem Verdacht zu befreien suchen, eng in ihrem Schlepptau zu stehen. Bezeichnend ist die gezielte Abgrenzung von den Neulingen: Die SED begnüge sich nicht damit, neue Kräfte dem demokratischen Aufbau zuzuführen, nur sie allein verwandle ihre Mitglieder in Sozialisten.

Weitaus distanzierter gegenüber der Bauernpartei als in Mecklenburg verhielt sich der sächsische SED-Landesverband. Neben SED-Funktionären begegneten in Sachsen auch Industriearbeiter ${ }^{337}$ und einfache Mitglieder der DBD feindlich ${ }^{338}$. Dies hing auch mit der anderen Wirtschafts- und Sozialstruktur Sachsens zusammen, wo nur 2,5\% aller SED-Mitglieder zur Gruppe der Bauern zählten, aber über $50 \%$ zur Industriearbeiterschaft ${ }^{339}$. Im SED-Landessekretariat nahm

332 MLHA BPA Schwerin IV/2/1/27, Protokoll Landesvorstandssitzung SED, 24. 5. 1948, Rede Bürgers Bl. 29-32, hier Bl. 31.

333 Vgl. MLHA BPA Schwerin IV/L/2/13/624, Bl. 26, Aktenvermerk zu Giese, 18. 6. 1948, Bl. 27 Bericht eines Kreisrates zu Giese, 9. 6. 1948.

334 In Brandenburg, Mecklenburg und Sachsen wurde zumindest 1948 der Einbruch in das Rekrutierungsfeld der bürgerlichen Parteien vehement versucht. Reinert vermutet, daß die Gründung der DBD in Brandenburg vorrangig in Orten mit hoher Präsenz der bürgerlichen Blockparteien erfolgte. Reinert, Parteien, S. 125; siehe für Mecklenburg MLHA BPA Schwerin IV/L/2/13/624, Bl. 27, Bericht eines Kreisrates zu Giese, 9. 6. 1948; für Sachsen vgl. SStAD BPA SED LL A/864, Bl. 31 f., Mitteilung Abt. LW an Sekretariat, 3. 11.1948.

335 Vgl. Bürger in MLHA BPA Schwerin IV/2/1/27, Protokoll Landesvorstandssitzung SED, 24. 5. 1948, Bl. 29.

336 Neues Deutschland, 17.6. 1948.

337 So ein Sonderinformationsbericht des LV der SED Sachsen am 13. 9. 1948, SStAD BPA SED LL A/864, Bl. 41-45, hier Bl. $41 \mathrm{f}$.

338 Vgl. z. B. Diskussion im Sekretariat LV SED Sachsen, SStAD BPA SED LL A/782, B1. 83, Protokoll Sekretariat, 22. 4. 1948.

339 Entscheidungen, Tabelle 8, soziale Zusammensetzung der SED in den einzelnen Ländern 1948. 
man die DBD-Gründung zum Anlaß, an die abschreckenden Beispiele von Bauernparteien in den osteuropäischen Nachbarstaaten zu erinnern ${ }^{340}$. Diese sammelten dort vielfach gegnerische Kräfte und versuchten, kommunistische Positionen zu unterlaufen. Erst nach Hilferufen der DBD und Aufforderungen der SMA verpflichtete sich die sächsische SED im Herbst 1948 zu massiverer Unterstützung für den Aufbau des DBD-Landesverbandes ${ }^{341}$. Absichtlich zeichneten die Berichte der Abteilung Landwirtschaft der SED Sachsens, die nach Berlin gingen, ein positiveres Bild über die Entwicklung der DBD als die DBD-interne, hier zuverlässigere Berichterstattung. Letzterer zufolge mußte Anfang November eine "enge Zusammenarbeit und ständige Verbindung " mit einer Reihe von Stellen erst hergestellt werden. Dies war auch auf Versäumnisse der SED zurückzuführen ${ }^{342}$.

Die SED beschloß ihrerseits auf der 10. Parteivorstands-Tagung im Mai 1948, die eigene Mitgliederwerbung zu verstärken ${ }^{343}$. Im Unterschied zur Rekrutierungspraxis der DBD fällt dabei auf, wie sehr die SED im Dorf auf in jeder Hinsicht „vorbildliche“ Landarbeiter, Bauern, Dorflehrer und parteilose Funktionäre der VdgB zielte. Überschneidungen mit der Klientel der Bauernpartei gab es besonders bei den Funktionären der VdgB. Hingegen hatte die SED auf dem Weg zur "Partei Neuen Typs" wenig Interesse an jenen, die sich in einer wirtschaftlichen Notlage und ungerecht behandelt sahen. Umgekehrt strebten diese kaum nach einer Mitgliedschaft in einer ideologisch geschulten Kaderpartei. Hierin lagen Chancen für die DBD.

Die VdgB befand sich hinsichtlich einer offiziellen Stellungnahme zur Bauernpartei in einer Zwickmühle ${ }^{344}$. Da die VdgB in der publizierten Version der Gründungsgeschichte der Bauernpartei ${ }^{345}$ eine tragende Rolle spielte, galt sie in der öffentlichen Meinung zumindest als Mitbegründerin. Tatsächlich aber war sie sowohl beim Entschluß zur Gründung als auch bei den näheren Planungen völlig übergangen worden. In der Gunst um die ländliche Bevölkerung mußten VdgB und DBD jedoch weitaus stärker konkurrieren als DBD und SED. Daran änderte auch der fast zeitgleiche Beschluß der DWK, der VdgB die gesamte Wirtschaftsberatung alleinverantwortlich zu übertragen, nichts Grundsätzliches ${ }^{346}$. Die DBD hingegen erhielt den bedeutenderen Part als politische Repräsentation. Sie wurde

340 SStAD BPA SED LL A/782, Protokoll Sekretariat, 22. 4. 1948, BI. 80-86.

341 Die SMA Sachsen forderte die Landes-SED bei einer Aussprache am 9.6. 1948 auf, der DBD mehr Aufmerksamkeit zu schenken, Bericht Buchwitz im Landessekretariat, 11. 6. 1948, SStAD BPA SED LL A/783, Bl. 24.

342 SStAD BPA SED LL A/864, Bl. 33 f., Abschrift Vorschläge des LV der DBD Sachsen zur Verbesserung der Lage der DBD im Lande Sachsen, 2. 11. 1948.

343 Entscheidungen, S. $117 \mathrm{f}$.

344 Aufgrund von Entnahmen der VdgB-Nachfolgeorganisationen 1990 waren die Akten zum Zeitpunkt der Benutzung unvollständig und erst vorläufig sortiert. Daher ist die Aktenbasis zu diesem Punkt eingeschränkt.

345 Vgl. die Veröffentlichungen über die Gründungsschritte in „Der Freie Bauer“, immerhin war der Gründungsaufruf dort abgedruckt worden.

346 Diese Kompetenz war der VdgB am 28.4., also vor der Landesgründungsversammlung der DBD in Schwerin am 29.4., eingeräumt worden. VO vom 28. 4. 1948, in: ZVOBl. 1948 I, Nr. 15. 
im August 1948 in den Block aufgenommen, was der $\mathrm{VdgB}$ wiederholt verweigert worden war und mit der Aufnahme der DBD nun gänzlich verspielt schien.

Öffentlich mußte die VdgB eine Stellungnahme abgeben, die mit dem Gründungsmythos konform ging. Diese Pflicht erfüllte sie am 6. Juni, nach der Konstituierung des Zonenausschusses der DBD am 28. Mai, noch bevor Programm und Statut der Bauernpartei publiziert vorlagen ${ }^{347}$. Darin gestand die VdgB der Bauernschaft das Recht auf eine politische Vertretung zu und bot eine Zusammenarbeit an. Gestrichen wurde eine Passage der ursprünglichen Fassung vom 31. Mai 1948 , in der unter anderem die Hoffnung geäußert wurde, die Bauernpartei möge sich zu einer starken demokratischen Partei entwickeln. Die VdgB betonte damit ihren überparteilichen Charakter sowie die Absicht, für alle wirtschaftlichen Belange der Bauern einzutreten.

In den VdgB-Führungsgremien herrschte keine einmütig positive Sicht gegenüber der Bauernpartei. Diese von Anfang an bestehende Trübung des Verhältnisses scheint bis in die sechziger Jahre immer wieder durch. Bereits auf der vorangegangenen Sitzung des Zentralvorstandes der VdgB am 21. Mai 1948 sollte eine Stellungnahme zur DBD erarbeitet werden. Das dort geäußerte Meinungsspektrum spiegelt die Einstellungen wider, die unter den VdgB-Kreistagsabgeordneten und SED-Mitgliedern dominierten ${ }^{348}$. Lediglich der 1 . Sekretär der VdgB, Kurt Vieweg, begrüßte die Gründung uneingeschränkt ${ }^{349}$. Otto Körting, ein ehemaliges SPD-Mitglied und offenbar weniger über die Hintergründe im Bilde als Vieweg, lehnte die Parteigründung eigentlich ab; da man jedoch nichts dagegen unternehmen könne und um keine Einflußmöglichkeiten zu versäumen, plädierte er dafür, sofort auf die Gestaltung der DBD einzuwirken. Anton Jadasch erwartete kaum etwas von der Bauernpartei, deren Vertreter vom parlamentarischen System zuviel erhoffen würden; letztlich sei die Bauernschaft außerstande, ihre Beschlüsse, auch wenn sie auf dem Lande mehrheitlich gefaßt wurden, insgesamt durchzusetzen. Angesichts der damals labilen Lage der VdgB hielt Reder die Gründung gar für bedenklich; Brauer warnte vor einer drohenden „Zersplitterung des Bauerntums“, weshalb die VdgB eine machtvolle berufsständische Organisation bilden müsse. Rudolf Albrecht, DBD-Gründer in Brandenburg, blieb im Hintergrund und schied auf dieser Sitzung angeblich aufgrund der neuen Arbeitslast aus dem Gremium aus. Unter Umständen reagierte er damit auf Intrigen in-

347 Entschließung der 6. Vorstandssitzung des ZVdgB, 31. 5. 1948 (eine Stimmenthaltung von Jadasch), SStAD LV VdgB Sachsen, 88 [Abschrift]. Der Wortlaut wurde leicht abgeändert in „Der Freie Bauer“, 6.6. 1948, veröffentlicht, abgedruckt bei Wernet, Rolle, S. 261; zu Streichungen vgl. MLHA LV VdgB Mecklenburg, 48, Mitteilung der Pressestelle des DBS, 31. 5. 1948, mit Korrekturen.

348 Vgl. SStAD LV VdgB Sachsen, 88, Niederschrift Sitzung der VdgB-Kreistagsabgeordneten am 27. 4. 1948 und Leserzuschriften an die Zeitung "Der freie Bauer“; Wernet-Tietz, Bauernverband, S. 114.

349 SStAD LV VdgB Sachsen, 88, Abschrift des Protokolls der 5. Vorstandssitzung der ZVdgB am 21.5. 1948. Lt. Körting sollte jedes Vorstandsmitglied beantworten, ob „sich eine Aufgabentrennung zwischen einer Bauernpartei und der VdgB in wirtschaftliche und politische Aufgaben konsequent durchführen" lasse, ob man zu ihr ein besonderes Verhältnis pflegen könne, und ob die VdgB die Bildung einer Bauernpartei aktiv unterstützen solle. 
nerhalb des Zentralvorstandes der VdgB gegen ihn ${ }^{350}$. Öffentlich begrüßte die VdgB-Führung die Bauernpartei, intern verhielt sich der Zentralvorstand sehr reserviert. Der VdgB blieb gar keine andere Wahl, als das beste aus der vereinbarten Tätigkeitsabgrenzung zu machen.

Die Gründung der Bauernpartei in Mecklenburg mußte von der VdgB auf Anweisung der sowjetischen Kommandanturen personell wie finanziell mitgetragen werden. Der VdgB-Landesverband war verstimmt gegenüber der DBD, der Landessekretär Hans Mirau unterminierte die Zusammenarbeit ${ }^{351}$. Am 20. September 1948 zitierte die VdgB den DBD-Landesvorsitzenden Franz Pilarski zu sich. Er sollte zu Ereignissen in den Kreisen Stellung nehmen, wonach Bauernparteiler die VdgB als Großbauernorganisation verunglimpfen würden. Mirau schärfte Pilarski ein, es sei an der Zeit, daß "der Vorstand der DBD einmal klare Linien herausbringt, wie sich die Vertreter der DBD zu verhalten haben “352. Das einstmals gute Verhältnis zwischen Mirau und Goldenbaum war infolge der Parteigründung getrübt. Dazu trug die Arroganz bei, mit der der frischgebackene Parteivorsitzende dem früheren Weggenossen begegnete ${ }^{353}$. Für den weiteren Aufbau der DBD war daher von seiten der VdgB-Landesverbände kaum Hilfe zu erwarten. Es gelang der DBD nicht, sich von Anfang an in den Schlüsselpositionen der VdgB zu verankern. Die SED wollte diesen Einfluß von Beginn an kleinhalten und trieb parallel zur DBD-Gründung die Gleichschaltung der Massenorganisation voran.

Die Parteispitzen von CDU und LDP reagierten auf die Bildung der neuen Parteien umgehend mit öffentlichen Stellungnahmen. Während die LDP beide schnell und eindeutig ablehnte ${ }^{354}$, reagierte die CDU auf die Bauernpartei als potentielle Konkurrenz zunächst gelassen, weil sie deren Erfolgsaussichten gering einschätzte ${ }^{355}$. Aus CDU-Sicht war die NDPD im Sommer 1948 der gefährlichere Gegner ${ }^{356}$. Die bürgerlichen Parteien in Sachsen ließen die SED wissen, daß sie

350 Indizien dafür in SAPMO VdgB 136, Schreiben Viewegs, 13. 9. 1948. Vgl. zur Überforderung Albrechts auch Wernet, Rolle, S. 261, streng vertraulicher Bericht über die personelle Zusammensetzung des Zonenausschusses der DBD Juni 1948 an Dahlem und Gniffke.

351 Lt. Sitzungsprotokollen des VdgB-Landesvorstands von April bis Juni war die Organisation des Landesverbandes erst am 28.4. 1948 neuerlich geregelt worden. Wehmer hatte den Landesvorsitz übernommen. Obwohl Goldenbaum auf den LV-Sitzungen vom 23. 4. und 19.6. 1948 anwesend war, enthalten die Protokolle keine Aussagen zur DBD; MLHA LV VdgB Mecklenburg, 5. Auffälligerweise sind weitere Protokolle aus dieser Zeit nicht überliefert. Zu Mirau siehe Beiträge Pilarskis in ACDP VI-052-0141, Protokoll PV, 26. 8. 1948.

352 MLHA LV VdgB Mecklenburg, 5, Sitzung des engeren Vorstandes des LV VdgB, 20. 9. 1948.

353 Vgl. ACDP VI-052-0141, Protokoll PV, 26. 8. 1948.

354 Vgl. die zahlreichen Pressestimmen, z.B. im LDP-Organ „Der Morgen“, 4. 5. 1948, Hamann in „Thüringische Landeszeitung“, 14. 5. 1948, LDP-Informationen, 1948, Nr. 8 , S. 155, Nr. 14, S. 259.

355 Pressestimmen der CDU in „Union teilt mit“, 1948, Nr. 9, S. 3, Nr. 5, S. 4 f. SStAD BPA SED LL A/864, SED LV Information 13. 9. 1948, Bl. 43. Vgl. Wernet-Tietz, Bauernverband, S. 115.

356 „Union teilt mit“, 1948, Nr. 5, S. 5. 
sofort gegen die neuen Parteien vorgehen würden, sobald die Bauernpartei sozialistische Tendenzen verfolge ${ }^{357}$.

Für die Bestimmung des künftigen Verhältnisses spielte es auch eine Rolle, wie sich die DBD ihrerseits auf der ersten größeren Veranstaltung, der Parteikonferenz am 16./17. Juli 1948, gegenüber den anderen Blockparteien präsentierte. Dort hatte sich Goldenbaum unmittelbarer Kritik an den Bürgerlichen enthalten. Er warnte sogar diejenigen Parteikollegen, die von Behinderungen seitens der CDU und LDP berichteten, vor kleinlichem Übermut der Unerfahrenen gegenüber den bereits etablierten Parteien ${ }^{358}$. Ein Jahr später allerdings nahm die DBDParteiführung sehr übel, daß zu ihrem 1. Parteitag 1949 in Mühlhausen keine CDU-Vertreter erschienen waren. Jetzt attackierte Goldenbaum die CDU; auch warf er Bischof Otto Dibelius vor, schon während der Zeit des Nationalsozialismus „oben geschwommen“ zu sein 359 .

Die LDP wertete die Bauernpartei 1948 als „Interessenhaufen ohne echten politischen Gehalt “ 360 und betrachtete ihre Gründung als ein weiteres Steinchen in der politischen Auseinandersetzung. Im Vergleich zu den gewichtigeren Problemen der LDP im Sommer 1948 - sie kämpfte gegen SED und SMAD um ihr Überleben ${ }^{361}$ - war die Gründung von NDPD und DBD sicherlich von untergeordneter Bedeutung.

Die bürgerlichen Parteien argumentierten übereinstimmend, daß einer Interessenpartei, die sich noch dazu berufsständisch definiere, kein politisches Gewicht zukommen werde ${ }^{362}$. Sie hielten sich selbst für die bessere Alternative und bauten ganz auf die entsprechende Entscheidung der ländlichen Welt. In ihren Begründungen häufen sich anthropologische Stereotypen, etwa über das „Wesen der Bauern“. Nirgends sprachen sie die wirtschaftlichen Nöte der bäuerlichen Bevölkerung und die besonders schwierige Situation der Neubauern an; nirgends griffen sie die Unterrepräsentation der Bauern in Parlamenten auf - also jene Argumente, die die Bauernpartei wiederum für ihre Gründung ins Feld führte. Nach Auffassung der LDP suche keine andere Partei als sie, „agrarpolitische Ziele zu verwirklichen, die der Mentalität des Bauern mehr entsprechen und den Fortbestand und die Förderung seiner Wirtschaft mehr garantieren können!“363 Die CDU-Führung vertraute auf ihre bäuerlichen Wähler, die sich für die CDU aufgrund „sittlicher" und weltanschaulicher Erwägungen entscheiden würden und kleinliche Interessen außer acht ließen ${ }^{364}$. Bauerntum allein sei keine Weltanschauung ${ }^{365}$. Otto Nuschke machte 1948 kein Hehl daraus, daß er es für besser gehalten hätte, statt der Neugründungen den Entscheidungs- und Bewegungs-

357 SStAD BPA SED LL A/783, Sekretariatssitzung, 16. 8. 1948, Bl. 223.

358 Vgl. ACDP VI-052-0002, Protokoll der 1. Parteikonferenz.

359 Protokoll des 1. PT der DBD 1949, Ausführungen Goldenbaums, S. 59-62.

360 „Der Morgen“, 4. 5. 1948.

361 Sommer, Liberal-Demokratische Partei Deutschlands, S. 50-52.

362 "Der Morgen“, 4. 5. 1948, „Union teilt mit“, 1948, Nr. 5, S. 5.

363 "Der Morgen“, 18. 7. 1948.

364 "Union teilt mit“, 1948, Nr. 7, S. 12.

365 Ebd., 1948, Nr. 5, S. 5. Walter Rücker, „Wozu Bauernpartei?“, in: Ebd., August 1949. 
spielraum der bestehenden Parteien zu vergrößern ${ }^{366}$. Tatsächlich eröffneten sich nur einer Partei mehr Handlungsoptionen: der SED.

Auf der Kreis- und Gemeindeebene wurde die DBD-Gründung von den bürgerlichen Parteien oftmals, wie z.B. im November 1948 in Sachsen, als reine Zweckgründung eingestuft "mit dem Ziel, eine Schwächung der LDP und CDU zu erreichen, die auf Veranlassung der SED geschehen " sei ${ }^{367}$. Bis dahin waren der DBD Sachsens schon gewisse Einbrüche in die Reihen der „Bürgerlichen“ gelungen. Dabei konnte sie sich zuweilen auf übergetretene Funktionäre der LDP und CDU stützen ${ }^{368}$. Im Einzelfall ist schwer zu klären, ob nicht LDP- und CDU-Mitglieder versuchten, rechtzeitig Einfluß in den Ortsgruppen der DBD zu gewinnen, oder ob sich die Ortsgruppen der bürgerlichen Parteien und die DBD gemeinsam gegen die SED verbündeten. Beide Varianten sind belegt. In Brandenburg suchten CDU und LDP anfangs in der DBD eine Verbündete gegen die SED. So profilierte sich die VdgB dort bei den Wahlen 1946 in Gegnerschaft zur SED ${ }^{369}$; dies mag die Hoffnungen der „Bürgerlichen“ begünstigt haben, denn nach außen hin war die VdgB die Keimzelle der DBD-Gründung. Rudolf Albrecht berichtete von DBD-Versammlungen in Gemeinden, wo sich CDU- und LDP-Mitglieder engagierten 370 . Insgesamt jedoch versuchten Mitglieder bürgerlicher Parteien, den Parteiaufbau der DBD zu erschweren ${ }^{371}$.

Ab dem Spätsommer 1948 verhärteten sich die Fronten zwischen den Blockparteien ganz deutlich. CDU und LDP mußten zusehen, wie NDPD und DBD auf ihre Kosten im politischen System etabliert wurden. Die Bauernpartei wurde am 5. August zusammen mit dem FDGB in den zentralen Block aufgenommen, die NDPD folgte am 7. September ${ }^{372}$. CDU und LDP konnten sich dagegen kaum wehren, hatten sie zuvor doch erfolgreich die Aufnahme von Massenorganisationen mit der Begründung zu verhindern gesucht, es handle sich um keine Parteien. Am 5. August 1948 trat der zentrale Block wieder zusammen, der seit dem 17. Februar nicht mehr getagt hatte. Er konnte nun weiter zur Durchsetzung der führenden Rolle der SED instrumentalisiert werden und den Parlamentarismus weiter aushöhlen. Außerdem erreichte die Bauernpartei noch im Juli 1948 bei der SMAD die Verschiebung der für Herbst des Jahres vorgesehenen Kommunalwahlen und deren künftige Zusammenlegung mit den für 1949 anstehenden Kreis- und Landtagswahlen ${ }^{373}$. Auch die VdgB-Wahlen wurden ins Jahr 1949 vertagt. In diesem Jahr fand sich bekanntlich mit der Staatsgründung ein weiterer Anlaß, um Kommunal-, Kreis- und Landtagswahlen auf 1950 zu verlegen.

366 Ebd., Mai 1948, S. 4. Vgl. auch Richter, Ost-CDU, S. 105.

367 SStAD BPA SED LL A/864, Sonderinformationsberichte des LV der SED Sachsen, 13. 9. 1948, Bl. 41-45, hier Bl. 41.

368 Ebd. Abt. LW an Sekretariat Dresden, 3. 11. 1948, Bl. 31.

369 Siehe oben S. 61.

370 ACDP VI-052-0141, Protokoll PV, 26. 8. 1948.

371 Vgl. Beispiele in ACDP VI-052-0141, Protokolle PV-Sitzungen 7. 8., 26. 8. und 11. 11. 1948.

372 Vgl. Suckut, Blockpolitik, S. $251 \mathrm{ff}$. und S. $287 \mathrm{ff}$.

373 Vgl. Beschlußantrag dazu auf der ersten Parteikonferenz am 16./17. 7.1948 gefaßt. ACDP VI-052-0002. 
Da die SMAD parallel zu den Neugründungen offensichtlich den anderen Parteien erlaubte, ungehindert Ortsgruppen zu gründen, fürchtete die CDU-Führung die Bauernpartei im Jahr 1948 kaum als Konkurrentin ${ }^{374}$. Denn im Unterschied zur DBD verfügte die CDU bereits über einen funktionierenden Organisationsapparat, den sie nun zur Mitgliederwerbung einsetzen konnte; auch war sie auf dem Land vergleichsweise stärker verankert als die LDP. Ihr Einfluß war seit Jahresbeginn besonders unter den Altbauern angewachsen ${ }^{375}$. In der LDP stellten die sogenannten „freien Bauern“ im Jahr 1952 zwar keinen unerheblichen Mitgliederanteil ${ }^{376}$, der Prozentsatz der Behörden-Angestellten, vorrangig in Städten ansässig, bestimmte jedoch das Gesicht der Partei.

Die freiere Zulassung von Grundeinheiten hatte eine weitere Signalwirkung: Sie bedeutete für CDU und LDP, daß sich ihre Wahlchancen für die Kommunalwahlen 1948 erheblich verbessern würden, schienen doch viele Nachteile der restriktiven Praxis beim Urnengang 1946 überwunden. Bedenkt man, mit welchem Aufwand die SMAD 1946 den Wahlsieg der SED garantieren wollte, so steht ihr Vorgehen 1948 in Kontinuität dazu: Zwar gestattete sie einerseits den Blockparteien den Ausbau der Basis, andererseits aber installierte sie zwei neue Blockparteien, die die Macht der SED zunehmend abstützten. Mit der Durchführung von Einheitslistenwahlen 1950 verloren die Blockparteien ihre theoretische Chance auf eine politische Mehrheit. Sitze wurden nach vorher festgelegtem Schlüssel vergeben, tatsächliche Stimmengewinne waren für die Bestimmung der politischen Mitsprache bedeutungslos geworden.

\section{Frühe Resonanz der Bauernpartei bei der Landbevölkerung}

Direkte Äußerungen der Landbevölkerung zur Gründung der Bauernpartei sind kaum zu ermitteln. Die Ausführungen stützen sich daher vornehmlich auf mittelbare Zeugnisse. Hier interessiert zunächst die Resonanz auf die Parteigründung. Unter Resonanz werden im folgenden öffentliche Äußerungen und politische Handlungen verstanden, die eindeutig mit der Bauernpartei in Verbindung stehen, wie z.B. ein Parteieintritt oder der Besuch von Parteiversammlungen.

Viele DBD-Gründungsfunktionäre berichteten von einer Euphorie unter der Landbevölkerung nach dem Entstehen der Partei. Obgleich dies sicherlich nur für einen kleinen Teil zutrifft, bestärkte dieses Phänomen das Selbstverständnis und die Legitimation der Bauernpartei. Sehr nahe am Geschehen - dafür sprechen die erzählerischen und emotionalen Details - stand ein Bericht aus dem Kreis Anklam über die Landesgründungsversammlung in Schwerin am 29. April 1948: Der Be-

374 Siehe oben, Kap. II.1., S. 78.

375 Zum Anstieg der bäuerlichen Mitglieder der CDU vgl. Dowidat, Veränderung, S. $526 \mathrm{f}$. Der Anteil der bäuerlichen Mitglieder in Mecklenburg stieg zwischen Juni 1948 und Juni 1949 von 27443 (=18,6\% der Gesamtmitglieder dort) auf 29019 (=19,6\%). In Sachsen dagegen fiel deren Zahl von $72992(=12,7 \%)$ auf $70092(=12,4 \%)$.

376 Statistik zur Sozialstruktur der LDPD. Sommer, Liberal-Demokratische Partei, S. 312. 
richterstatter erfuhr von der Gründung zusammen mit einer Gruppe von Bauern auf dem Feld und „die Nachricht schlug ein. Wir mussten feststellen, daß die Anwesenden gar nicht recht wußten, ob sie sich freuen sollten, [...] denn es wurden Zweifel laut, ob es auch wirklich an dem sein wird, daß endlich auch der Bauer den Platz einnehmen soll, der ihm im Leben des Volkes gebührt." Früher habe man über „den Bauern immer geringschätzig die Nase gerümpft“, man habe ihn als „Mist-Bauern“ abqualifiziert, heute jedoch habe er "so große Pflichten, die er ehrlich und treu erfüllt". Weiter sprach er von tiefem Mißtrauen der Interessierten, die befürchteten, „daß dieser kleine Anlaß dieses ersten Aufkeimens einer neuen Tat vielleicht von bürokratischen Regierungsstellen unterdrückt wird oder wieder im Sande verläuft" 377 .

Da bis Juli/August 1948 die Ankündigungen zur Bauernpartei keine oder nur vage programmatische Aussagen enthielten, wurde in der Partei und deren Umfeld besonders darüber diskutiert, für welchen Teil der ländlichen Bevölkerung sie offenstehen sollte. So ist es nicht verwunderlich, daß auf Gründungsversammlungen der DBD soziale Differenzierungen innerhalb der Bauernschaft bewußt vermieden wurden, um die Resonanz nicht von vornherein auf eine bestimmte Gruppe, etwa die Klein- und Neubauern zu verengen. Angehörige verschiedener politischer Lager fühlten sich in der Anfangszeit von der Bauernpartei angesprochen. Während ein Vertreter aus Rügen die Leitung der Partei für die „alten Sozialisten" der SPD reklamierte, forderte ein parteiloser Bauer aus Bergfeld/Kreis Güstrow, einheitlich nur noch von „deutschen Bauern“ zu sprechen, nicht von Alt- und Neubauern ${ }^{378}$.

DBD-interne Berichte, die pauschal über die Resonanz „der Bauern“ informieren, erschweren eine schichtspezifische Zuordnung der unterschiedlichen Reaktionen der ländlichen Bevölkerung ${ }^{379}$. Als Tenor kristallisiert sich auf der Basis verschiedenster Quellen heraus, daß die Gründung einer Bauernpartei von der ländlichen Bevölkerung überwiegend positiv und interessiert aufgenommen wurde, wenngleich mit abwartendem Mißtrauen durchmischt. Diese pauschale Aussage bedarf näherer Auffächerung.

In Mecklenburg ist eine erheblich aufgeschlossenere Haltung zur DBD unter der Bauernschaft festzustellen als vergleichsweise in Sachsen ${ }^{380}$. Der Grund hierfür liegt zunächst im Gewicht der Initialzündung und im schlichtweg besser organisierten Aufbau der Partei381. Außerdem war bis August 1948 Schwerin bzw. Mecklenburg die politische Drehscheibe der gesamten DBD. Die schlechtere Re-

377 ACDP VI-052-0001/a, Protokoll Landesgründungsversammlung in Schwerin, 29.4. 1948.

378 Ebd., Redebeiträge Ernst Treß und Arnim Dietz.

$379 \mathrm{Vgl}$. etwa die rhetorisch vereinheitlichten Berichte der Delegationen aus allen Kreisen Mecklenburgs auf der Landesgründungsversammlung in Schwerin am 29.4. 1948, ebd.

$380 \mathrm{Vgl}$. ebd. sowie ACDP VI-052-0141, Protokoll PV, 26. 8. 1948. SStAD BPA SED LL A/864, Sonderinformationsberichte des LV der SED Sachsen, 13. 9. 1948, Bl. 41-45.

381 Zwar liegen für Mecklenburg mehr DBD-interne Berichte vor, denen man im Vergleich zu sächsischen SED-Berichten eine positivere Aussageabsicht unterstellen muß. Die für Sachsen belegten kritischen Resonanzen sind grundsätzlich auch in Mecklenburg nachweisbar, allerdings in deutlich geringerem Ausmaß und weniger vehement. 
sonanz in Sachsen dürfte ihrerseits zur Verzögerung der Parteibildung in Sachsen beigetragen haben. Unter der sächsischen Bevölkerung lösten die Neugründungen heftige Diskussionen aus. Die dortige SED berichtete, daß sich die Einwohner zwar weitaus stärker für die Bauernpartei als für die NDPD interessierten ${ }^{382}$. Insgesamt lehnten sie aber unabhängig von einer Parteizugehörigkeit die Neugründungen mit dem Argument ab, daß seit der Weimarer Republik bekannt sei, wohin eine solche Aufsplitterung des Parteiensystems führe. Vor allem SED-Mitglieder dächten in diesem Sinne. Betriebsarbeiter sähen in der DBD eine Standesund Wirtschaftspartei und fürchteten ,in Verkennung der gegenwärtigen Bauernpolitik [!][...] eine weitere Stärkung der Macht der Bauern " 383 und eine Verschärfung des Stadt-Land-Gegensatzes. Einer separaten Partei für die Bauern hielten sie entgegen, daß die VdgB als Organisation schon genug sei. Der Berichterstatter schloß sich der Sicht der SED-Arbeiterschaft an und unterstrich den Führungsanspruch der SED. In bürgerlichen Kreisen unterstellte man, so der Bericht weiter, den neuen Parteien zusätzlich die Absicht, dadurch LDP und CDU schwächen zu wollen. Da diese in Sachsen deutlich mehr Gewicht besaßen als in Mecklenburg, hat dieses Machtverhältnis auf die gedämpfte Aufnahme der DBD in ländlichen Bevölkerungskreisen zurückgewirkt.

Das Interesse für die Bauernpartei überwog zunächst bei denjenigen, die an die Existenz einer solchen Partei politische Erwartungen und wirtschaftliche Vorteile knüpften ${ }^{384}$. Darunter waren zum einen Neubauern, die auf eine Verbesserung ihrer wirtschaftlichen Misere hofften ${ }^{385}$, und sich gleichzeitig nicht völlig politisch abstinent verhielten. Für Sachsen-Anhalt betonte der Landesvorsitzende Richter, daß Neubauern aufgrund von "Hemmungen“ - damit meinte er Minderwertigkeitsgefühle, geschürt durch eine traditionelle Umgebung - vor einem Engagement in der DBD zurückschreckten ${ }^{386}$. Ruddat, der sich als erfahrener Parlamentarier aus Ostpreußen ausgab, warf den Einheimischen unter den mecklenburgischen Neubauern Untertanenmentalität vor, sie würden „immer noch warten auf das Kommen ihres Herrn“"387. Bei den „Umsiedlern“ unter ihnen dominiere dagegen die Hoffnung auf Rückkehr in die Heimat.

Nur ein geringer Teil der Altbauern Mecklenburgs zeigte von Anfang an Interesse und politisches Engagement für die Bauernpartei ${ }^{388}$. Sofern bei ihnen eine positive Resonanz vorlag, dauerte sie oft nur solange an, wie die programmatische

382 SStAD BPA SED LL A/864, Sonderinformationsberichte des LV der SED Sachsen, 13. 9. 1948, Bl. 41-45.

383 Ebd., hier Bl. 42.

384 Vgl. SAPMO NY 4090/507, Schreiben der Abt. Werbung, Presse, Rundfunk des ZK der SED an Grotewohl, 30.6. 1948. Die Einstellung zur Bauernpartei in Thüringen sei beherrscht vom Mißtrauen der VdgB. Die SED sei mit bisheriger VdgB Thüringens nicht zum Ziel gekommen.

385 ACDP VI-052-0001/a, Protokoll Landesgründungsversammlung in Schwerin, 29.4. 1948, Redebeitrag Schroer und Pilarski.

386 ACDP VI-052-0141, Protokoll PV, 7. 8. 1948.

387 ACDP VI-052-0001/a, Protokoll Landesgründungsversammlung in Schwerin, 29.4. 1948, Beitrag Ruddat.

388 Aufschlußreich dazu der später redigierte Beitrag Pilarskis auf der Landesgründungsversammlung. 
Ausgestaltung der Bauernpartei zugunsten der Neubauern und der politischen Linie der SED noch nicht vollzogen war; es sei denn, altbäuerliche Ortsvorsitzende konnten sich abgeschottet von den Parteileitungen in ihren Dörfern einen Freiraum sichern. Der Kreis Parchim scheint innerhalb Mecklenburgs ein Sonderfall zu sein. Hier traten Altbauern mit einer Hektarfläche bis ca. 15 ha, die auf eine kommunistische Vergangenheit vor 1933 zurückblickten, der DBD bei. In diesem Fall dürfte die Herkunft Goldenbaums aus Parchim eine Rolle gespielt haben ${ }^{389}$. Das Beispiel relativiert zugleich allzu strikte Typologisierungen in sozialistisch aufgeschlossenere Neubauern und politisch konservativ ausgerichtete Altbauern.

In erster Linie rechnete sich die Bauernpartei gute Chancen bei denjenigen Altbauern aus, denen die CDU „zu christlich“, die LDP „zu kapitalistisch“ und die SED zu sozialistisch war, die sich aber eine bäuerliche Interessenpolitik herbeisehnten ${ }^{390}$. Insgesamt gesehen reagierten auch die Altbauern aufgeschlossen, sofern sie nicht eng an die Blockparteien CDU und LDP gebunden waren. Bei vielen reichte dieses Interesse aber nicht dazu aus, um ihr grundsätzliches Mißtrauen auszuräumen und sie zum Parteieintritt zu bewegen ${ }^{391}$. In Sachsen erwogen vergleichsweise mehr Altbauern aus der SED als aus den bürgerlichen Parteien einen Übertritt in die $\mathrm{DBD}^{392}$. Auf nichtöffentlichen Versammlungen in Sachsen-Anhalt 1948 äußerten die anwesenden Bauern, nichts mit Kommunisten zu tun haben zu wollen ${ }^{393}$. Als Trend zeichnet sich ab, daß sich bäuerliche SED-Mitglieder, unabhängig von der Kategorie Alt- oder Neubauer, lebhaft für die Bauernpartei interessierten ${ }^{394}$. In Führungskreisen sowohl der SED als auch der DBD war man über eine solch geringe Bindungskraft der SED verblüfft ${ }^{395}$. Eine mögliche Massenabwanderung von der SED wurde jedoch frühzeitig gestoppt. Quer zur Einteilung in Alt- und Neubauern liegt auch die beträchtliche Gruppe der ehemaligen Mitglieder der NSDAP oder jener Funktionäre des Reichsnährstandes, die als Mitläufer eingestuft worden waren. Die offizielle Verkündung des Endes der Entnazifizierung durch den SMAD-Befehl Nr. 35 vom 26. Februar 1948396 eröffnete den nominellen Parteigenossen den Wiedereintritt ins politische Leben. In Konkurrenz zur NDPD zielte auch die DBD auf dieses bäuerliche Segment. Parteiintern wurden sie häufig als Gruppe der bisher quasi zwangsweise "politisch uninteressierten“ Bauern geführt, die „heute sehr stark an unserer Bauernpartei interessiert ${ }^{\star 397}$ seien.

389 ACDP VI, unverz. Best. LV Mecklenburg, Aufstellungen Kreisvorstände Mecklenburg $1948 / 1949$.

390 Vgl. Ausführungen Kochs auf der Landesgründungsversammlung, 29. 4. 1948, ACDP VI-052-0001/a.

391 Dies galt vor allem für die über 50jährigen Bauern, die bislang parteilos gewesen waren, so berichtete Martin für Sachsen, ACDP VI-052-0141, Protokoll PV, 8. 10. 1948.

392 SStAD BPA SED LL A/864, Sonderinformationsberichte des LV der SED Sachsen 13. 9. 1948, Bl. 41-45, hier Bl. 41.

393 ACDP VI-052-0141, Protokoll PV, 26. 8. 1948, Beitrag Frau Pilz.

394 Ebd. SStAD BPA SED LL A/864, Bl. 41-45, Berichte aus Plauen und Stollberg.

395 Vgl. ACDP VI-052-0141, Protokoll PV, 26. 8. 1948.

396 Van Melis, Entnazifizierung, S. 245-249.

397 Vgl. Redebeitrag Kochs auf der Landesgründungsversammlung der DBD am 29. 4. 1948 in Schwerin, ACDP VI-052-0001/a. 
Die Gründung stieß auf nur geringe Resonanz bei Jugendlichen und Frauen auf dem Land. Wie gesehen, mußten Frauen nachträglich in den Parteivorstand eingebaut werden. Allerdings spielten sie offensichtlich eine erhebliche Rolle bei der Entscheidung ihrer Männer für oder gegen einen Parteieintritt ${ }^{398}$. Ob sich der Mann gar um einen Funktionärsposten bewarb, dürfte auch nicht über die Köpfe der Frauen hinweg entschieden worden sein; denn dies bedeutete in der Regel mehr Arbeit für sie. Oft entzogen sich Bauern, die auf DBD-Versammlungen anwesend waren, einem Parteieintritt mit der Begründung, sie müßten dies erst noch mit ihren Frauen besprechen. Auffällig hoch ist die Zahl der Funktionärspaare in der Anfangszeit der DBD 399 .

Zur Resonanz auf die Parteigründung zählt auch ein ausgeprägtes Informationsbedürfnis beim aufgeschlosseneren Teil der Landbevölkerung. Funktionäre berichteten nicht nur über eine gehörige Portion Mißtrauen, sondern auch über genaue Nachfragen bezüglich der Positionen der DBD zu bestimmten Fragen. Zum Fragenkatalog gehörte etwa, wie es um eine erneute Währungsreform stehe, ob die DBD für eine zweite Bodenreform - gemeint war damit eine weitere Enteignungswelle - oder für die Errichtung von Kolchosen eintrete, und wie die DBD ihr Verhältnis zur SED sehe ${ }^{400}$.

Schließlich gestattet auch die Entwicklung der Mitgliederzahlen Rückschlüsse auf die Resonanz. Nur für Thüringen liegen für 1948 Angaben zur Zusammensetzung der Mitglieder vor. Die 2057 thüringischen Bauernparteiler setzten sich zu $82 \%$ aus vorher Parteilosen und zu $15 \%$ aus ehemaligen SED-Mitgliedern zusammen ${ }^{401} .90 \%$ der bäuerlichen Mitglieder lagen in der Größengruppe bis 20 ha landwirtschaftlicher Nutzfläche, ungefähr $10 \%$ sogar bis 50 ha. Es gelang nur ein schwacher Einbruch in die Mitgliederbasis von LDP und CDU ${ }^{402}$.

Insgesamt zeigen die hier eher impressionistisch eingefangenen Aussagen aus der Landbevölkerung, daß für die Bauernpartei in ihrer Anfangsphase durchaus Interesse bis hin zum Wunsch nach Mitgliedschaft vorhanden war. Somit hing sie also nicht allein an ihren Ziehmüttern SED und SMAD. Diese bestimmten freilich die Politik.

398 Ebd., Wortbeitrag Katharina Walter, Thüringen, und von Frau Pilz, Sachsen-Anhalt.

399 Siehe die paarweise Auflistung der Anwesenden auf der 1. Parteikonferenz am 16./17. 7. 1948; ACDP VI-052-0002.

400 So z. B. für Sachsen berichtet, ACDP VI-052-0141, Protokoll PV, 8. 10. 1948.

401 Ebd., Protokoll PV, 3. 12. 1948, Ausführungen von Hoffmann.

402 Ebd., Protokoll PV, 1. 11. 1948. 